UNIVERSIDADE DE SÃO PAULO

FACULDADE DE MEDICINA DE RIBEIRÃO PRETO

JOANA CAROLINA MARTINS SIMÕES

Análise da morfologia facial e da força de mordida nas deformidades dentofaciais 
JOANA CAROLINA MARTINS SIMÕES

\section{Análise da morfologia facial e da força de mordida nas deformidades} dentofaciais

\section{Versão Original}

Dissertação apresentada à Faculdade de Medicina de Ribeirão Preto da Universidade de São Paulo para a obtenção do título de Mestre em Ciências Médicas.

Área de Concentração: Morfofisiologia de Estruturas Faciais.

Orientadora: Prof ${ }^{\mathrm{a}}$. Dr ${ }^{\mathrm{a}}$. Luciana Vitaliano Voi Trawitzki 
Autorizo a reprodução e divulgação total ou parcial deste trabalho, por qualquer meio convencional ou eletrônico, para fins de estudo e pesquisa, desde que citada a fonte.

Simões, Joana Carolina Martins

Análise da morfologia facial e da força de mordida nas deformidades dentofaciais. Ribeirão Preto, 2017.

123p. :il. ; $30 \mathrm{~cm}$

Dissertação de Mestrado, apresentada à Faculdade de Medicina de Ribeirão Preto/USP. Área de concentração: Morfofisiologia de Estruturas Faciais.

Orientador: Trawitzki, Luciana Vitaliano Voi

1. Face. 2. Força de mordida. 3. Deformidade dentofacial. 
Nome: Simões, Joana Carolina Martins

Título: Análise da morfologia facial e da força de mordida nas deformidades dentofacias

Dissertação apresentada à Faculdade de Medicina de Ribeirão Preto da Universidade de São Paulo para a obtenção do título de Mestre em Ciências Médicas.

Área de Concentração: Morfofisiologia de Estruturas Faciais.

Aprovado em:

Banca examinadora

Prof. Dr.

Instituição:

Julgamento:

Prof. Dr.

Instituição:

Julgamento:

Prof. Dr.

Instituição:

Julgamento: 
A Deus, o Altíssimo e Onipotente, que com sua infinita misericórdia trilha meus caminhos diários sob a sua luz e proteção e pelo manto sagrado de Maria nossa Mãe.

“Nada é impossível para aquele que tem fé verdadeira. Quem tem fé, tudo pode."

(Mateus 17: 20-21)

Ao meu pai Abelardo, exemplo de perseverança, determinação, lealdade e sobre tudo, amor à vida e à sua família! A você meu herói, com todo o meu amor, muito obrigada por seus ensinamentos e valores, que em meu coração, assim como você e seu legado, sempre viverão! Até logo!

“Pois caminhamos pela fé e não pela visão..." (2 Coríntios 5: 7)

À minha mãe Vilma, luz da minha vida, fortaleza e razão ímpar do meu viver! Aquela que não mede esforços para nos ver felizes! Que os nossos sorrisos sejam sempre o reflexo da sua alegria sem fim!

“O amor é paciente, o amor é prestativo (...) Tudo desculpa, tudo crê, tudo espera, tudo suporta (...) Agora, portanto, permanecem estas três coisas: a fé, a esperança e o amor. A maior delas, porém, é o amor." (1 Coríntios 13: 4-13)

Aos meus irmãos Abelardo Filho e Fernando José, os meus maiores escudos de proteção e carinho. Sem vocês eu não seria como sou! A vocês eu dou a minha vida, a vocês eu dou todo o meu amor!

“Caiam mil ao seu lado e dez mil à sua direita, a você nada atingirá (...) Eu o livrarei, porque a mim se apegou. Eu o protegerei, pois conhece o meu nome (...) Eu o livrarei e glorificarei." (Salmo 91: 7-15) 


\section{À minha orientadora de profissão e vida, Prof $^{\mathrm{a}}$. Dr ${ }^{\mathrm{a}}$. Luciana Vitaliano Voi Trawitzki.}

Que mesmo sem saber, me instrui aos caminhos do bem e do respeito. $E$, a meu ver, o mais importante: ensina-me além dos livros e publicações, com simples palavras e gestos de esmero.

A sua competência é inquestionável, mas a sua humanidade é soberana! Pelas mãos de Deus, a senhora constrói lindas histórias de amor e dedicação ao que se ama! A minha admiração e gratidão eterna por me acolher em cada momento!

\section{“A benção do Senhor é a recompensa para quem é fiel, e a benção dele floresce num instante." (Eclesiástico 11: 22)}

À minha amiga, madrinha, cunhada e irmã de alma Anaí. Quem Deus me presenteou para ser minha leal companheira de todos os momentos! Agradecer a você é muito pouco, Bete..

Eu te amo e já amo meu sobrinho que ainda dentro de você está!

À minha querida cunhada Letícia, por integrar-se à nossa família com todo seu respeito e amor. Obrigada por me compreender e estar comigo em cada momento, Lelê!

A todos da minha família, em especial minha Avó Vina, fonte soberana de sabedoria entre nós e honestidade! Você é nosso exemplo mais sólido de amor à família!

Se tem algo que a USP me presenteou e, do qual mais me orgulho, são as minhas amizades. Formamos uma família unida e sólida, o nosso GAP, como assim carinhosamente nos chamamos. A vocês, minhas amigas Aline Bruna, Carolina, Cristiane, Mayara, Marcela, Patrícia e Renata, eu agradeço a paciência e amor. Vocês também, além de fonoaudiólogas competentes, são autoras indiretas desse trabalho. Em especial, à Pá, amiga leal e disposta a fazer a buscar o infinito para me ajudar em todas as etapas desse estudo e em todos os 
momentos da minha vida! E à Cris, amiga serena e sensata, por me aconselhar e por ficar comigo até os minutos finais!"

Aos meus amigos de infância Ana Júlia, Bruna, Bruno, Fernando, Lucas, Luciana e Marcos. Vocês dispensam descrições! Sempre juntos, mesmo de longe! Obrigada por tudo! Em especial agradeço à Lu, por sua lealdade e bondade!

À querida Luciana Aguiar, que possui um coração acolhedor imenso e contribuiu em todos os momentos! Mais uma vez Lú, muito obrigada!

Às amigas e companheiras de pós-graduação Alice, Denise, Franciele e Monize. Vocês foram fundamentais para o meu dia a dia! Contem comigo para sempre!

À Tais Grechi, meu exemplo de competência profissional, autenticidade e valores! Que há muitos anos me ensina os diversos caminhos da Fonoaudiologia. Por sua generosidade em compartilhar conhecimentos científicos e experiências vividas e por sua preocupação com meu bem estar! Você é uma mulher admirável!

À Melissa Picinato-Pirola, que também muito me ensinou dentro da Motricidade Orofacial. Desde o início me incentivou para que este trabalho se concretizasse. Você também é um grande exemplo para mim!

Ao Denny Garcia, que em sua grande sabedoria, torna compreensível até os ensinamentos mais difíceis. Obrigada por contribuir imensamente com este trabalho! 
À Fernanda Sidequersky e Lúcia Gíglio, por ajudarem a construir cada etapa deste estudo. Empenharam-se além do exigido, mesmo sem ser solicitado, e merecem meus agradecimentos.

À Carina Borges, por seu companheirismo no ambulatório e troca de experiências!

À Porfa ${ }^{\mathrm{a}}$. Dra . Claudia Maria de Felício, por ser uma grande incentivadora da pesquisa científica e profissional ícone para a Fonoaudiologia. Obrigada professora por me permitir a realização desse sonho sob suas considerações diárias! É um grande privilégio!

Ao Prof. Dr. Francisco Veríssimo de Melo-Filho, por apoiar e incentivar a Fonoaudiologia e por sua atenção em todos os momentos que humildemente me ensinou. Obrigada pela sua participação na banca de qualificação deste trabalho, por transmitir seus conhecimentos e despertar em mim o interesse e paixão cada vez maior por essa área. O meu respeito ao senhor!

Aos Professores e componentes da minha banca de mestrado: Prof. Dr. Luiz Carlos Conti de Freitas, Prof. Dr. Samuel Porfírio Xavier e Prof ${ }^{a}$. Dr ${ }^{a}$. Silvana Bommarito Monteiro, que com extrema humildade aceitaram participar e enriquecer este trabalho, dividindo seus conhecimentos comigo!

A todos os funcionários e pós-graduandos da Casa 18, Casa 19 e Centro Especializado de Otorrinolaringologia e Fonoaudiologia (CEOF HCFMRP-USP), os quais sempre prontamente me atenderam e, com carinho, fizeram parte deste estudo! 
Aos professores e funcionários do Departamento de Oftalmologia, Otorrinolaringologia e Cirurgia de Cabeça e Pescoço HCFMRP-USP, por me abrirem os caminhos na pós-graduação e acrescentarem conhecimento ao meu crescimento profissional. Em especial à Maria Cecília Onofre, por sempre disponibilizar sua atenção às minhas dúvidas!

A todas as professoras do Curso de Fonoaudiologia da Faculdade de Medicina de Ribeirão Preto da Universidade de São Paulo. Sem vocês eu não chegaria até aqui! A minha eterna gratidão! E aos alunos do curso de Fonoaudiologia, por me ensinarem tanto e acrescentarem experiência à minha aspiração pela docência.

À CAPES, pelo incentivo à pesquisa e apoio financeiro necessário para a concretização desse trabalho.

Por fim, agradeço principalmente aos pacientes e voluntários que participarem dessa pesquisa. Sem vocês ela não seria possível. E a todos que indiretamente colaboraram para que isto se tornasse possível. A minha eterna gratidão e que Deus Ihes recompense! 
Simões, JCM. Análise da morfologia facial e da força de mordida nas deformidades dentofaciais [dissertação]. Ribeirão Preto: Universidade de São Paulo, Faculdade de Medicina de Ribeirão Preto; 2017. 123f.

A função mastigatória é uma das principais constituintes do sistema estomatognático e impreterivelmente antecede a absorção de nutrientes pelo organismo humano. A força de mordida é um componente dessa função e um indicador clínico do funcionamento desse sistema. Em sujeitos com deformidade dentofacial, a mastigação está prejudicada devido ao desequilíbrio das relações esqueléticas e musculares maxilomandibulares e da oclusão. A abordagem investigativa tridimensional é única que possui a vantagem de avaliar a morfologia facial nos três planos do espaço, tal como se configura a face humana e a deformidade dentofacial. Portanto, o objetivo deste trabalho foi analisar a variação da morfologia facial em diferentes medidas tridimensionais, assim como verificar possível assimetria na força de mordida e diferenças na distribuição de força e área dos contatos oclusais entre sujeitos com deformidades dentofaciais padrão dentoesquelético II, padrão dentoesquelético III e controles. O estudo foi realizado com 77 sujeitos que compuseram dois diferentes grupos, a saber: deformidade dentofacial (DDF) e controle (GC). $\mathrm{O}$ grupo com o diagnóstico de deformidade dentofacial (DDF) foi subdividido segundo a classificação da mesma. Assim, 20 sujeitos classe II (4 homens e 16 mulheres, com média de idade de 26 anos) integraram o subgrupo DDF II, 32 classe III (15 homens e 16 mulheres, com média de idade de 27 anos) formaram o DDF III e 25 voluntários saudáveis ( 9 homens e 16 mulheres, idade média de 24 anos) compreenderam o GC. Todos foram submetidos à avaliação tridimensional da morfologia facial, por meio de escaneamento facial a laser, medidas de força de mordida pelo gnatodinamômetro, análise da distribuição de força oclusal e área de contato dentário pelo sistema T-Scan. As comparações entre GC e DDF foram realizadas pela Análise de Variância (ANOVA) para amostras independentes. O teste de correlação de Spearman foi aplicado para avaliar as possíveis associações entre as medidas de força de mordida e as medidas antropométricas, além da análise de regressão linear múltipla para identificar as variáveis antropométricas associadas à força de mordida. Foi adotado nível de significância de 5\%. Na investigação da morfologia, os sujeitos com DDF apresentaram características específicas e compatíveis com as classes II e III esqueléticas, com aumento da altura facial principalmente em retrognatas. A força de mordida foi menor para o grupo DDF, porém não se diferenciou entre os grupos e não houve assimetrias nesse quesito. $A$ área de contato oclusal evidenciou-se mais deficitária para sujeitos com padrão dentoesquelético III, porém a distribuição de força oclusal não demonstrou diferenças entre os grupos. Pode-se concluir o método de análise tridimensional confirmou achados específicos relevantes no que diz respeito às deformidades dentofacias estudadas. E as proporções faciais foram consideradas fatores influenciadores da magnitude da força de mordida em sujeitos com a deformidade dentofacial.

Palavras-chave: Face. Força de mordida. Deformidade dentofacial. 
ABSTRACT 
Simões, JCM. Facial Morphology and bite force analysis in dentofacial deformities [dissertation]. Ribeirão Preto: University of São Paulo, School of Medicine of Ribeirão Preto; 2017. $123 f$.

The masticatory function is the one of the main constituents of stomatognathic system and necessarily precedes the absorption of nutrients by the human organism. Bite force is a component of this function and a clinical parameter of this system's health. In dentofacial deformity, chewing is impaired due the imbalance of skeletal and muscular maxillomandibular relationships and of the occlusion. Three-dimensioal investigative approach is unique and has the advantage about the evaluation of facial morphology in the three planes of space, such as the configuration of the human face and dentofacial deformity. Therefore, the objective of this study was to analyze the variation of facial morphology in different three-dimensional measurements, as well as to verify possible asymmetry in bite force and the difference in the distribution of force in dental arc and occlusal contact area between subjects with dentofacial deformities class II, class III and control. The study was performed with 77 subjects who composed two different groups: dentofacial deformity (DDF) and control (CG). The group of dentofacial deformity (DDF) was subdivided according to its classification. Thus, 20 class II subjects (4 men and 16 women, mean age of 26 years old) were included in the DDF II subgroup, 32 class III (15 men and 16 women, mean age of 27 years old) formed DDF III, and 25 healthy volunteers ( 9 men and 16 women, mean age of 24 years old) comprised the CG. All were submitted to the threedimensional assessment of the facial morphology by laser scanning, bite force measurements by gnatodynamometer, analysis of occlusal force distribution and occlusal contact area by the T-Scan system. Comparisons between CG and DDF groups were performed by Analyses of Variance (ANOVA) for independent samples. Spearman's correlation test was applied to evaluate the possible association between bite force and anthropometric measurements, as well as multiple linear regression analysis to identify the anthropometric variables associated to the bite force. A significance level of $5 \%$ was adopted. In the investigation of morphology the subjects with dentofacial deformities presented specific features and compatible with the skeletal class II and skeletal class III, with increase of facial height, mainly in retrognathic subjects. The bite force was lower for DDF, did not differentiate between the groups and there were no asymmetries about them. The occlusal contact area was found to be poorer for subjects with class III deformity, but the occlusal force distribution did not show differences between the groups. It can be concluded the three-dimensional analysis method confirmed specific and relevant findings to the studied dentofacial deformities. And the facial proportions were considered factors influencing the magnitude of the bite force in subjects with deformity.

Keywords: Face. Bite force. Dentofacial deformity. 
Figura 1. Fluxograma da composição do grupo deformidade dentofacial.Erro! Indicador não definido.

Figura 2. Fluxograma da composição do grupo controle. 51

Figura 3. A. Digitalizador; B. Sistema FastSCAN ${ }^{\mathrm{TM}}$ completo. 56

Figura 4. A. Escaneamento facial; B. FastSCAMTM e imagem 3D. 57

Figura 5. Modelo ilustrativo dos pontos antropométricos faciais. 58

Figura 6. Distâncias lineares. A. Altura facial; B. Largura facial; C. Terço médio facial, D. Terço inferior facial; E. Altura maxilar; F. Altura mandibular. 60

Figura 7. Distâncias lineares. A. Distância linear Td-Chd; B. Distância linear Te-Che; C. Comprimento maxilar; D. Comprimento mandibular. 61

Figura 8. A. Proporções faciais. A. Altura/largura facial; B. Terço médio/terço inferior facial; C. Altura maxilar/altura mandibular facial; D. Assimetria entre os lados; E. Relação maxilomandibular. 63

Figura 9. A. Gnatodinamômetro Eletrônico; B. Avaliação da força de mordida. 65

Figura 10. A. Sensor; B. Suporte e T-Scan. 66

Figura 11. A. Conjunto do sensor, suporte e T-Scan; B. Avaliação da distribuiç̧ão de força oclusal e área de contato oclusal.

Figura 12. Gráfico ilustrativo com o registro da distribuição de força oclusal e área de contato oclusal.

Figura 13. A. Imagem original dos contatos oclusais fornecida pelo equipamento; B. Imagem segmentada mostrando a área dos contatos em preto. 68 
Quadro 1. Descrição dos pontos antropométricos (Farkas, 1994). .............................. 58

Quadro 2. Identificação e descrição das distâncias lineares faciais................................ 59

Quadro 3. Identificação e descrição das proporções faciais...........................................62

Quadro 4. Descrição das variáveis relativas à força de mordida.................................. 65

Quadro 5. Descrição das variáveis relativas à distribuição de força e área de contato

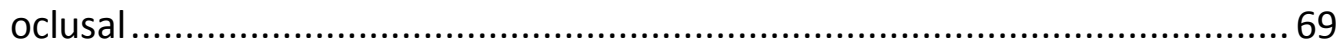


Tabela 1. Média e desvio padrão das distâncias lineares entre os pontos antropométricos na comparação entre os três grupos. .72

Tabela 2. Média e desvio padrão das proporções faciais na comparação entre os três grupos. 73

Tabela 3. Média e desvio padrão da força de mordida e diferença percentual entre os lados na comparação entre os três grupos. .74

Tabela 4. Média e desvio padrão dos parâmetros da distribuição de força oclusal na comparação entre os três grupos. .75

Tabela 5. Média e desvio padrão dos parâmetros da área e assimetria de área oclusal na comparação entre os três grupos. .76

Tabela 6. Coeficiente de correlação entre as distâncias antropométricas e proporções faciais e a força de mordida nos grupos deformidade dentofacial padrão dentoesquelético II, padrão dentoesquelético III e grupo controle.

Tabela 7. Variáveis relacionadas às distâncias antropométricas significativamente associadas à força de mordida, segundo critério de informação de Akaike (AIC). .78

Tabela 8. Variáveis relacionadas às proporções faciais significativamente associadas à força de mordida, segundo critério de informação de Akaike (AIC) .78 
2D

3D

AD

$\mathrm{AE}$

AMIOFE

ASADE

AT

Chd

Che

CIEDEF

DDF

DDF II

DDF III

DPL

DTM

FA

FD

FE

FM D

FM E

FM

FP

G

GC

Gn

HCFMRP-USP
Bidimensional

Tridimensional

Índice da área do lado direito

Índice da área do lado esquerdo

Protocolo de Avaliação Miofuncional Orofacial com Escores

Índice de assimetria de área total do lado direito e esquerdo.

Índice da área total do lado direito e esquerdo

Cheilion direito

Cheilion esquerdo

Centro Integrado de Estudos das Deformidades da Face

Grupo deformidade dentofacial

Grupo deformidade dentofacial padrão dentoesquelético II

Grupo deformidade dentofacial padrão dentoesquelético III

Índice de assimetria de FM entre os lados direito e esquerdo

Desordem temporomandibular

Índice de força relativa à máxima força anterior de ambos os lados

Índice relacionado à força relativa máxima do lado direito

Índice relacionado à força relativa máxima do lado esquerdo

Força de mordida do lado direito

Força de mordida do lado esquerdo

Força de mordida

Índice de força relativa à máxima força posterior de ambos os lados

Glabela

Grupo controle

Gnátio

Hospital das Clínicas da Faculdade de Medicina de Ribeirão Preto da Universidade de São Paulo 
LISE Laboratório de Investigação do Sistema Estomatognático

MyHC Cadeia pesada de miosina

$\mathbf{N}$

Newton

NAPCF - USP Núcleo de Apoio à Pesquisa em Morfofisiologia Craniofacial da Universidade de São Paulo

Sn

Subnasal

Sto

Estômio

$\mathbf{T}$

Tragus médio

Td

Tragus direito

Te

Tragus esquerdo

TO

Tempo de oclusão 


\section{SUMÁRIO}

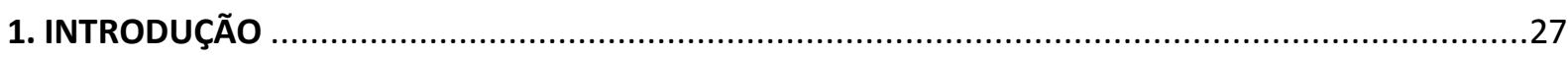

2. OBJETIVOS

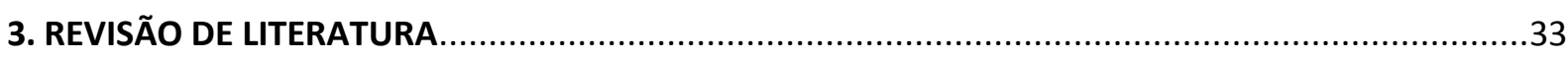

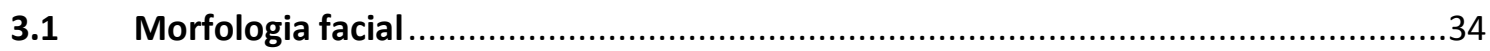

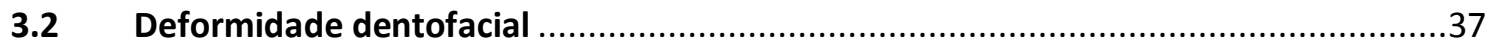

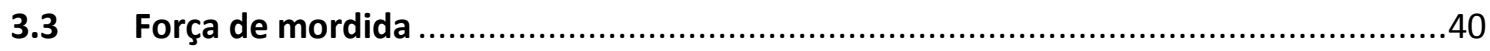

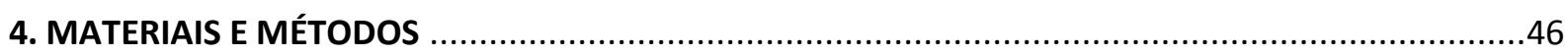

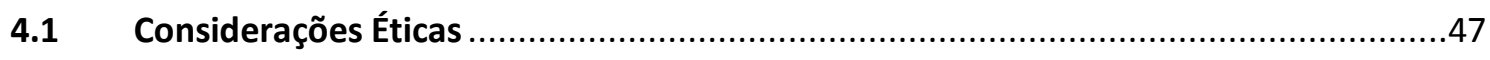

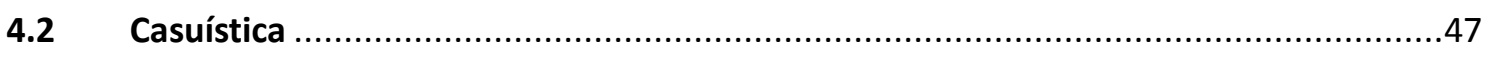

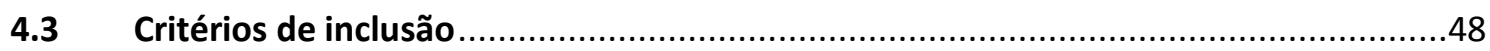

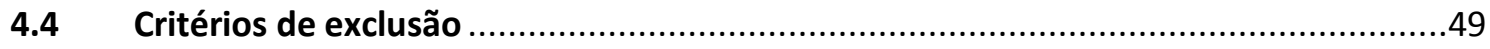

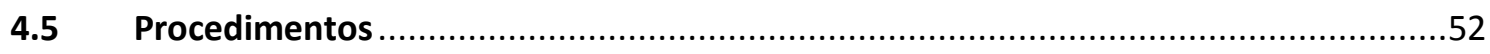

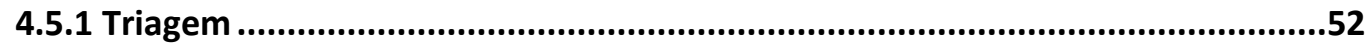

4.5.2 Avaliação da Condição Miofuncional Orofacial .................................................52

4.5.3 Avaliação Tridimensional da Morfologia Facial ...............................................55

4.5.4 Avaliação da Força de Mordida .......................................................................64

4.5.5 Análise da Distribuição de Força Oclusal ...........................................................65

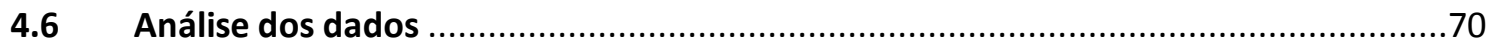

5. RESULTADOS

5.1 Morfologia facial (distâncias lineares) …....................................................... 72

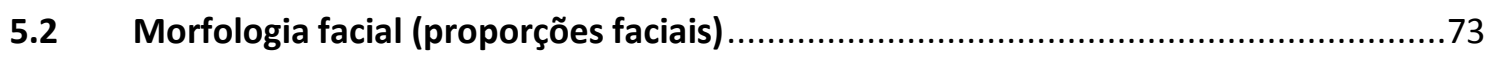

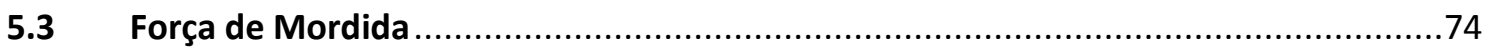

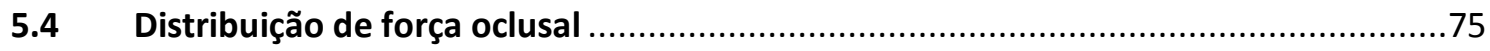

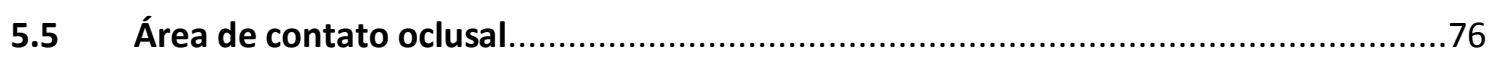

5.6 Correlação entre as distâncias antropométricas e proporções faciais e a força de mordida....................................................................................................................................77 


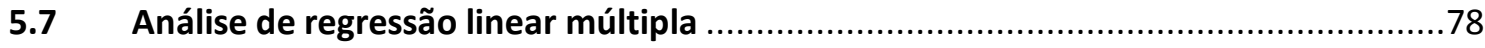

6. DISCUSSÃO

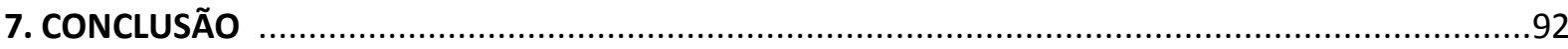

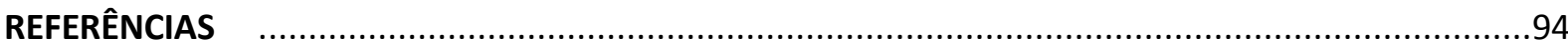

APÊNDICES

ANEXO 
1. INTRODUÇÃO 
Falar, bocejar e mastigar são ações coordenadas e imprescindíveis para o sistema motor oral. Têm em comum a participação conjunta dos lábios, língua, dentes e músculos mandibulares e são dependentes do controle neural (van der Bilt et al., 2011). Por fim, integram o complexo estomatognático e, associadas às demais estruturas, permitem o funcionamento harmônico da face (Maciel et al., 2011).

O conhecimento sobre os aspectos anatômicos e fisiológicos que envolvem os músculos mastigatórios é necessário para a compreensão da biomecânica mandibular (Coelho-Ferraz et al., 2010). E assim, a mastigação é uma função que gera interesse aos profissionais da saúde, em virtude do seu potencial de influência e manutenção da integridade do complexo orofacial (Felício et al., 2008). Esse conhecimento é relevante, visto que não é raro o planejamento terapêutico para essa função (Coelho-Ferraz et al., 2010), pois diversas alterações podem provocar prejuízos na performance mastigatória, como a presença da deformidade dentofacial (van der Bilt et al., 2011; Picinato-Pirola et al., 2012).

A deformidade dentofacial apresenta relações esqueléticas desfavoráveis aliadas às alterações oclusais e pode contribuir para o detrimento do sistema estomatognático, uma vez que gera desequilíbrio principalmente na função dos músculos elevadores da mandíbula (van den Braber et al., 2002; Trawitzki et al., 2006a).

A recuperação da função mastigatória é tida como um dos principais desígnios da cirurgia corretiva da deformidade, pelo notório desgaste dessa função (Kobayashi et al., $1993,2001)$ e por ser a queixa funcional mais recorrente dos sujeitos acometidos por esta patologia (Trawitzki et al., 2009).

Os músculos elevadores produzem a força de mordida, que é considerada um indicador preciso e confiável, sendo uma referência clínica significativa para avaliar o estado da biomecânica do sistema muscular mastigatório (Proffit et al., 1989; Koç et al., 2010).

Assim, por meio de parâmetros quantitativos é possível definir a capacidade funcional do complexo estomatognático (Trawizki et al., 2011) e, devido à integração de suas estruturas, o estudo da morfologia facial complementa o entendimento da fisiopatologia desse sistema (Melo e Bianchini, 2015). 
Nesse sentido, a face humana configura-se imprescindível no desempenho dos papéis de mastigação, deglutição, respiração e comunicação (Verzé et al., 2012). Apresentase em caráter tridimensional (Geng, 2011) e em constante estado de mudança ao longo da vida (Wen et al., 2015). Assim, considera-se que a abordagem investigativa craniofacial é necessária para a determinação das dimensões faciais (Allanson, 1997; Ward et al., 2000) e quantificar esses padrões faciais é alvo de interesse para as áreas relacionadas ao diagnóstico de patologias que envolvem a cirurgia craniofacial como uma das formas de tratamento (Wen et al., 2015).

Alguns conceitos ainda não são totalmente claros no contexto das deformidades dentofacias. Esta população específica, em que as relações esqueléticas estão desequilibradas, apresenta deficiência na musculatura elevadora da mandíbula com consequente menor potencial gerador de força de mordida (Trawitzki et al., 2011) e prejuízo na eficiência mastigatória (Picinato-Pirola et al., 2012), devido à complexidade das desproporções maxilomandibulares e oclusais. Assim, é pertinente tentar compreender a morfologia facial junto ao comportamento dos músculos mastigatórios também nessas condições de evidente desarmonia muscular e esquelética.

Apesar de aceito que existe ampla relação entre a função dos músculos mastigatórios e a morfologia craniofacial (Proffit et al., 1983; Kiliaridis et al., 1993; Ingervall e Minder, 1997; Raadsheer et al., 1999; Throckmorton et al., 2000; Sondang et al., 2003; Castelo et al., 2008; Bonakdarchian et al., 2009; Alhaija et al., 2010; Custodio et al.. 2010; Koç et al., 2010; van Spronsen, 2010), na literatura constam poucos trabalhos que se propuseram investigar a correspondência entre a biomecânica dos músculos mastigatórios com as dimensões esqueletais na presença da deformidade dentofacial (Throckmorton et al., 1995, 1999, 2000; Zarrinkelk et al., 1995, 1996; Thorckmorton e Ellis III, 2001; Harada et al., 2003). Os mesmos utilizaram apenas a metodologia bidimensional para o diagnóstico e focaram nos resultados cirúrgicos da correção da deformidade. Exceto Throckmorton et al (2000), que tentaram identificar essas relações, bem como as variáveis com potencial de influência na força muscular.

Dessa forma, apesar das desproporções maxilomandibulares apresentarem discrepâncias tridimensionais (3D) (Suzuki-Okamura et al., 2015), assim como se configura a 
estrutura facial em múltiplos planos do espaço (Geng, 2011), a sua principal abordagem diagnóstica ainda é bidimensional (2D) (Hajeer et al., 2004; Shimomatsu et al., 2012; Verzé et al., 2012 Suzuki-Okamura et al., 2015). Isso ocorre, embora já apontado a eventual perda e distorções de informações quando o método 2D pretende avaliar a estrutura 3D (Ferrario et al., 1999; Hajeer et al., 2004; Alves et al., 2009; Verzé et al., 2012), sendo que o uso da tridimensionalidade parece ser mais autêntico e apropriado para a avaliação precisa da deformidade (Sforza et al., 2007). Considera-se ainda que uma análise facial completa não deva limitar-se à análise de tecidos duros, mas também, incluir a contribuição dos tecidos moles (Ferrario et al., 2002).

Então, em função da limitação tecnológica da abordagem bidimensional (Jacobson e Sadowski, 1995; Ferrario et al., 1999; Hajeer et al., 2004; Alves et al., 2009; Cheung et al., 2011; Verzé et al., 2012) e dos aspectos remanescentes sobre o assunto, considera-se oportuno saber se a tecnologia de análise facial tridimensional, a qual apresenta vantagem por seu caráter investigativo fiel à estrutura craniofacial e à configuração complexa da deformidade, pode acrescentar conhecimento e elucidar questões ainda debatidas, uma vez que exposto o íntimo relacionamento das estruturas faciais, bem como a ausência de trabalhos que tenham utilizado a metodologia em questão para associar a morfologia facial com a força de mordida.

Nesse sentido, dentre a literatura que embasou este estudo, nenhum outro trabalho utilizou a mesma ou abordagem tridimensional semelhante para avaliar a população brasileira, na presença ou ausência da deformidade dentofacial. Tendo em vista que a estrutura craniofacial varia conforme características étnicas, hereditárias e fatores ambientais (Bianchini et al., 2002; Berretin-Félix et al., 2010), faz-se relevante a investigação também nessa população. 
2. OBJETIVOS 


\section{Objetivo geral}

Analisar a variação da morfologia facial em diferentes medidas tridimensionais, assim como verificar possível assimetria na força de mordida e diferenças na distribuição de força e área dos contatos oclusais entre sujeitos com deformidades dentofaciais padrão dentoesquelético II, padrão dentoesquelético III e sujeitos controles.

\section{Objetivos específicos}

- Determinar os parâmetros médios e desvio padrão de medidas antropométricas de tecido mole facial (distâncias lineares e proporções faciais), por meio de análise tridimensional; assim como os valores de força de mordida e índice de assimetria de força entre os lados; o tempo de oclusão e a distribuição de força oclusal anteroposterior e laterolateral; e a área de contato oclusal, em sujeitos com deformidades dentofaciais padrão dentoesquelético II, padrão dentoesquelético III e sujeitos controles.

- Analisar as diferenças nos parâmetros, acima mencionados, entre os grupos estudados;

- Identificar possível correlação entre as medidas antropométricas de tecido mole (morfologia facial) e a força de mordida. 


\subsection{Morfologia facial}

A face humana é considerada uma superfície complexa e não planar, ou seja, apresenta componentes dos três planos do espaço, com características de altura, largura e profundidade (Throckmorton et al., 1999; Geng, 2009). Essa estrutura desempenha um papel essencial na comunicação interpessoal humana e na execução das funções estomatognáticas (Verzé et al., 2012).

O crescimento e desenvolvimento craniofacial compreendem um processo morfogenético, a fim de alcançar o equilíbrio estrutural e funcional entre os tecidos moles e duros (Enlow, 1993). É considerado complexo, uma vez que a maxila e mandíbula atuam em um espaço que exige uma mudança contínua e adaptativa das estruturas esqueléticas e musculares, sendo que o crescimento global maxilomandibular ocorre aproximadamente até os 14 anos para meninas e 16 anos de idade para os meninos (Enlow, 1993; Moorrees et al.,1995).

Assim, a face adulta parece ser determinada tanto por influência genética, como por fatores ambientais, em que a atividade muscular mastigatória apresenta significativo potencial (Tecco et al., 2011). Portanto, uma relação harmoniosa entre os componentes do sistema estomatognático contribui para um adequado crescimento e desenvolvimento das bases ósseas da face (Pereira et al., 2005). Sendo que tal complexo é responsável, ainda, pelo equilíbrio do próprio sistema (Felício, 1999).

Os músculos e os ossos, aos quais estão ligados, se relacionam intimamente desde o a fase embrionária. Conforme o esqueleto cresce há um ajuste constante nas relações entre ele e o músculo, como parte natural desse crescimento e desenvolvimento. Dessa forma, a variação na função do músculo afeta notoriamente o osso ao qual está ligado (Enlow, 1997).

O complexo craniofacial prende-se à base do crânio, a qual determina características dimensionais, angulares e topográficas da face. Existem dois extremos para a forma da cabeça, a dolicocéfala que compreende uma face estreita e longa, ou tipo facial leptoprosopo e forma braquicéfala, que corresponde a uma face larga e curta, ou tipo facial euriprosopo (Arnett e Bergman, 1993; Enlow, 1997). As características ósseas, musculares e 
funcionais de cada tipo facial são peculiares e influenciam diretamente nas funções de mastigação, deglutição, respiração e fala (Bianchini, 2002).

A avaliação da morfologia facial é uma ferramenta indispensável na prática clínica e na pesquisa (Schlickmann et al., 2008). A sua avaliação quantitativa permite o entendimento mais amplo desse complexo. E a mesma pode ser obtida por diferentes métodos e instrumentos (Ferrario et al., 1999).

O crescimento craniofacial ocorre de maneira alterada em sujeitos com deformidade dentofacial e acarreta mudanças nas estruturas faciais, especialmente nos músculos mastigatórios (Trawitzki, et al., 2011). A tríade tecido mole (pele, tecido conjuntivo, gordura e músculo), tecido duro (ossos e cartilagem) e dentes possui papel decisivo para a determinação do planejamento do tratamento ortodôntico e cirúrgico. Por isso, os casos de deformidade dentofacial exigem uma avaliação detalhada da superfície de tecido mole e tecido duro, bem como o posicionamento dentário (Plooij et al., 2011).

A cefalometria radiográfica é uma abordagem tradicional e consagrada pela literatura para descrever as relações das diferentes partes do complexo craniofacial, como dentes, tecido ósseo e muscular (Jacobson e Sadowsky, 1995; Allanson, 1997; Bianchini, 2002; Gandini et al., 2005; Alessandri-Bonetti et al., 2015). É, sem dúvida, o método mais empregado para avaliação da morfologia facial nos casos de deformidade dentofacial (Throckmorton et al., 1995, 1999, 2000; Zarrinkelk et al., 1995, 1996; Thorckmorton e Ellis III, 2001; Harada et al., 2003; Nooreyazdan et al., 2004; Johnston et al., 2006; Pereira-Stabile et al., 2012; Becker et al., 2014; Valizadeh et al., 2015). Entretanto, apesar de sua consagração, estudos têm apontado que outros métodos mais atuais e preparados tecnologicamente podem exercer grande potencial no complemento da avaliação da deformidade dentofacial. Visto que, com a cefalometria radiográfica, além da exposição do sujeito à radiação (Jacobson e Sadowsky, 1995; Akhil et al., 2015) e da difícil visualização do tecido mole pela imagem fornecida devido à sobreposição dos ossos na musculatura, pode haver perdas de informações por ser uma metodologia bidimensional avaliando uma estrutura tridimensional, como a face (Enlow, 1997; Ferrario et al., 1999; Hajeer et al., 2004; Alves et al., 2009; Verzé et al., 2012; Porto et al., 2014; Akhil et al., 2015). 
O conceito 2D, das radiografias e fotografias, compreende dois eixos (vertical e horizontal) do sistema de coordenadas Cartesiano, correspondentes à altura e largura. Enquanto que, o conceito 3D engloba o eixo $x$ (dimensão transversal), $y$ (dimensão vertical) e $z$ (dimensão anteroposterior, o eixo da profundidade). As coordenadas $x, y, z$ definem um espaço multidimensional e mais fidedigno à estrutura craniofacial (Hajeer et al., 2004).

A fim de solucionar essas limitações tecnológicas na habilidade de mensurar com precisão tecidos moles e duros em 3D, outros métodos têm sido utilizados em associações para aprimorar a avaliação e diagnóstico da deformidade dentofacial. A tomografia computadorizada (CT) e tomografia computadorizada por feixe cônico (CBCT), apesar do alto custo e da exposição do sujeito à radiação, permite a clara visualização das estruturas do complexo craniofacial, principalmente de duro, mas também tecido mole (Hajeer et al., 2004; Akhil et al., 2015). Essa metodologia pode ser considerada um guia tridimensional para o planejamento ortodôntico e cirúrgico (Porto et al., 2014). Mas, ainda é majoritariamente utilizada para a avaliação dos resultados, esqueléticos e musculares, após a cirurgia ortognática (Terajima et al., 2008, 2009; Cheung et al., 2011; Kang et al., 2011; Steinbacher, 2015; Suzuki-Okamura et al., 2015).

Atualmente, tem sido descrita na literatura uma variedade de técnicas de aquisição de imagem 3D por meio de sistemas óticos, como a estereofotogrametria, que possui a habilidade de converter fotografias em modelos tridimensionais de face e o scanner a laser (Hajeer et al., 2004). Esta tecnologia utiliza a identificação de um feixe de laser refletido para construir a imagem tridimensional, com a possibilidade de mesurar ângulos, distâncias lineares e na superfície, bem como volume facial. É considerada uma ferramenta minimamente invasiva, em ausência de contato físico e radiação, de rápida aplicação e confiável para a avaliação da morfologia facial nos três planos do espaço, por meio de antropometria indireta (Thali, 2003; Hajeer et al., 2004; Loppold et al., 2014; Steinbacher et al., 2015, Zecca et al., 2016).

A literatura demonstra que no caso da deformidade dentofacial as desproporções tridimensionais do esqueleto facial são frequentemente refletidas na musculatura subjacente (Dagys, 1987; Suzuki-Okamura et al., 2015). Portanto, se o tecido mole pode refletir o tecido duro, é possível estimar sua configuração por meio da inspeção das 
estruturas moles (McCance et al., 1997; Zecca et al., 2016). Entretanto, o sistema de escaneamento tridimensional facial a laser tem sido utilizado principalmente em casos de avaliação do tratamento cirúrgico e funcional da deformidade (Soncul e Bamber, 2004; Kau et a., 2006; Alves et al., 2009; Shimomatsu et al., 2012; Verzé et al., 2011, 2012; Ovsenik et al., 2013; Patel et al., 2015).

\subsection{Deformidade dentofacial}

No final do século XIX foi proposta por Angle a mais clara e simples classificação de normalidade da oclusão dentária, ainda utilizada como parâmetro essencial pelos clínicos e pesquisadores contemporâneos. Nesse sentido, a premissa de Angle é fundada na relação anteroposterior entre dentes maxilares e mandibulares, em que se existir uma linha dentária de oclusão e a cúspide mesiovestibular do primeiro molar superior ocluir no sulco mesiovestibular do primeiro molar inferior, então se encontra a chamada oclusão normal. A partir disso, qualquer desvio nesse esquema de oclusão ideal de Angle é considerado má oclusão, as chamadas classe I, classe II e classe III de Angle (Angle, 1907; Proffit et al., 2013).

Na presença apenas da má oclusão dentária, ou seja, considerando unicamente a relação sagital dos molares, se houver uma adequada relação esquelética, o tratamento ortodôntico é suficiente para alinhar os dentes e corrigir a oclusão desfavorável (Bailey et al., 1999). Entretanto, pode haver discrepância no esqueleto facial, os denominados Padrão II e Padrão III, resultantes do degrau sagital entre maxila e mandíbula (Capelozza Filho, 2004). Quando estes se manifestam em concomitância à má oclusão dentária, são então chamados de deformidades dentofacias (Relle e Silegy, 2004).

As deformidades dentofaciais são definidas como problemas de má oclusão dentária e esquelética de grande magnitude, sendo os desequilíbrios do esqueleto facial inseparáveis aos desarranjos dentários (Okazaki, 1999; Relle e Silegy, 2004). A etiologia da deformidade dentofacial ainda não é totalmente compreendida, pode ser produto de uma condição congênita e hereditária, associada ou não a um distúrbio no crescimento e desenvolvimento. Fato que torna sua classificação ainda mais complexa, pois representa a combinação de 
problemas nos múltiplos planos do espaço (Relle e Silegy, 2004; AAOMS, 2012, 2013). De forma geral, no que diz respeito ao sentido anteroposterior, a hipoplasia mandibular é comumente associada à má oclusão dentária classe II de Angle e os sujeitos apresentam aumento da convexidade facial e retrusão mandibular. O oposto ocorre na hiperplasia mandibular, a qual é geralmente ligada à classe III de Angle e as características mais comuns são o perfil facial côncavo e prognatismo mandibular. Esta deformidade pode ocorrer, ainda, concomitantemente à hipoplasia maxilar (Relle e Silegy, 2004).

Em razão da íntima relação do complexo ósseo e muscular facial, o sistema estomatognático busca mecanismos compensatórios às suas estruturas e funções frente às desarmonias estabelecidas. Entretanto, as adaptações miofuncionais podem variar dependendo da magnitude e dos tipos de deformidades (Marchesan e Bianchini, 1999).

Tem sido demonstrado que a mastigação é uma das principais funções afetadas por essas desproporções dentárias e esqueléticas (Throckmorton et al., 1996, 2006; van den Braber et al., 2002, 2004; Iwase et al., 2006; AAOMS, 2013). E em virtude disso, os estudos têm apontado que em sujeitos com deformidade dentofacial há um prejuízo na atividade eletromiográfica dos músculos mastigatórios (Tate et al., 1994; Throckmorton et al., 1995; Zarrinkelk et al., 1995; Harper et al., 1997; van der Braber et al., 2004; Trawitzki et al., 2006a, 2010), menores valores de força de mordida (Tate et al., 1994; Throckmorton et al., 1995, 1996; Zarrinkelk et al., 1995; Iwase et al., 1998; van der Braber et al., 2004; Iwase et al., 2006; Goto et al., 2008; Trawitzki et al., 2011), menor espessura dos músculos masseteres (Trawitzki et al., 2006b, 2011), diminuição da área de contato oclusal (Iwase et al., 1998; Kobayashi et al., 2001; Ohkura et al., 2001; Iwase et al., 2006; Goto et al., 2008) e redução da eficiência mastigatória (Tate et al., 1994; Iwase et al., 2006 Picinato-Pirola et al., 2012).

Outros danos em decorrência à deformidade dentofacial são tão significativos quanto aos funcionais. Essa patologia pode produzir consequências negativas em termos sociais e psicológicos, visto que os sujeitos apresentam-se socialmente em desvantagem devido à sua baixa auto-estima e baixos níveis de autoconfiança (Rankin e Borah, 2001; Murphy et al., 2011; Soh e Narayan, 2013). Gera um impacto principalmente em relação à estética facial e inabilidades funcionais, sendo a mastigação uma das principais queixas (Laufer et al., 1976; Trawitzki et al., 2006a; Soh e Narayan, 2013). Portanto, a deformidade dentofacial não afeta 
apenas questões estruturais ou funcionais do complexo craniofacial, mas também interfere diretamente na qualidade de vida dos sujeitos. Em virtude disso, exige percepções e motivações que sejam favoráveis para o sucesso do tratamento (Soh e Narayan, 2013).

Como modalidade terapêutica, a cirurgia ortognática é um método consagrado para o tratamento da deformidade desde o século XIX, nos Estados Unidos (Steinhouser, 1996). É definida como procedimentos cirúrgicos reconstrutivos para anormalidades da maxila, mandíbula ou ambas. Envolve o tratamento ortodôntico pré-cirúrgico para alinhamento e nivelamento dos arcos dentários às bases ósseas e a escolha das técnicas cirúrgicas mais apropriadas, o que vai depender, também, das percepções do paciente sobre os aspectos vantajosos ou não das mesmas (Xavier et al., 2009; Murphy et al., 2011). Proporciona a correção da deformidade esquelética por meio do reposicionamento maxilomandibular, a fim de favorecer a harmonia facial e o aspecto funcional (Murphy et al., 2011; AAOMS, 2012, 2013; Kilinc e Ertas, 2015).

Portanto, os produtos da cirurgia ortognática são os efeitos estéticos positivos e o equilíbrio esquelético facial, os quais favorecem a execução das funções mastigação, respiração, deglutição e fala (Trawitzki et al., 2009). Contudo, esse tratamento isolado não garante a recuperação muscular completa (Marchesan e Bianchini, 1999) e o desempenho adequado dessas funções estomatognáticas (Trawitzki et al., 2009). Assim, outras especialidades não cirúrgicas, sendo a Fonoaudiologia uma delas, podem desempenhar um importante papel na complementação ao tratamento, que deve ser multiprofissional (Marchesan e Bianchini, 1999; Trawitzki et al., 2009; AAOMS, 2012).

Os sujeitos que são submetidos ao tratamento ortodôntico e cirúrgico para a correção das relações esqueléticas e dentárias desfavoráveis, são caracterizados por diversas morfologias craniofaciais (Rowlerson et al., 2005). Sendo a recuperação da função mastigatória um dos principais objetivos da cirurgia ortognática (Kobayashi et al., 2001; Iwase et al., 2006; AAOMS, 2013), estudos tentam ainda investigar quais as prováveis relações entre a estrutura óssea e as condições musculares, e quais variáveis que realmente são determinantes para a biomecânica orofacial e recuperação das funções estomatognáticas em sujeitos com tais deformidades. Alguns autores acreditam que a altura anterior da face, assim como em sujeitos sem a deformidade dentofacial, exerça significativa 
influência na força de mordida (Throckmorton et al., 1995, 1999, 2000; Zarrinkelk et al., 1995, 1996; Thorckmorton e Ellis III, 2001; Harada et al., 2003), visto que a relação anteroposterior maxilomandibular parece não ser um potencial influenciador (Throckmorton et al., 2000).

\subsection{Força de mordida}

A musculatura esquelética humana possui como suas principais funções mecânicas a capacidade de produzir força e gerar energia. Os músculos esqueléticos mantêm a integridade do esqueleto e permitem o desempenho das atividades necessárias e inerentes e à vida (Harridge, 2007). O sistema arquitetônico dos músculos mandibulares se destaca por sua singularidade em relação aos músculos do tronco e dos membros (Korfage et al., 2005b).

Os músculos mandibulares participam de uma gama de tarefas motoras, como a fala, mastigação e deglutição. Para desempenhar as distintas funções, que requerem diferentes velocidades de contração, eles devem ser abeis para controlar precisamente a posição mandibular e aplicar variadas modulações de força. Essa especificidade muscular se deve à complexa anatomia da composição de suas fibras musculares (Korfage et al., 2005a).

A funcionalidade dos músculos mandibulares é altamente dependente das propriedades fisiológicas de suas unidades motoras, que são caracterizadas como a combinação de um único neurônio motor e todas as fibras musculares que ele inerva (Korfage et al., 2005a). Uma fibra muscular contém diversas miofibrilas, que são compostas por sarcômeros, os quais são constituídos das proteínas actina e miosina e são considerados a própria unidade funcional contrátil da fibra muscular. Dessa forma, é possível dizer que a velocidade de contração da unidade motora está diretamente relacionada à myosin heavy chain ou cadeia pesada de miosina (MyHC), dentro das fibras musculares. Com base nas isoformas que a MyHC contém, as fibras musculares são classificadas em capacidade de velocidade de contração lenta e resistente (Tipo I) e capacidade de velocidade de contração rápida e mais fatigável (Tipo II - IIA, IIB, IIX) (Korfage et al., 2005a; Grunheid et al., 2009). 
De uma forma abrangente, quando um músculo é composto por um único tipo de fibra ele possui a capacidade de se especializar em um tipo de atividade. Entretanto, reduz sua habilidade de realizar outras ações. Dessa forma, tendo em vista que os músculos mandibulares desempenham multitarefas, há uma seleção de distintos tipos de fibras musculares. Sendo assim, é possível dizer que o considerável número de fibras híbridas na composição desse grupo muscular, tanto nos elevadores (temporais, masseteres e pterigóideos), quanto nos abaixadores (milohióideo, digástrico, geniohióideo) da mandíbula, é provavelmente em conseqüência da especificidade e abrangência de sua demanda funcional (Korfage et al., 2005a, b).

Então, quando uma tarefa motora é exigida, como a manutenção da contração em resistência à gravidade, para fornecer baixa velocidade de contração, as fibras lentas e resistentes à fadiga são recrutadas, a fim de contribuir com a maior parte da produção de força. Porém, quando alta velocidade de contração muscular é necessária, como em uma tarefa de fala ou mordida isométrica, as principais contribuintes são as fibras mais rápidas. Em relação à função mastigatória, pode ser esperado como resultado majoritário a atividade das fibras mais lentas e se a velocidade ou força de mastigação aumentar, assim fibras adicionais (rápidas e fatigáveis) são também empregadas (Korfage et al., 2005a).

A mastigação é, portanto, uma função neuromuscular altamente coordenada que exige um elevado arranjo dos músculos mastigatórios, os quais tem como principal objetivo a fragmentação do bolo alimentar em partículas suficientes para iniciar o processo de deglutição, sendo também o primeiro passo para a digestão e absorção de nutrientes (Karkaziz e Kolssioni, 1998; Turker, 2002; van den Braber et al., 2002; Ikebe et al., 2011; van der Bilt, 2011).

Para o desempenho dessa função, os neurônios motores são necessariamente ativados por três principais fontes: o córtex motor, o qual deve iniciar e interromper a mastigação; o gerador de padrão central, localizado no tronco cerebral e responsável pela atividade rítmica de abertura e fechamento da mandíbula associados aos movimentos de lábios, língua e bochechas; e os receptores periodontais, que são a poderosa entrada periférica e encarregada pelo ajuste preciso das forças mastigatórias em resposta à exigência da consistência alimentar (Turker, 2002; Lund e Kolta, 2006; van der Bilt, 2011). 
Dessa forma, o comportamento mastigatório exige o envolvimento de diferentes estruturas que exercem papel significativo em cada etapa dessa função. Pode-se dizer que para que haja um efetivo desempenho da mastigação, deve haver o trabalho conjunto dos nervos trigêmeo, facial e hipoglosso, músculos elevadores da mandíbula, supra e infrahióideos, bucinadores, músculos da língua, lábios e pescoço, além da mandíbula, maxila, articulação temporomandibular, dentes, periodonto e palato (Felício, 1999).

O complexo sistema mastigatório gera a contração isométrica e coordenada da musculatura elevadora da mandíbula, a qual é responsável pela produção de força mastigatória (Calderon et al., 2006; Douglas, 2006; Castelo et al., 2010). A força é, portanto, um dos principais componentes desse sistema, sendo definida como a capacidade dos músculos elevadores da mandíbula em desempenhar a máxima pressão dos dentes mandibulares contra os dentes maxilares (Pellizer e Muench, 1997; Castelo et al., 2010).

A força de mordida tem sido alvo de estudo principalmente em virtude do seu potencial de influência no desenvolvimento da função mastigatória (Sondang et al., 2003; Pereira-Cenci, 2007) e por ser considerada um importante indicador funcional do complexo estomatognático (van der Bilt et al., 2008).

A eficiência mastigatória é a própria capacidade do indivíduo de triturar o alimento, por meio de ciclos mastigatórios. Muitos fatores são conhecidos como importantes indutores às alterações no padrão dessa performance, como a área de contato oclusal, presença e grau de má oclusão, fluxo salivar, consistência alimentar, força de mordida, idade, sexo e feedback sensorial (van der Bilt, 2011).

Considerando que a força de mordida é um dos preditores chave para a promoção da saúde desse sistema (Hatch et al., 2000) e buscando melhor compreender o comportamento mastigatório, estudos tem relacionado essa grandeza com diversas variáveis.

Em relação à idade, os valores de força de mordida parecem aumentar na infância durante o período de crescimento (Braun et al., 1996), tendem a ser ainda maiores, porém estáveis, na fase adulta (Braun et a., 1995) e podem declinar em idade mais avançada (Ikebe et al., 2005). Entretanto, considera-se que depois da idade adulta a diminuição da força de 
mordida esteja associada à perda de dentes e xerostomia. Contudo, essas não são consideradas características fisiológicas da idade. Assim, se a saúde oral e o número de dentes forem preservados com o aumento da idade, deve também haver uma manutenção adequada da habilidade mastigatória, já que a idade por si só não parece ser um fator de risco para a disfunção desse sistema (Hatch et al., 2000; Ikebe et al., 2005, 2011).

É evidente na literatura que há discrepância na força de mordida entre homens e mulheres (Bakke et al., 1990; Kiliaridis et al., 1993; Pelizzer e Muench, 1998; Calderon et al., 2006; Pereira-Cenci et al., 2007; Pizolato et al., 2007; Palinkas et al., 2010; Varga et al., 2011; Andersen e Sonnesen, 2013; Takaki et al., 2014), devido principalmente às diferenças anatômicas musculares entre os gêneros (Hatch et al., 2000; Pizolato et al., 2007). Tendo em vista que a força de mordida na infância é igual para meninos e meninas (Sonnesen et al., 2001; Sonnesen e Bakke, 2007), essa disparidade parece então, se concretizar na apenas idade adulta, após o crescimento e desenvolvimento craniofacial e conseqüente aumento de massa muscular dos músculos elevadores da mandíbula (Kiliaridis et al., 1993).

Os elementos dentários funcionais parecem ser um fator de peso no que diz respeito ao sistema estomatognático. Sem dúvida, a força de mordida é associada ao número de elementos dentários (Sonnesen e Bakke, 2005; Koç et al., 2010). Valores reduzidos de força de mordida são frequentemente atribuídos aos prejuízos na dentição (Bakke, 2006), perda de elementos dentários (Hatch et al., 2000) e uso de próteses dentárias (Pellizer e Muench, 1998).

A fragmentação das partículas alimentares também é amplamente dependente da área de contato oclusal (van der Bilt, 2011; Wang et al., 2011) e a área posterior, principalmente, está intimamente ligada à performance mastigatória (Julien et al., 1996; Gomes et al., 2011). Alguns autores observaram que existe uma redução da força de mordida associada à diminuição da área de contato oclusal, sendo o oposto também verdadeiro. Ou seja, maior área de contato contribui para valores melhores de força de mordida (Ingervall e Minder, 1997; Goto et al., 2008, Gomes et al., 2011; Lepley et al., 2011) e melhor eficiência mastigatória (Tate et al., 1994; Gomes et al., 2011).

Há tempos, é amplamente aceito que existe relação entre a morfologia craniofacial e a força de mordida (Alhaija et al., 2010). Os músculos mastigatórios podem exercer 
influência sobre o crescimento e desenvolvimento craniofacial, pois movimentam a mandíbula e empregam forças reacionárias aos dentes e às articulações temporomandibulares (Hannam e McMillan, 1994). Nesse sentido, a força de mordida pode ser um reflexo da forma, tendo em vista a geometria do sistema de alavanca mandibular. Esse sistema explana como determinadas diferenças na morfologia facial podem afetar a vantagem biomecânica dos músculos. Isto é, os elevadores da mandíbula parecem ter mais vantagem biomecânica quando o ramo mandibular está mais verticalizado e o ângulo goníaco mais agudo. Contudo, quando o ângulo goníaco aumenta, a vantagem biomecânica diminui, resultando em menor força de mordida (Throckmorton, 1980). Em virtude disso, diferentes autores constataram que em sujeitos face longa a força de mordida é menor do que em sujeitos face curta ou equilibrada (Proffit et al., 1983; Kiliaridis et al., 1993; Ingervall e Minder, 1997; Raadsheer et al., 1999; Throckmorton et al., 2000; Sondang et al., 2003; Castelo et al., 2008; Bonakdarchian et al., 2009; Alhaija et al., 2010; Custodio et al.. 2010; Koç et al., 2010; van Spronsen, 2010).

Com o propósito de esmiuçar as grandezas envolvidas com a força de mordida, têm sido feitas associações entre a espessura dos músculos mastigatórios e a força exercida por eles. Estudos demonstraram que ambas variáveis estão intimamente relacionadas, ou seja, quanto maior a espessura e tamanho desses músculos, principalmente os masseteres, mais elevada é a força de mordida (Raadsheer et al., 1999; Hatch et al., 2000; Pereira et al., 2007; Castelo et al., 2010; Uchida et al., 2011).

Porventura, em decorrência ao desarranjo oclusal e da biomecânica muscular, as más oclusões tem sido objeto de interesse dos pesquisadores, dado a sua conexão com a força de mordida (Bakke et al., 2006). A literatura demonstra que em diferentes tipos de más oclusões dentárias existe uma nítida redução nos valores da força dos músculos elevadores da mandíbula (Sonnesen et al., 2001; Castelo et al., 2008; Miyawaki et al., 2005; Andersen e Sonnesen, 2013; Araújo et al., 2014; Roldán et al., 2015). Nesse sentido, visto que as deformidades dentofaciais compreendem múltiplas desproporções oclusais, esqueléticas e musculares, também apresentam valores reduzidos de força de mordida em relação aos sujeitos sem esse tipo de má formação (Tate et al., 1994; Throckmorton et al., 1995, 1996, 1998; Zarrinkelk et al., 1995, 1996; Ellis III et al., 1996; Harada et al., 2000; Ohkura et al., 2001; Iwase et al., 2006; Goto et al., 1998; Trawitzki et al., 2011). Ainda não é 
explícita a causa exata de valores inferiores de força de mordida nessa população específica (Throckmorton, 2006), porém muito se especula sobre a pobre vantagem biomecânica dos músculos elevadores da mandíbula e a redução dos contatos oclusais (Ellis III et al., 1996; Tate et al., 1994; Harada et al., 2000).

Apesar da consagração pela literatura sobre a avaliação da força de mordida para a investigação de diversos parâmetros relacionados à anatomofisiopatologia do sistema estomatognático, o exame de força de mordida pode variar conforme o número de dentes em contato, local de mensuração no arco dentário, unilateral ou bilateral máxima intercuspidação dentária e equipamento utilizado (Bakke, 2006; Koç et al., 2010). Alguns dos principais estudos sobre o assunto divergem em sua metodologia aplicada, entretanto as ferramentas mais empregadas são: transdutores de pressão (Tate et al., 1994; Throckmorton et al., 1996; Throckmorton e Ellis III, 2001; Rentes et al., 2002); gnatodinamômetro (Pizolato et al., 2007; Pereira-Cenci et al., 2007; Trawitzki et al., 2011; Araújo et al., 2014; Kobayashi et al., 2014; Marquezin et al., 2014; Takaki et al., 2014), Occlusal Force Meter (Alhaija et al., 2010; Antonarakis e Kiliaridis, 2015) e Dental Prescale (Harada et al., 2000; Sondang et al., 2003; Miyawaki et al., 2005; Ikebe et al., 2005, 2011; Uchida et al., 2011; Moroi et al., 2015). 


\subsection{Considerações Éticas}

Inicialmente este estudo foi encaminhado ao Comitê de Ética em Pesquisa do Hospital das Clínicas da Faculdade de Medicina de Ribeirão Preto da Universidade de São Paulo (HCFMRP-USP) e recebeu a aprovação pelo mesmo para o seu desenvolvimento, através do processo HCRP $n^{\circ} 7722 / 2014$ (Anexo).

A partir dos critérios previamente estabelecidos para a composição deste estudo, os sujeitos foram convidados a cooperar em participação voluntária. $E$ então, foram esclarecidos quanto à proposição e aplicação do estudo, riscos, benefícios, despesas e possibilidade de desistência da participação em qualquer etapa, sem prejuízos ou interferência no seguimento médico e fonoaudiológico institucional. Em sequência, o TERMO DE CONSENTIMENTO LIVRE E ESCLARECIDO (Apêndices A, B) foi devidamente assinado pelo participante e pesquisador.

O presente estudo constitui-se de parte do trabalho "Relações morfofuncionais nas desordens temporomandibulares e nas deformidades dentofaciais", desenvolvido pelo Núcleo de Apoio à Pesquisa em Morfofisiologia Craniofacial da Universidade de São Paulo (NAP CF - USP).

\subsection{Casuística}

Compuseram a amostra sujeitos com o diagnóstico de deformidade dentofacial, bem como sujeitos saudáveis, de idades entre 18 e 45 anos, dos sexos feminino e masculino.

O Centro Integrado de Estudos das Deformidades da Face do Hospital das Clínicas da Faculdade de Medicina de Ribeirão Preto da Universidade de São Paulo (CIEDEF - HCFMRP USP) é composto por uma equipe de cirurgiões de cabeça e pescoço, fonoaudiólogos, ortodontistas e psicólogo e dedica-se ao tratamento transdisciplinar de patologias, a incluir a deformidade dentofacial. Os sujeitos, com tal diagnóstico colaboradores com este estudo, 
foram provenientes do CIEDEF e, portanto, apresentavam respectiva documentação ortodôntica para eventual consulta.

O grupo denominado deformidade dentofacial (DDF) abrangeu sujeitos com presença de alterações esqueléticas no sentido sagital associadas à classificação de Angle de má oclusão (Angle, 1907). Assim, foram incluídos sujeitos com retrognatismo mandibular e/ou excesso de crescimento maxilar, associados à classe II de Angle e sujeitos com presença de prognatismo mandibular e/ou deficiência maxilar associados à classe III de Angle.

O subgrupo DDF II foi composto por 20 sujeitos (4 homens e 16 mulheres), com média de idade de 26 anos e IMC médio 22,5 (mínimo 19,4 e máximo 34,1). E o subgrupo DDF III foi composto por 32 sujeitos (15 homens e 17 mulheres), com média de idade de 27 anos e IMC médio 24,41 (mínimo 18 e máximo 32,5). Os sujeitos de ambos os grupos apresentaram-se em preparo ortodôntico para a cirurgia ortognática.

O grupo denominado controle (GC) abrangeu sujeitos saudáveis, com relação molar ideal (classe I de Angle) (Angle, 1907)), provenientes da cidade de Ribeirão Preto. Foi composto por 25 sujeitos (9 homens e 16 mulheres), com média de idade de 24 anos e IMC médio 22,9 (mínimo 17,9 e máximo 29,4).

A casuística supracitada do estudo foi organizada de acordo com os fluxogramas apresentados nas Figuras 1 e 2. E todos os sujeitos foram eleitos em conformidade com os critérios de inclusão e exclusão descritos a seguir.

\subsection{Critérios de inclusão}

Para o grupo DDF, foram incluídos no estudo sujeitos de nacionalidade brasileira, com o diagnóstico da deformidade dentofacial padrão dentoesquelético II e padrão dentoesquelético III com indicação cirúrgica para a correção da deformidade, na presença ou ausência de alterações oclusais e esqueléticas concomitantes nos sentidos transversal e vertical. 
Para o grupo controle, foram incluídos sujeitos de nacionalidade brasileira, saudáveis, com oclusão dentária em classe I, segundo a classificação de Angle (Angle, 1907), presença de no mínimo 28 dentes permanentes e overjet e overbite entre 2 e $4 \mathrm{~mm}$.

\subsection{Critérios de exclusão}

Não foi selecionado qualquer sujeito com histórico de trauma, hiperplasia condilar, tumor ou cirurgia nas regiões da cabeça e pescoço, distúrbio neurológico central ou periférico e uso crônico de medicamentos analgésicos, anti-inflamatórios ou psicotrópicos.

Em relação ao grupo DDF, foram excluídos ainda os sujeitos com mais de uma ausência dentária por lado de arcada superior e inferior.

Em relação ao GC, também foram excluídos os sujeitos com presença qualquer diagnóstico de má oclusão dentária ou esquelética, distúrbio miofuncional orofacial, presença de sinais e sintomas de desordem temporomandibular (DTM) e em período concomitante de tratamento ortodôntico, fisioterápico ou fonoaudiológico. 
Figura 1. Fluxograma da composição do grupo deformidade dentofacial.

\section{Recrutamento grupo DDF}

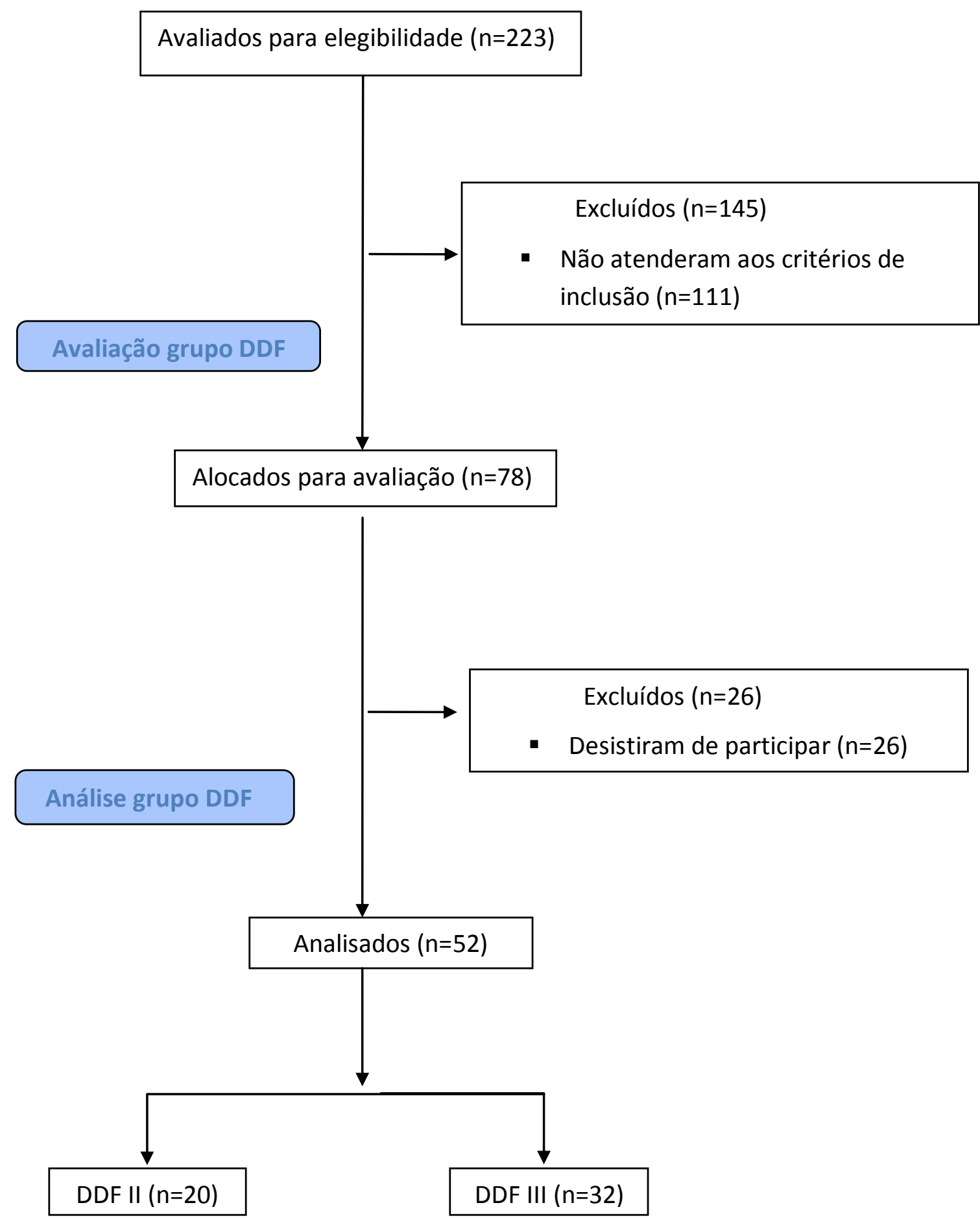

DDF: grupo deformidade dentofacial; DDF II: grupo deformidade dentofacial padrão dentoesquelético II; DDF III: grupo deformidade dentofacial padrão dentoesquelético III.

Fonte: Simões (2017). 
Figura 2. Fluxograma da composição do grupo controle.

\section{Recrutamento GC}

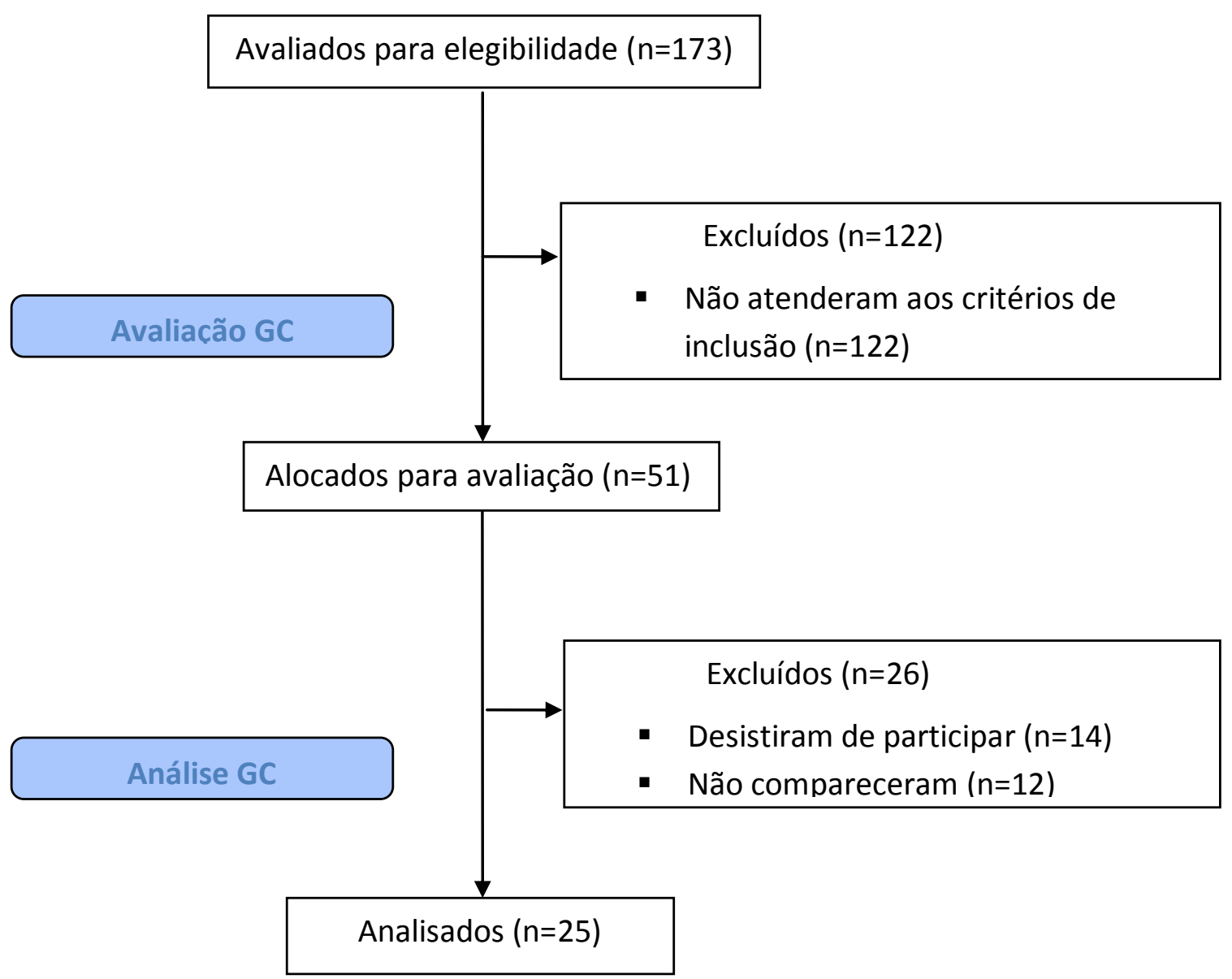

GC: grupo controle;

Fonte: Simões (2017). 


\subsection{Procedimentos}

A etapa de investigação fonoaudiológica proposta neste estudo foi realizada no Laboratório de Investigação do Sistema Estomatognático (LISE) do Curso de Fonoaudiologia do Departamento de Oftalmologia, Otorrinolaringologia e Cirurgia de Cabeça e Pescoço da Faculdade de Medicina de Ribeirão Preto da Universidade de São Paulo (FMRP-USP). E todos os procedimentos realizados ocorreram preferencialmente em um único dia para cada sujeito convocado.

\subsubsection{Triagem}

A triagem foi realizada com o propósito de constituir os grupos do estudo. Por meio de uma entrevista dirigida os sujeitos foram selecionados, respeitando com rigor os critérios de inclusão e exclusão estabelecidos.

\subsubsection{Avaliação da Condição Miofuncional Orofacial}

A avaliação da condição miofuncional orofacial foi adotada apenas com o propósito de selecionar o grupo controle ao constatar precisamente a ausência de distúrbio miofuncional orofacial e ruídos articulares. Foi realizada mediante ao Protocolo de Avaliação Miofuncional Orofacial com Escores (AMIOFE) (Felício e Ferreira, 2008). Por meio deste, é possível que o avaliador manifeste numericamente a sua percepção quanto ao estado das estruturas orofaciais e funções estomatognáticas. A partir do estudo de De Felício et al. (2012), esse instrumento foi validado para a população adulta e, baseado em seus escores, é possível determinar a presença e ausência de distúrbio miofuncional orofacial.

O AMIOFE segue o princípio da atribuição de uma nota para cada um de seus itens relativos à aparência, postura, mobilidade das estruturas orofaciais e funções 
estomatognáticas, sendo que quanto maior o escore, melhor é a condição miofuncional. Essa concessão é feita da seguinte forma para as estruturas e funções:

- Quanto ao aspecto e condição postural é concebível a atribuição de um escore total máximo de 18 para todos os itens dentro da normalidade, sendo que (3) é a nota para indicação de ausência de alteração, (2) para alteração discreta, (1) para alteração severa. Atribuiu-se para os lábios quando considerado vedados sem tensão (3), ocluídos com tensão discreta (2), ausência de oclusão leve (2) e severa (1); para a mandíbula foi considerado a manutenção do espaço funcional livre (3), ausência de espaço funcional livre (2), boca aberta (2) e abertura excessiva de boca (1); para as bochechas foi tido como normal (3), com leve volume aumentado/flácida ou arqueada (2) e volume severo (1); para a face quando analisada a simetria entre os lados direito e esquerdo atribuiu-se (3), assimetria leve (2) e severa (1); para a língua foi ponderado a normalidade quando contida em cavidade oral (3), interposta aos arcos dentários por adaptação (2) e protruída em excesso (3); para o palato duro foi considerado normal (3), estreito leve (2) e severo (1).

- Quanto à mobilidade de lábios (protrusão, retração e lateralidade), língua (protrusão, retração, elevação, abaixamento e lateralidade), mandíbula (abaixamento, elevação, lateralidade e protrusão) e bochechas (inflação, sugação, retração e lateralidade) é concebível a atribuição de um escore total máximo de 57. Foi considerado 12 para a normalidade dos movimentos de lábios, 18 de língua, 15 de mandíbula e 12 de bochechas, seguindo o critério de escore (3) para adequação aos movimentos, (2) para imprecisão e (3) para inabilidade severa.

- Quanto à função de respiração é concebível a atribuição de um escore total máximo de 3, sendo que adotou-se (3) para o modo respiratório nasal, (2) para oronasal leve e (1) para oronasal severa.

- Quanto à função de mastigação foi adotada a padronização do alimento bolacha Bono (Nestlé ${ }^{\oplus}$, São Paulo, Brasil) sabor chocolate. É concebível para essa prova a atribuição de um escore total máximo de 10, que inclui o padrão de mordida e trituração do alimento. Assim, (3) foi considerado para o padrão de mordida com dentes incisivos, (2) dentes posteriores e (1) para ausência de mordida. E (4) para o tipo bilateral alternada, (3) bilateral simultânea, (2) preferencial (66\% do mesmo lado), (1) crônica (95\% do mesmo lado), (1) 
trituração anterior e (1) para não realização da função. Adicionalmente, foram considerados outros comportamentos e sinais de alteração, sendo que a ausência do comportamento adicionou escore (1) e presença (0) não acrescentou escore. Foram classificados indesejados os seguintes itens: movimentação de cabeça ou outras partes do corpo, postura alterada e escape extra oral do alimento.

- Quanto à função de deglutição de sólido foi adotada a padronização do mesmo alimento bolacha Bono (Nestlé ${ }^{\circledR}$, São Paulo, Brasil) sabor chocolate e deglutição do líquido água. É concebível para essa prova a atribuição de um escore total máximo de 16, sendo que foram considerados para os comportamentos dos lábios: (4) para ausência de esforço labial, (3) oclusão labial com discreto esforço, (2) esforço moderado e (1) esforço severo; para o comportamento da língua: (3) quando contida em cavidade oral, (2) para adaptação ou disfunção e (1) para a protrusão excessiva da língua. Adicionalmente a eficiência da deglutição foi ponderada quando para o bolo sólido: (3) não houve repetição de deglutição do mesmo bolo, (2) houve uma única repetição e (1) houve deglutições múltiplas; para o líquido (3) não houve repetição de deglutição do mesmo bolo, (2) houve uma única repetição e (1) houve deglutições múltiplas. E foram considerados outros comportamentos e sinais de alteração, sendo que a ausência do comportamento adicionou escore (1) e presença (0) não acrescentou escore. Foram classificados indesejados os seguintes itens: movimentação de cabeça, tensão dos músculos faciais e escape de alimento.

Para a avaliação foi utilizada uma filmadora digital marca/modelo JVC HDD Everio GZ-MG630 e um tripé ajustado quanto à altura e distância de 1 metro do sujeito, conforme padronização estabelecida por De Felício et al. (2010).

Durante o exame os sujeitos foram instruídos a permanecer sentados, em cadeira confortável com encosto, com os pés apoiados no chão, ombros e braços relaxados. No decorrer das análises da aparência e postura das estruturas orofaciais, os sujeitos foram orientados a permanecer sentados apenas com contato de olho com a lente da câmera para a observação correta do avaliador. Nas provas de mobilidade, foram instruídos a seguir o modelo fornecido pelo avaliador. Já na tarefa de mastigação, foram orientados a realizar o padrão mais próximo possível do habitual, assim como nas tarefas de deglutição de sólido e líquido. 
A última etapa do AMIOFE é composta pela avaliação funcional da oclusão. Esta foi realizada por meio de um paquímetro digital da marca Mitutoyo ${ }^{\circledR}$, modelo 500-144B (Suzano, São Paulo, Brasil). A princípio verificou-se a presença ou ausência do desvio de linha média. Por conseguinte, a medida de abertura bucal foi extraída a partir da realização do sujeito da máxima abertura bucal, distância interincisal acrescida do valor do trespasse vertical. Enquanto isso, para a lateralidade o sujeito foi instruído a realizar a máxima excursão da mandíbula para um dado e depois para o outro lado, considerando a linha média (coincidente ou não). E para o movimento de protrusão, os sujeitos realizaram a máxima excursão da mandíbula para frente e também foi considerado o valor do trespasse vertical. Foi verificada, ao final, a presença ou ausência de desvios mandibulares aos movimentos de abertura e protrusão e presença ou ausência de ruído articular, segundo a palpação em região das articulações temporomandibulares.

\subsubsection{Avaliação Tridimensional da Morfologia Facial}

A avaliação tridimensional da morfologia facial foi realizada por meio de um escaneamento facial a laser advindo do FastSCAN ${ }^{\mathrm{TM}}$ Scorpion laser scanner (Polhemus, Inc., Colchester, USA). Esse equipamento digitaliza de forma rápida e conveniente a superfície de qualquer objeto em uma série de pontos que se encaixam no espaço 3D. Assim, o software transforma esses dados em um objeto 3D detalhado. O conjunto FastSCAN ${ }^{\mathrm{TM}}$ é composto por uma haste confeccionada para o encaixe das mãos, com uma câmera acoplada em cada extremidade e uma fonte de laser na região central. Possui ainda uma unidade de processamento, um receptor em formato de cubo pequeno, um transmissor em formato de cubo maior, e o software FastSCAN ${ }^{\mathrm{TM}}$ (Figura 3. A, B). 
Figura 3. A. Digitalizador; B. Sistema FastSCAN ${ }^{\mathrm{TM}}$ completo.
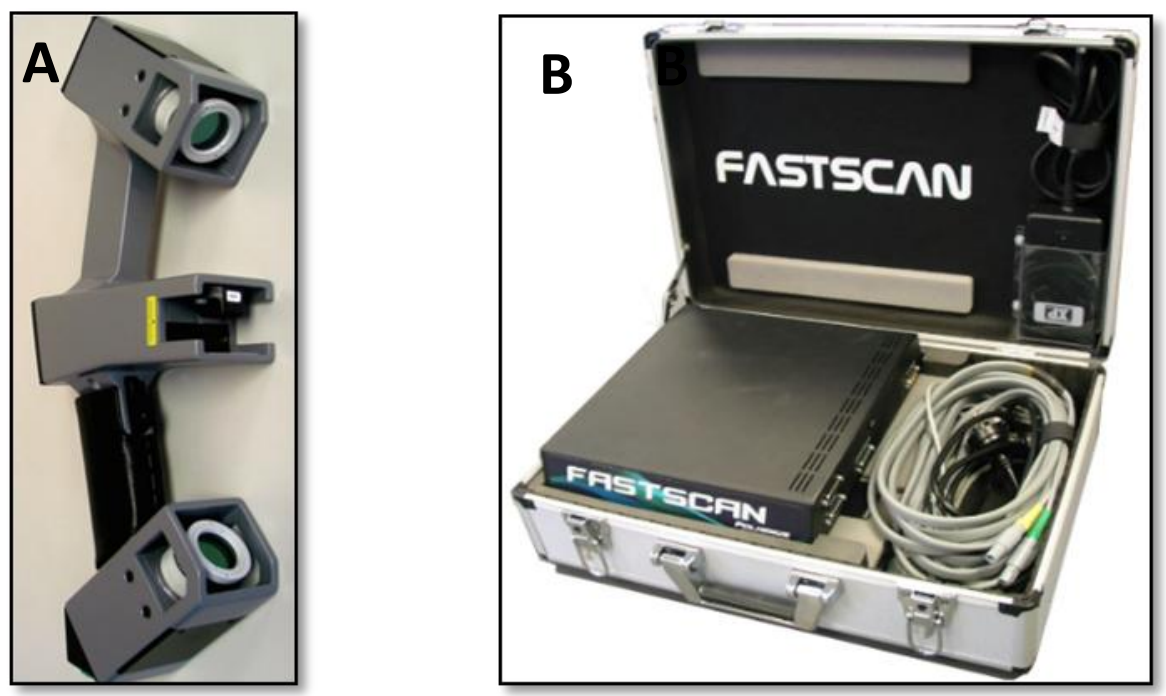

Fonte: Simões (2017).

Trata-se de uma fonte de laser que é projetada sobre a face do sujeito e a luz, então, é refletida e capturada pelas duas câmeras. Para adquirir a imagem, o sensor receptor foi adaptado à cabeça do sujeito com o auxílio de um suporte plástico, com a finalidade de corrigir eventuais movimentos da cabeça. O transmissor, ajustado a um pedestal de costas para o sujeito e de acordo com a sua estatura, envia a imagem para o computador acoplado e, então, a superfície escaneada é reconstruída tridimensionalmente em um modelo virtual (Figura 4. B).

No próprio laboratório que os exames foram efetuados, foi realizado um teste com o sistema FastSCAN ${ }^{\mathrm{TM}}$, em que a confiabilidade apresentou-se menor que $1 \mathrm{~mm}$, a qual certificou segurança para a execução das avaliações.

Para que o procedimento fosse realizado, o sujeito foi orientado a permanecer em pé, em postura ereta, de costas para o pedestal, com olhar em direção ao horizonte e mantendo a posição natural de cabeça (Figura 4. A). Todos foram instruídos a adotar sua expressão facial habitual de repouso (neutra), com a musculatura facial e corporal relaxada. Durante o exame, os indivíduos não foram autorizados a usar adereços como brincos, óculos ou bonés. 
Figura 4. A. Escaneamento facial; B. FastSCAM ${ }^{\mathrm{TM}}$ e imagem 3D.
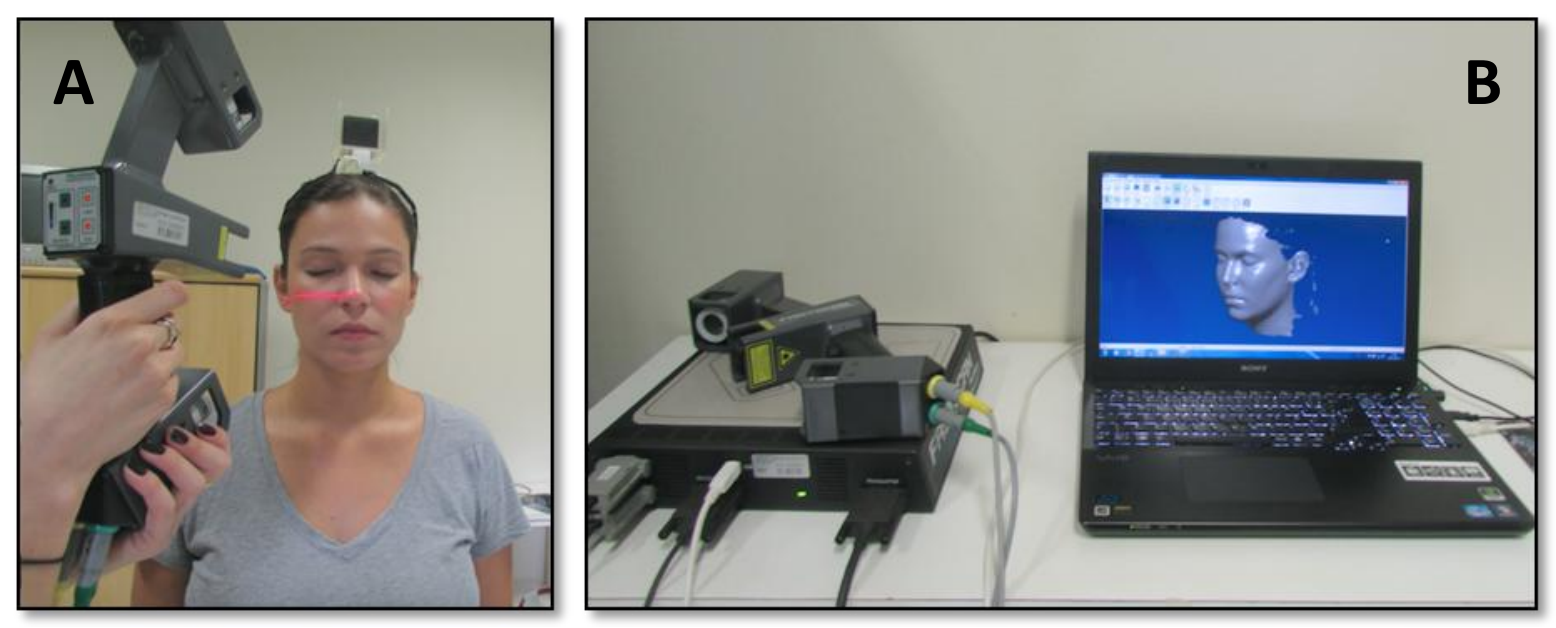

Fonte: Simões (2017).

Para a obtenção das medidas das dimensões faciais, foi confeccionado um protocolo específico (Quadros 1, 2 e 3), embasado em literatura, o qual contém pontos antropométricos de tecido mole facial, segundo Farkas, 1994 (Figura 5). A partir dos mesmos, foram criadas as medidas das distâncias lineares (Figuras 6. A, B, C, D, E, F; Figuras 7. A, B, C, D) e das proporções faciais inerentes aos objetos de estudo da pesquisa (Figuras 8. $A, B, C, D, E)$. Após o escaneamento, foram assinalados manualmente os pontos e proporções de interesse na imagem tridimensional. O software utilizado foi o Geomagic Studio 2013 (Geomagic, Research Triangle Park, NC, USA). 
Quadro 1. Descrição original dos pontos antropométricos de tecido mole facial definida por Farkas (1994).

\begin{tabular}{|c|c|}
\hline Ponto de referência & Descrição da localização do ponto \\
\hline Glabela (G) & Ponto mais proeminente da linha média entre as sobrancelhas. \\
\hline Subnasal (Sn) & $\begin{array}{c}\text { Ponto médio do ângulo da base da columela, em que a borda do } \\
\text { septo nasal e da superfície superior do lábio se encontram. }\end{array}$ \\
\hline Tragus direito (Td) & $\begin{array}{c}\text { Ponto localizado no encaixe da margem superior do tragus do } \\
\text { lado direito. }\end{array}$ \\
\hline Tragus esquerdo (Te) & $\begin{array}{c}\text { Ponto localizado no encaixe da margem superior do tragus do } \\
\text { lado esquerdo. }\end{array}$ \\
\hline Estômio (Sto) & $\begin{array}{c}\text { Ponto localizado no cruzamento da linha média vertical da face } \\
\text { com a fissura labial horizontal entre os lábios em oclusão. }\end{array}$ \\
\hline Cheilion direito (Chd) & Ponto localizado na comissura labial do lado direito. \\
\hline Cheilion esquerdo (Che) & Ponto localizado na comissura labial do lado esquerdo. \\
\hline Gnátio (Gn) & Ponto médio mais inferior do contorno da mandíbula. \\
\hline
\end{tabular}

Fonte: Simões (2017).

Figura 5. Modelo ilustrativo dos pontos antropométricos faciais, segundo Farkas (1994).

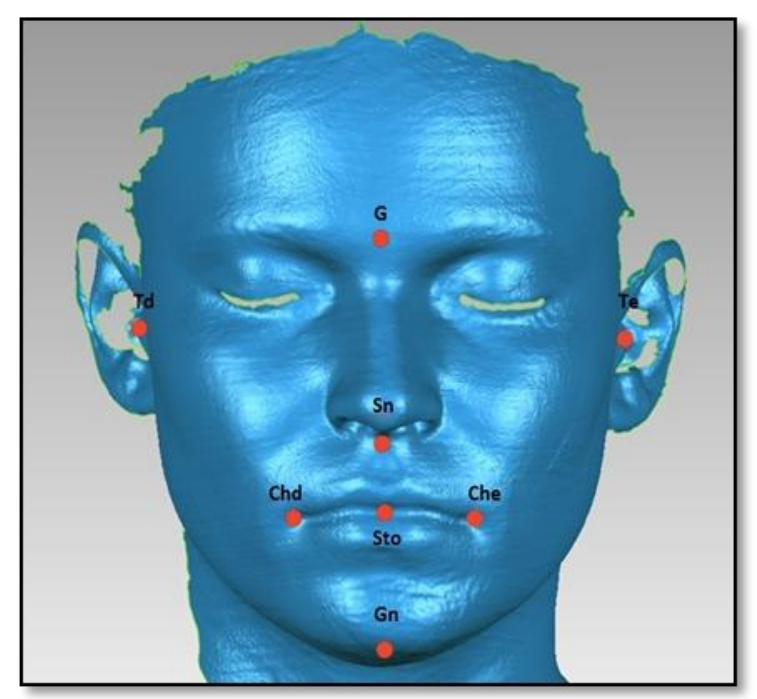

G: glabela; Td: tragus direito; Te: tragus esquerdo; Sn: subnasal; Sto: estômio; Chd: cheilion direito; Che: cheilion esquerdo; Gn: gnátio.

Fonte: Simões (2017). 
Quadro 2. Identificação e descrição das distâncias lineares confeccionadas para o estudo.

\begin{tabular}{|c|c|l|}
\hline Distâncias lineares (mm) & Modelo & \multicolumn{1}{|c|}{ Descrição da distância } \\
\hline Alustrativo & Figura 6. A & $\begin{array}{l}\text { Medida linear, em milímetro, relativa à } \\
\text { distância entre os pontos G-Gn. }\end{array}$ \\
\hline Largura facial & Figura 6. B & $\begin{array}{l}\text { Medida linear, em milímetro, relativa à } \\
\text { distância entre os pontos Td-Te. }\end{array}$ \\
\hline Terço médio & Figura 6. C & $\begin{array}{l}\text { Medida linear, em milímetro, relativa à } \\
\text { distância entre os pontos G-Sn. }\end{array}$ \\
\hline Terço inferior & Figura 6. D & $\begin{array}{l}\text { Medida linear, em milímetro, relativa à } \\
\text { distância entre os pontos Sn-Gn. }\end{array}$ \\
\hline Altura maxilar & Figura 6. E & $\begin{array}{l}\text { Medida linear, em milímetro, relativa à } \\
\text { distância entre os pontos Sn-Sto. }\end{array}$ \\
\hline Altura mandibular & Figura 6. F & $\begin{array}{l}\text { Medida linear, em milímetro, relativa à } \\
\text { distância entre os pontos Sto-Gn. }\end{array}$ \\
\hline Td-Chd & Figura 7. A & $\begin{array}{l}\text { Medida linear, em milímetro, relativa à } \\
\text { distância entre os pontos Td-Chd. }\end{array}$ \\
\hline Te-Che & Figura 7. B & $\begin{array}{l}\text { Medida linear, em milímetro, relativa à } \\
\text { distância entre os pontos Te-Che. }\end{array}$ \\
\hline Comprimento mandibular & Figura 7. D & $\begin{array}{l}\text { Medida linear, em milímetro, relativa à } \\
\text { distância entre os pontos T-Gn, sendo T o } \\
\text { ponto médio entre Td e Te. } \\
\text { distância entre os pontos T-Sn, sendo T o } \\
\text { ponto médio entre Td e Te. }\end{array}$ \\
\hline Figura 7. C
\end{tabular}

Fonte: Simões (2017). 
Figura 6. Distâncias lineares. A. Altura facial; B. Largura facial; C. Terço médio facial, D. Terço inferior facial; E. Altura maxilar; F. Altura mandibular.


Fonte: Simões (2017). 
Figura 7. Distâncias lineares. A. Distância linear Td-Chd; B. Distância linear Te-Che; C. Comprimento maxilar; D. Comprimento mandibular.
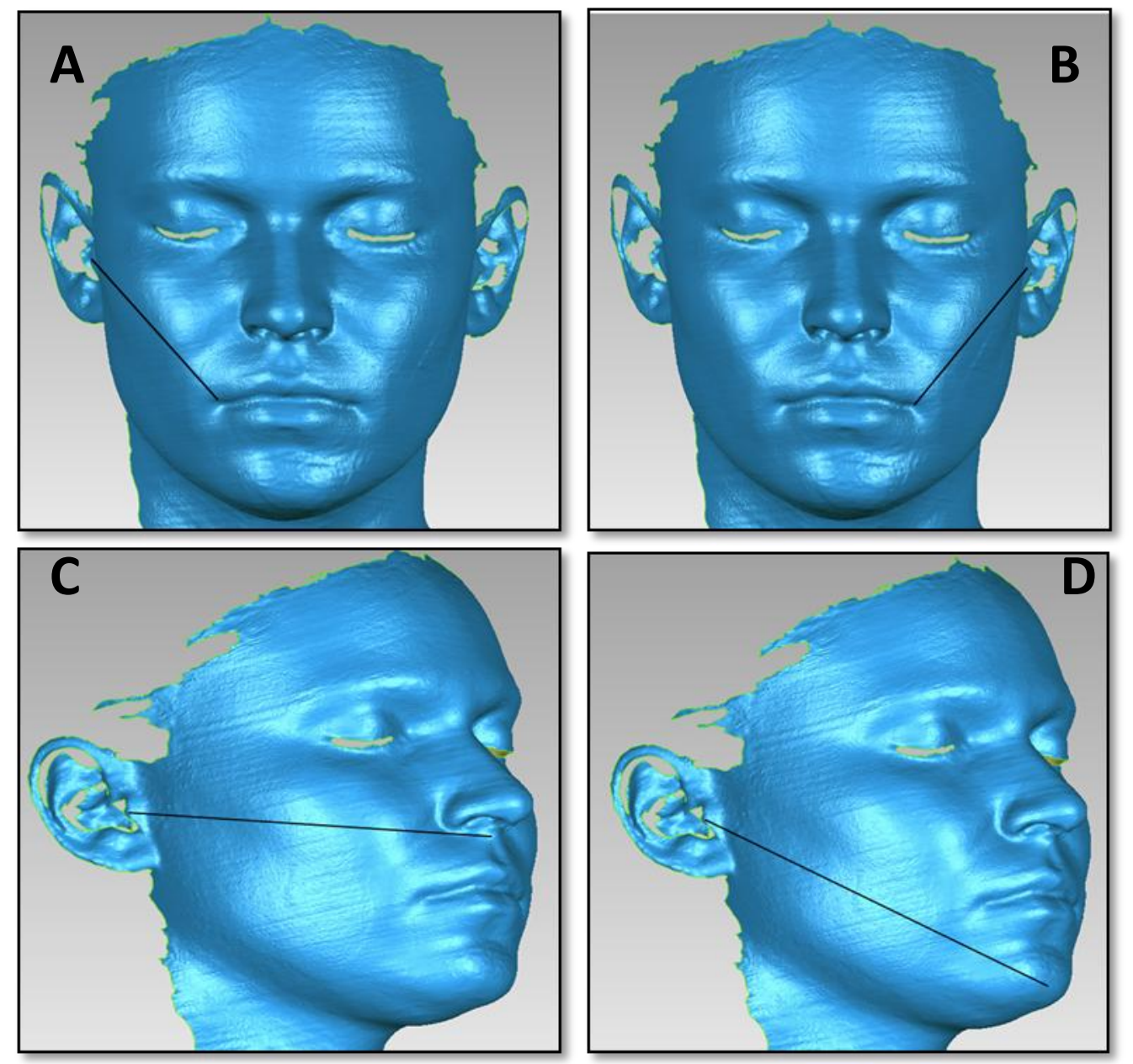

Fonte: Simões (2017). 
Quadro 3. Identificação e descrição das proporções faciais conceccionadas para o estudo.

\begin{tabular}{|c|c|l|}
\hline Proporções de referência (\%) & Modelo ilustrativo & \multicolumn{1}{|c|}{ Descrição da variável } \\
\hline Altura/Largura (\%) & Figura 8. A & $\begin{array}{l}\text { Índice, expresso em valor } \\
\text { percentual, relativo à razão da altura } \\
\text { facial (distância linear G-Gn) com a } \\
\text { largura facial (distância linear Td-Te). }\end{array}$ \\
\hline Terço médio/Terço inferior (\%) & Figura 8. B & $\begin{array}{l}\text { Indice, expresso em valor } \\
\text { percentual, relativo à razão das } \\
\text { distâncias do terço médio com o } \\
\text { terço inferior (distâncias lineares G- } \\
\text { Sn/Sn-Gn). }\end{array}$ \\
\hline Altura maxilar/mandibular (\%) & Figura 8. C & $\begin{array}{l}\text { Índice, expresso em valor } \\
\text { percentual, relativo à razão das } \\
\text { distâncias do terço inferior, em } \\
\text { termos de altura maxilar e altura } \\
\text { mandibular (distâncias lineares Sn- } \\
\text { Sto/Sto-Gn). }\end{array}$ \\
\hline Assimetria entre lados (\%) & Figura 8. D & $\begin{array}{l}\text { Diferença percentual relativo à } \\
\text { assimetria entre os lados direito e } \\
\text { esquerdo (Td-Chd/Te-Che). }\end{array}$ \\
\hline $\begin{array}{l}\text { Índice, expresso em valor } \\
\text { percentual, relativo à razão da } \\
\text { relação maxilomandibular, em } \\
\text { termos de comprimento maxilar e } \\
\text { comprimento mandibular (distâncias } \\
\text { lineares T-Sn/T-Gn). }\end{array}$
\end{tabular}

Fonte: Simões (2017). 
Figura 8. A. Proporções faciais. A. Altura/largura facial; B. Terço médio/terço inferior facial; C. Altura maxilar/altura mandibular facial; D. Assimetria entre os lados; E. Relação maxilomandibular.
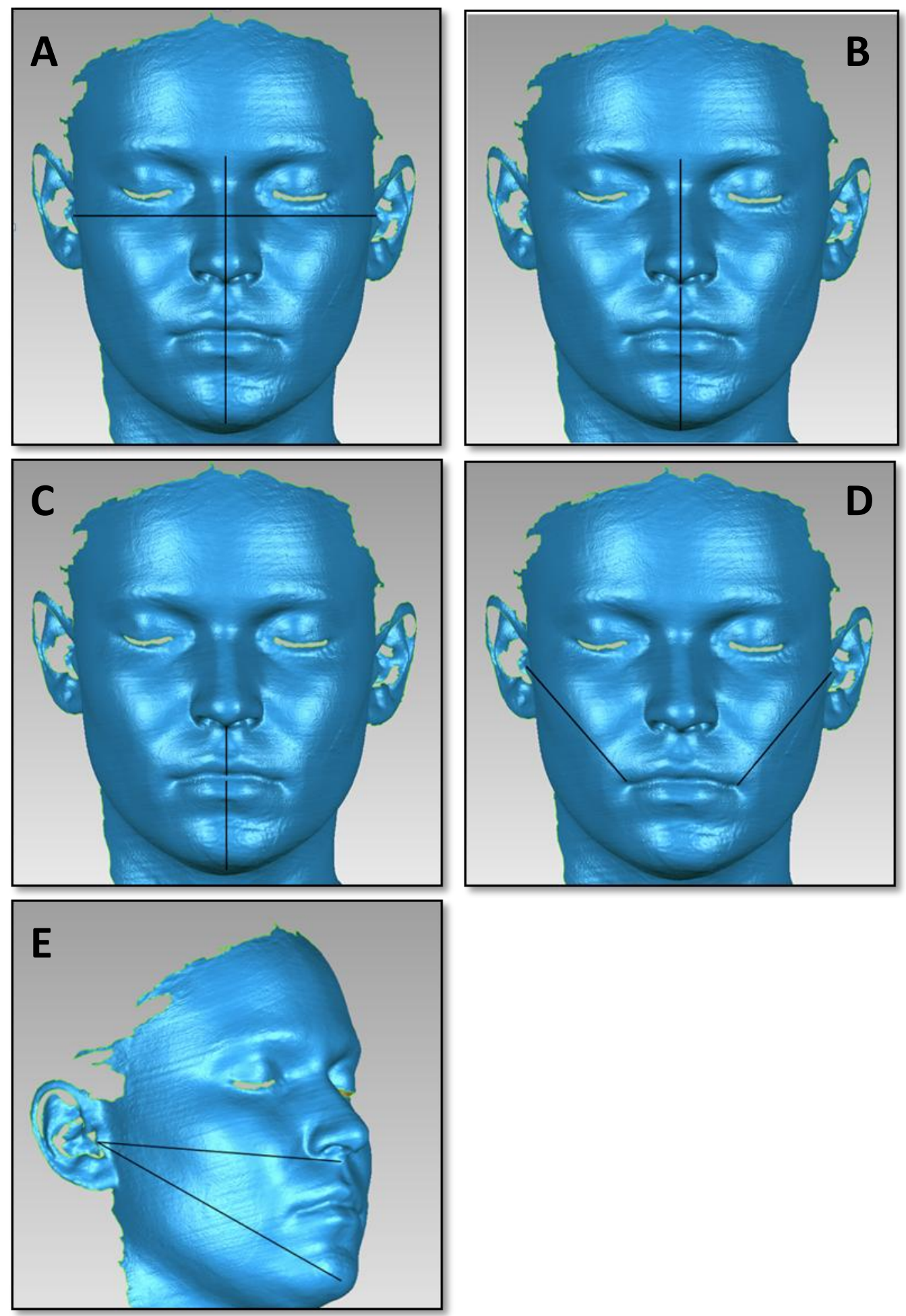

Fonte: Simões (2017). 


\subsubsection{Avaliação da Força de Mordida}

A avaliação da força de mordida foi realizada por meio do Gnatodinamômetro Eletrônico (modelo DDK/M - Kratos ${ }^{\circledR}$ Equipamentos Industriais, Cotia, São Paulo, Brasil). Esse equipamento é considerado leve, além de portátil e, segundo seu fabricante, foi especialmente desenvolvido para a determinação da força de mordida em humanos com capacidade para até 980 Newtons. É construído em caixa de alumínio, possui alimentação por bateria alcalina, um display de cristal líquido com 5 dígitos para a leitura, memória de pico máximo e escalas de quilograma força (Kgf), newtons (N) e libras força (Ibf). É também constituído por uma célula de carga de aproximadamente $10 \mathrm{~mm}$, especificamente desenvolvida para este fim (Figura 9. A).

Para a mensuração da força de mordida, os sujeitos foram instruídos a sentar-se confortavelmente em cadeira, sem sustento para cabeça, com os pés apoiados no chão e ombros e braços em posição de relaxamento. As hastes do equipamento, as quais possuem em suas extremidades dois discos de teflon, foram revestidas com dedeiras descartáveis de látex e posicionadas nos primeiros molares dos arcos dentários dos sujeitos. Dessa forma, os mesmos foram orientados a aplicar a sua máxima força de mordida e mantê-la em isometria por aproximadamente 5 segundos. Foram realizados 3 registros para cada lado de arcada, alternadamente, com descanso muscular de 2 minutos entre cada apertamento dentário (Figura 9.B). Então, os valores obtidos foram gravados e foram utilizadas as médias dos lados direito e esquerdo para análise posterior. As variáveis computadas são apresentadas no Quadro 4. 
Figura 9. A. Gnatodinamômetro Eletrônico; B. Avaliação da força de mordida.
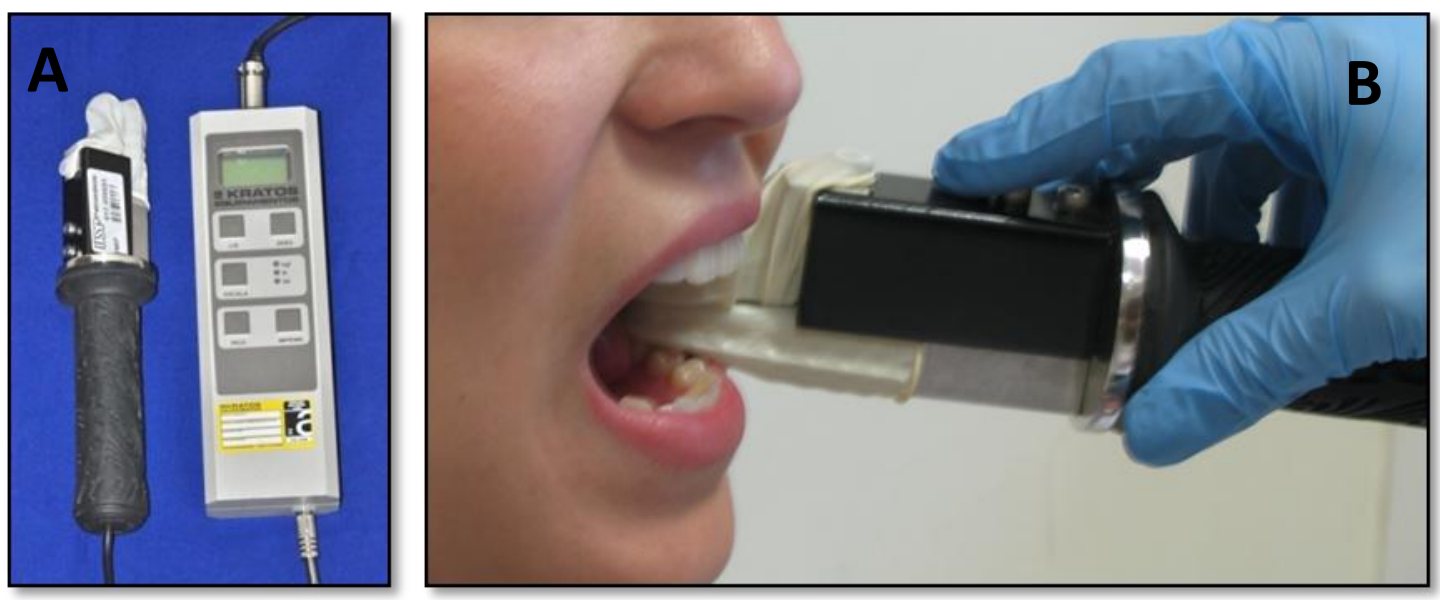

Fonte: Simões (2017).

Quadro 4. Descrição das variáveis relativas à força de mordida.

\begin{tabular}{|c|c|}
\hline Variável & Descrição \\
\hline FM D & $\begin{array}{l}\text { Índice, expresso em Newton, relativo ao valor médio da máxima força } \\
\text { de mordida do lado direito. }\end{array}$ \\
\hline FM E & $\begin{array}{l}\text { Índice, expresso em Newton, relativo ao valor médio da máxima força } \\
\text { de mordida do lado esquerdo. }\end{array}$ \\
\hline DPL & $\begin{array}{l}\text { Índice de assimetria, expresso em percentual, relativo à diferença da } \\
\text { máxima força de mordida entre os lados direito e esquerdo. }\end{array}$ \\
\hline
\end{tabular}

Fonte: Simões (2017).

\subsubsection{Análise da Distribuição de Força Oclusal}

A avaliação da distribuição de força oclusal foi realizada por meio do equipamento TScan8 (Tekscan Inc., Boston, MA, EUA). O sistema T-Scan8 é considerado confiável e de fácil domínio técnico. É uma ferramenta que permite registrar de forma dinâmica a força relativa das arcadas e a distribuição dos contatos dentários ao longo do tempo. Utiliza-se de um 
sensor digital para tais registros. Este se apresenta de forma descartável, com 1.370 células (de área de $1,6 \mathrm{~mm}^{2}$ ) sensíveis à pressão, e espessura de 0,1mm(Figura 10. A). O sistema TScan8(Figura 11. A) ainda compreende um suporte de material plástico, utilizado para acoplar o sensor, e que possui dois diferentes tamanhos, os quais são selecionados a partir do tamanho da cavidade oral do sujeito (Figura 10. B). Faz parte desse sistema o software Microsoft (MS) Windows-based e o hardware associado.

Para a execução do procedimento, os sujeitos foram instruídos a permaner sentados confortavelmente em cadeira sem suporte para a cabeça, com os pés apoiados no chão. O sensor acoplado ao suporte foi posicionado entre os arcos dentários e ajustado à cavidade oral do sujeito. Estes foram orientados a apertar o sensor em máxima intercuspidação dentária, aplicando a máxima força de mordida, constante do início ao final da prova. Foram realizados dois registros, com um breve intervalo entre eles para descanso da musculatura. Cada prova teve a duração de aproximadamente 6 segundos e, para as duas, o mesmo sensor foi utilizado (Figura 11.B). Por conseguinte, os dados foram registrados com em software do equipamento (Figura 12).

Figura 10. A. Sensor; B. Suporte e T-Scan.
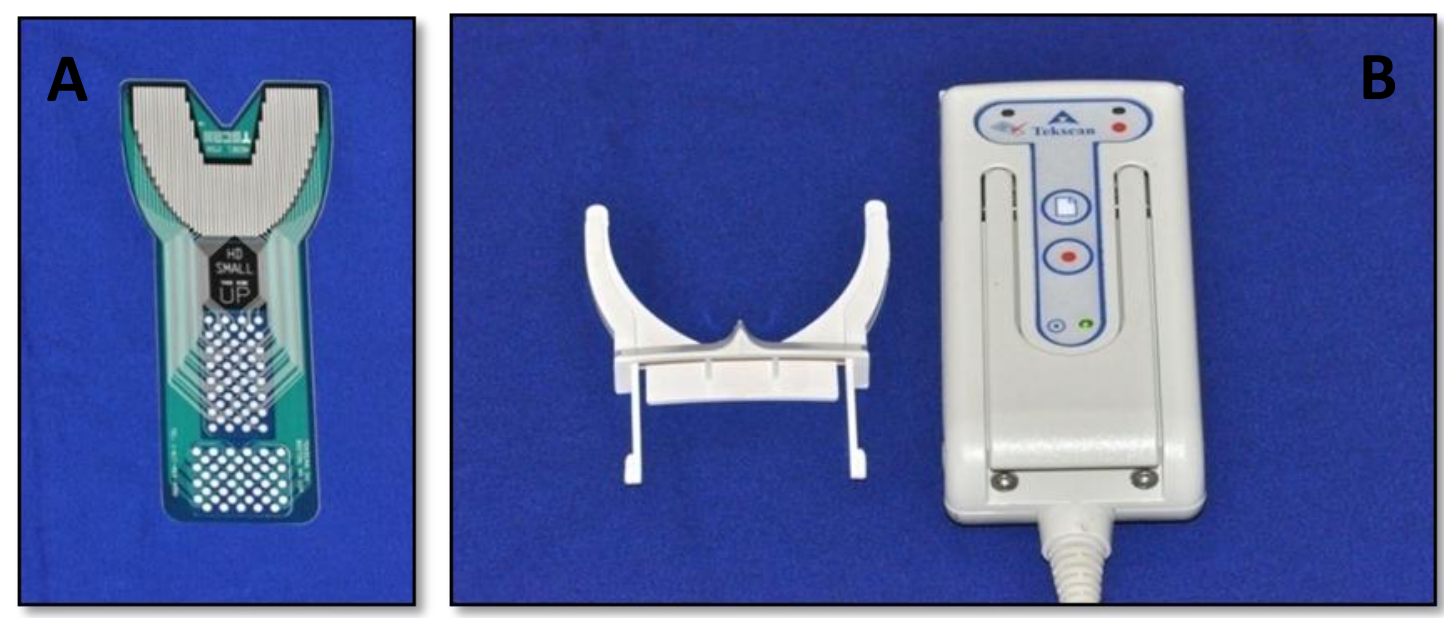

Fonte: Simões (2017). 
Figura 11. A. Conjunto do sensor, suporte e T-Scan; B. Avaliação da distribuição de força oclusal e área de contato oclusal.
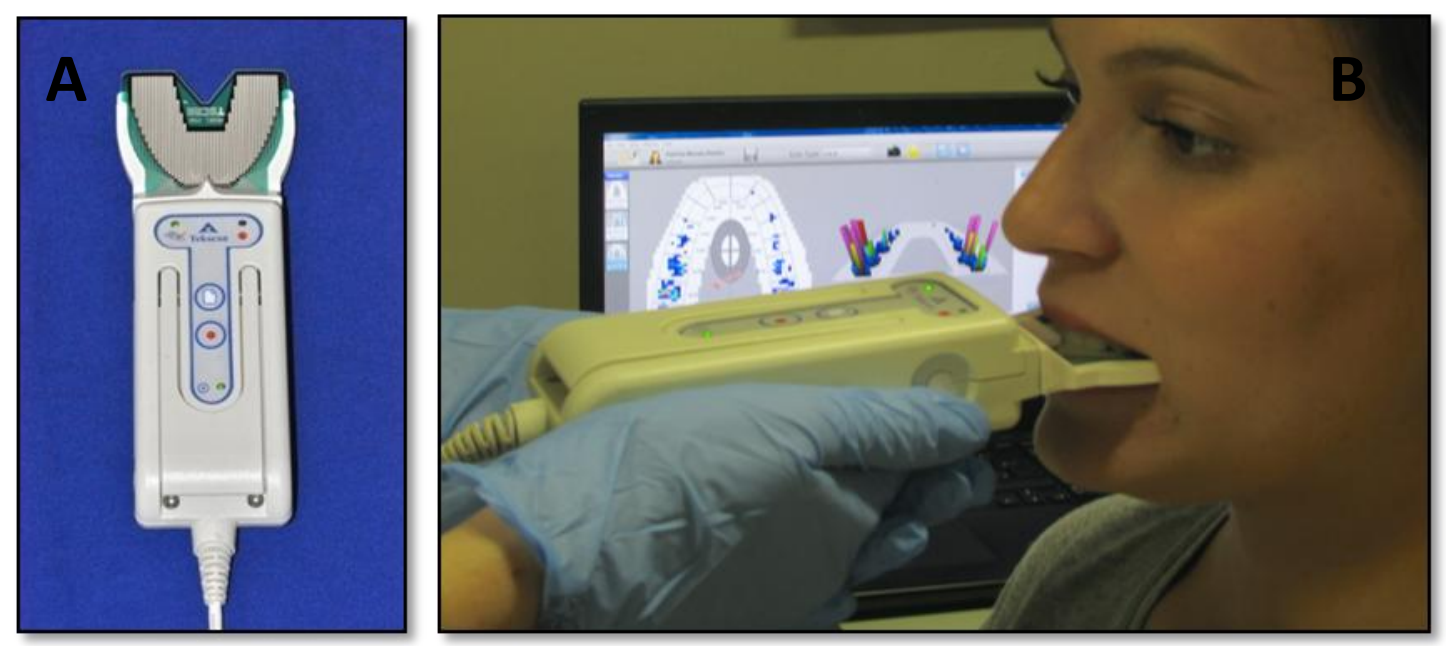

Fonte: Simões (2017).

O sistema fornece um gráfico completo com os registros em gravação contínua de toda a prova (Figura 12), porém para uma análise mais precisa dos dados, existem 3 possíveis formas de visualização, a saber: contatos iniciais, máxima intercuspidação dentária e máxima força relativa. Após a realização do exame, os seguintes parâmetros puderam ser avaliados: tempo de oclusão (TO), distribuição de força oclusal entre os lados esquerdo e direito e distribuição de força oclusal anteroposterior.

Figura 12. Gráfico ilustrativo com o registro da distribuição de força oclusal e área de contato oclusal.

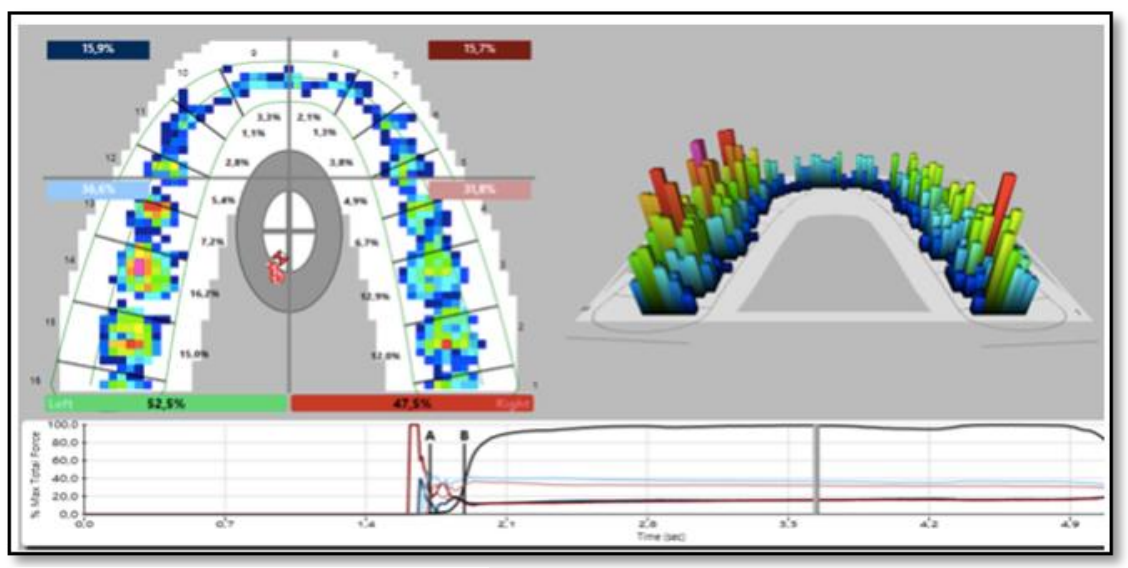

Fonte: Simões (2017). 
Para adquirir os parâmetros relacionados à área de contato oclusal foi desenvolvido um software específico, em ambiente Matlab versão 8.5 (MathWorks, Natick, MA, U.S.A.). O software utiliza a imagem colorida original fornecida pelo equipamento T-Scan8 (Figura 13.A), que mostra os contatos oclusais representados pelos vários elementos de sensores, em que cada um possui aproximadamente $1,6 \mathrm{~mm}^{2}$. Utilizando técnicas de processamento de imagens foi possível segmentar os contatos mostrados em preto pela Figura 13. B e estimar sua área total. Todas as gravações selecionadas foram referentes apenas ao momento de máxima força de mordida relativa fornecida pelo sistema (Quadro 5).

Figura 13. A. Imagem original dos contatos oclusais fornecida pelo equipamento; B. Imagem segmentada mostrando a área dos contatos em preto.
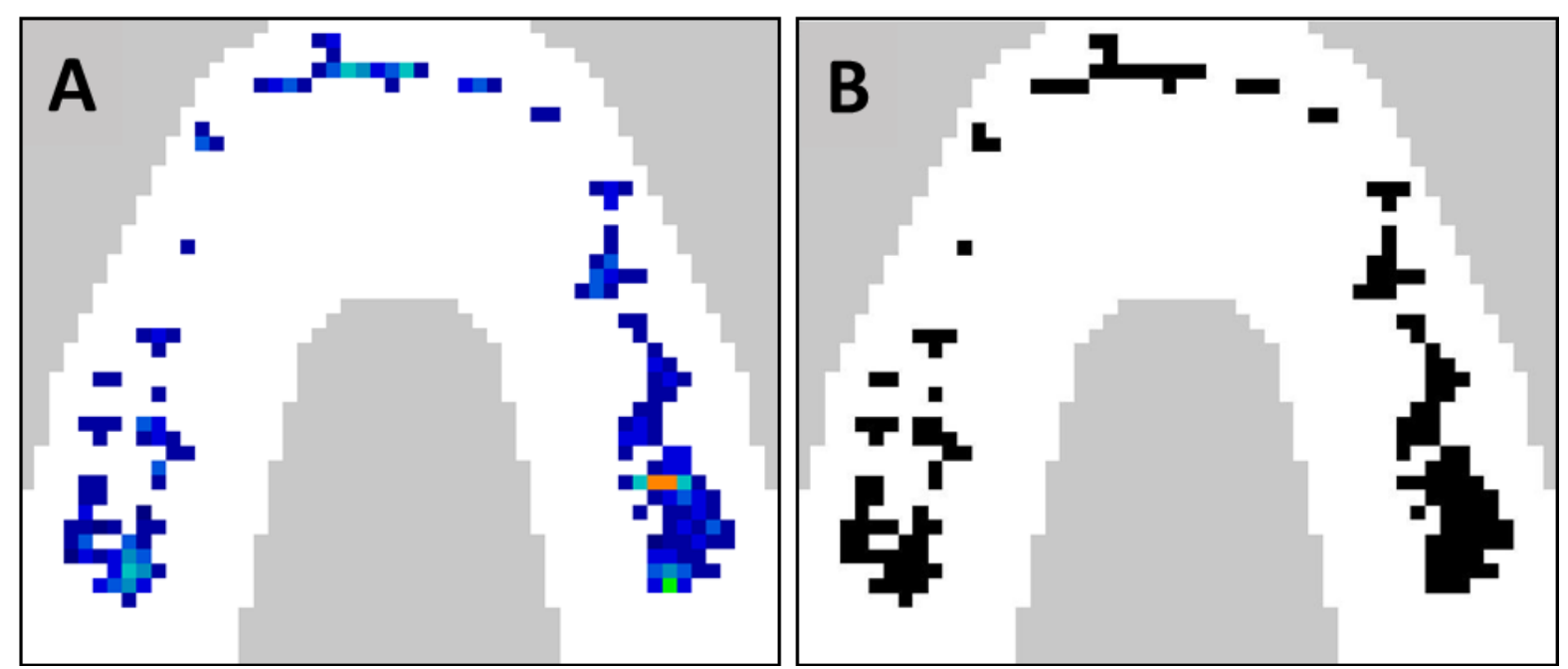

Fonte: Simões (2017). 
Quadro 5. Descrição das variáveis relativas à distribuição de força e área de contato oclusal.

\begin{tabular}{|c|c|c|}
\hline Variável & Definição & Descrição \\
\hline TO (s) & Tempo de oclusão. & $\begin{array}{l}\text { Tempo, medido em segundos, referente à } \\
\text { condição de máxima força. É computado a } \\
\text { partir do primeiro contato dentário até o } \\
\text { momento de } 95 \% \text { da máxima intercuspidação } \\
\text { na situação de máximo apertamento dentário. }\end{array}$ \\
\hline FE (\%) & $\begin{array}{l}\text { Índice relacionado à força } \\
\text { relativa máxima do lado } \\
\text { esquerdo. }\end{array}$ & $\begin{array}{l}\text { Distribuição da força oclusal total do lado } \\
\text { esquerdo, expressa em valor percentual, } \\
\text { referente à condição de máxima força, na } \\
\text { situação de máximo apertamento dentário. }\end{array}$ \\
\hline $\mathrm{FD}(\%)$ & $\begin{array}{l}\text { Índice relacionado à força } \\
\text { relativa máxima do lado direito. }\end{array}$ & $\begin{array}{l}\text { Distribuição da força oclusal total do lado } \\
\text { direito, expressa em valor percentual, } \\
\text { referente à condição de máxima força, na } \\
\text { situação de máximo apertamento dentário. }\end{array}$ \\
\hline FA (\%) & $\begin{array}{l}\text { Índice de força relativa } \\
\text { relacionada à máxima força } \\
\text { anterior de ambos os lados. }\end{array}$ & $\begin{array}{l}\text { Distribuição de força oclusal total anterior, } \\
\text { expressa em valor percentual, referente à } \\
\text { condição de máxima força, na situação de } \\
\text { máximo apertamento dentário. }\end{array}$ \\
\hline $\mathrm{FP}(\%)$ & $\begin{array}{l}\text { Índice de força relativa } \\
\text { relacionada à máxima força } \\
\text { posterior de ambos os lados. }\end{array}$ & $\begin{array}{l}\text { Distribuição de força oclusal total posterior, } \\
\text { expressa em valor percentual, referente à } \\
\text { condição de máxima força, na situação de } \\
\text { máximo apertamento dentário. }\end{array}$ \\
\hline$A D(\%)$ & Índice da área do lado direito. & $\begin{array}{l}\text { Distribuição dos contatos oclusais, expresso } \\
\text { em } \mathrm{mm}^{2} \text {, referente à área total do lado direito. }\end{array}$ \\
\hline$A E(\%)$ & Índice da área do lado esquerdo. & $\begin{array}{c}\text { Distribuição dos contatos oclusais, expresso } \\
\text { em } \mathrm{mm}^{2} \text {, referente à área total do lado } \\
\text { esquerdo. }\end{array}$ \\
\hline AT (\%) & $\begin{array}{l}\text { Índice da área total do lado } \\
\text { direito e esquerdo. }\end{array}$ & $\begin{array}{l}\text { Distribuição dos contatos oclusais relativos à } \\
\text { área total de ambos os lados, expresso em } \\
\mathrm{mm}^{2} .\end{array}$ \\
\hline $\operatorname{ASADE}(\%)$ & $\begin{array}{l}\text { Índice de assimetria de área total } \\
\text { entre lado direito e esquerdo. }\end{array}$ & $\begin{array}{l}\text { Diferença percentual entre a área total de dos } \\
\text { lados direito e esquerdo, expresso em } \mathrm{mm}^{2} \text {. }\end{array}$ \\
\hline
\end{tabular}

Fonte: Simões (2017). 


\subsection{Análise dos dados}

Os resultados foram apresentados por média e desvio padrão (DP). As comparações entre os grupos controle e de deformidades foram realizadas pela Análise de Variância (ANOVA) para amostras independentes. Quando a diferença estatística foi verificada, aplicou-se o pós-teste de Tukey-HSD (HonestlySignificantDifference). Nas variáveis em que os pressupostos para utilização da ANOVA não foram satisfeitos, alternativamente utilizouse o teste não paramétrico de Kruskall-Wallis, com pós-teste de Dunn. O teste de correlação de Spearman foi aplicado para avaliar as possíveis associações entre as medidas de força de mordida e as medidas antropométricas. Utilizou-se como abordagem multivariada a regressão linear múltiplapara identificar as variáveis antropométricas associadas à força de mordida, por meio do método de seleção stepwise, com critério de informação de Akaike (AIC). Todas as análises estatísticas foram realizadas pelo Software JMP (SAS Institute Inc., Cary, NC, U.S.A.). Foi adotado nível de significância de $5 \%(p<0,05)$. 
Os resultados serão apresentados em conformidade com os objetivos deste trabalho: a análise dos parâmetros da morfologia facial, força de mordida, distribuição de força dos contatos oclusais e área de contato oclusal entre as deformidades dentofaciais padrão dentoesquelético II e padrão dentoesquelético III, e em comparação com o grupo controle. Em seguida, serão apresentadas as correlações encontradas entre algumas das variáveis.

\subsection{Morfologia facial (distâncias lineares)}

Diante das distâncias lineares entre os pontos antropométricos previamente definidos, observou-se que houve diferença estatisticamente significativa $\left(p \leq 0,05^{*}\right)$ para todas as distâncias, exceto para a altura do terço médio da face (G-Sn), entre os três grupos. A Tabela 1 , a seguir, detalha as comparações.

Tabela 1. Média e desvio padrão das distâncias lineares entre os pontos antropométricos na comparação entre os três grupos.

\begin{tabular}{|c|c|c|c|c|c|c|c|}
\hline \multirow{2}{*}{ Distância (mm) } & \multicolumn{2}{|c|}{ DDF II $(N=20)$} & \multicolumn{2}{|c|}{ DDF III ( $N=32)$} & \multicolumn{2}{|c|}{$G C(N=25)$} & \multirow[t]{2}{*}{ P Valor * } \\
\hline & Média & DP & Média & DP & Média & DP & \\
\hline Altura facial & $132,3^{a}$ & 6,1 & $129,1^{a, b}$ & 7,2 & $126,6^{b}$ & 5,4 & $0,0162^{*}$ \\
\hline Largura facial & $140,9^{\mathrm{a}}$ & 8,4 & $146,9^{b}$ & 7,6 & $145,8^{a, b}$ & 6,5 & $0,0206^{*}$ \\
\hline Terço médio & 65,4 & 3,0 & 63,6 & 4,5 & 64,2 & 3,6 & 0,2703 \\
\hline Terço inferior & $70,9^{a}$ & 6,3 & $66,1^{b}$ & 5,2 & $64,1^{b}$ & 4,2 & $0,0002^{*}$ \\
\hline Altura maxilar & $24,5^{a}$ & 12,0 & $19,4^{b}$ & 2,8 & $20,6^{a, b}$ & 2,4 & $0,0227^{*}$ \\
\hline Altura mandibular & $49,7^{\mathrm{a}}$ & 6,9 & $47,1^{\mathrm{a}}$ & 3,7 & $43,7^{b}$ & 2,5 & $0,0001^{*}$ \\
\hline Comprimento maxilar & $98,5^{a, b}$ & 6,4 & $96,8^{a}$ & 7,0 & $102,7^{b}$ & 5,6 & $0,0033^{*}$ \\
\hline Comprimento mandibular & $110,3^{a}$ & 6,4 & $124,4^{b}$ & 7,2 & $119,3^{c}$ & 6,0 & $<, 0001^{*}$ \\
\hline Td-Chd & $103,4^{a}$ & 6,9 & $107,5^{b}$ & 4,7 & $106,9^{a, b}$ & 4,7 & $0,0263^{*}$ \\
\hline Te-Che & $101,1^{\mathrm{a}}$ & 5,2 & $106,5^{b}$ & 4,2 & $106,8^{b}$ & 4,3 & $<, 0001^{*}$ \\
\hline
\end{tabular}

Análise de Variância (ANOVA) para comparação de amostras independentes ( $\left.p \leq 0,05^{*}\right)$. As letras sobrescritas indicam as diferenças no pós-teste de Tukey-HSD. Grupos: DDF II: deformidade dentofacial padrão dentoesquelético II, DDF III: deformidade dentofacial padrão dentoesquelético III, GC: grupo controle. Variáveis: altura facial (G-Gn), largura facial (Td-Te), terço médio (G-Sn), terço inferior (Sn-Gn), altura maxilar (Sn-Sto), altura mandibular (Sto-Gn), comprimento maxilar (T-Sn), comprimento mandibular (T-Gn), distâncias Td-Chd e Te-Che.

Fonte: Simões (2017, p.72). 


\subsection{Morfologia facial (proporções faciais)}

A partir das cinco proporções estabelecidas, observou-se que houve diferença significante para quatro delas, a saber: relação altura/largura facial, terço médio/terço inferior, distâncias do terço inferior e relação maxilomandibular, entre os três grupos estudados, como pode ser visto na Tabela 2.

Tabela 2. Média e desvio padrão das proporções faciais na comparação entre os três grupos.

\begin{tabular}{lccccccc}
\hline \multirow{2}{*}{ Proporções faciais (\%) } & \multicolumn{2}{c}{ DDF II (N = 20) } & \multicolumn{2}{c}{ DDF III (N = 32) } & \multicolumn{2}{c}{ GC (N = 25) } & P Valor * \\
\cline { 2 - 7 } & Média & DP & Média & DP & Média & DP & \\
\hline Altura/Largura & $94,1^{\mathrm{a}}$ & 6,1 & $88,1^{\mathrm{b}}$ & 5,3 & $86,9^{\mathrm{b}}$ & 3,4 & $0,0001^{*}$ \\
Terço médio/Terço inferior & $92,8^{\mathrm{a}}$ & 8,8 & $96,7^{\mathrm{a}, \mathrm{b}}$ & 9,2 & $100,6^{\mathrm{b}}$ & 8,6 & $0,0248^{*}$ \\
Comprimento maxilar/mandibular & $89,4^{\mathrm{a}}$ & 3,9 & $77,8^{\mathrm{b}}$ & 3,3 & $86,2^{\mathrm{a}}$ & 3,6 & $<, 0001^{*}$ \\
Altura maxilar/mandibular & $44,7^{\mathrm{a}, \mathrm{b}}$ & 7,3 & $41,2^{\mathrm{a}}$ & 6,1 & $47,2^{\mathrm{b}}$ & 4,7 & $0,0042^{*}$ \\
Assimetria entre lados & 2,9 & 2,3 & 1,8 & 1,7 & 1,6 & 1,8 & 0,1552 \\
\hline
\end{tabular}

Teste Kruskal Wallis para amostras independentes $\left(p \leq 0,05^{*}\right)$. As letras sobrescritas indicam as diferenças no pós-teste de Dunn. Grupos: DDF II: deformidade dentofacial padrão dentoesquelético II, DDF III: deformidade dentofacial padrão dentoesquelético III, GC: grupo controle. Variáveis: altura facial/largura facial (G-Gn/Td-Te), terço médio/terço inferior (G-Sn/Sn-Gn), comprimento maxilar/mandibular (T-Sn/T-Gn), altura maxilar/mandibular (Sn-Sto/Sto-Gn), assimetria entre os lados (Td-Chd/Te-Che).

Fonte: Simões (2017, p.73). 


\subsection{Força de Mordida}

Em relação aos valores de força de mordida, observou-se que houve diferença estatisticamente significativa $\left(p \leq 0,05^{*}\right)$ tanto para força de mordida à esquerda, quanto para força de mordida à direita, bem como para o valor médio de ambos os lados juntos, em que o GC se diferiu em relação às deformidades, porém DDF II e DDF III não foram estatisticamente diferentes. Não houve diferença para o índice percentual de assimetria entre os grupos (Tabela 3).

Tabela 3. Média e desvio padrão da força de mordida e diferença percentual entre os lados na comparação entre os três grupos.

\begin{tabular}{lcccc}
\hline Variáveis & DDF II (N = 20) & DDF III (N= 32) & GC (N = 25) & p Valor * \\
\hline Média FM D (N) & $193,8(106,7)^{\mathrm{b}}$ & $198,9(102,9)^{\mathrm{b}}$ & $464,3(192,5)^{\mathrm{a}}$ & $<, 0001^{*}$ \\
Média FM E (N) $^{\mathrm{b}}$ & $213,3(125,8)^{\mathrm{b}}$ & $206,7(114,9)^{\mathrm{b}}$ & $448,2(184,9)^{\mathrm{a}}$ & $<, 0001^{*}$ \\
FM médio DE (N) & $203,6(112,6)^{\mathrm{b}}$ & $202,8(103,9)^{\mathrm{b}}$ & $456,3(186,3)^{\mathrm{a}}$ & $<, 0001^{*}$ \\
DPL (\%) & $18,8(12,9)$ & $18,3(17,4)$ & $10,5(7,6)$ & 0,1095 \\
\hline
\end{tabular}

Teste Kruskal Wallis para amostras independentes $\left(p \leq 0,05^{*}\right)$. As letras sobrescritas indicam as diferenças no pós-teste de Dunn. Grupos: DDF II: deformidade dentofacial padrão dentoesquelético II, DDF III: deformidade dentofacial padrão dentoesquelético III, GC: grupo controle. Variáveis: média FM D (média dos três registros de força de mordida do lado direito, em Newton), média FM E (média dos três registros da força de mordida do lado esquerdo, em Newton), FM médio DE (valor médio da força de mordida média do lado direito e esquerdo, em Newton), DPL (diferença percentual da força de mordida média do lado direito e esquerdo, referente à assimetria ente os lados).

Fonte: Simões (2017, p.74). 


\subsection{Distribuição de força oclusal}

Pode-se dizer que tempo de oclusão, em segundos, para a máxima intercuspidação dentária ( $p=0,0028$ ) apresentou-se diferente estatisticamente entre DDF II e GC e DDF III e GC, sendo que o DDF III apresentou o maior tempo, seguido pela DDF II e GC. O tempo não variou entre DDF II e DDF III. Em relação aos outros parâmetros da distribuição de força oclusal, não houve diferença estatisticamente significativa $\left(p \leq 0,05^{*}\right)$ para nenhum deles (Tabela 5).

Tabela 4. Média e desvio padrão dos parâmetros da distribuição de força oclusal na comparação entre os três grupos.

\begin{tabular}{lccccccc}
\hline Parâmetros (\%) & \multicolumn{2}{c}{ DDF II (N=20) } & \multicolumn{2}{c}{ DDF III (N=32) } & \multicolumn{2}{c}{ GC (N=25) } & \multirow{2}{*}{ P Valor * } \\
\cline { 2 - 6 } & Média & DP & Média & EP & Média & EP & \\
\hline FE & 49,9 & 12,5 & 51,7 & 17,8 & 50,8 & 8,4 & 0,9377 \\
FD & 50,1 & 12,5 & 48,3 & 17,8 & 49,2 & 8,4 & 0,9361 \\
FA & 24,8 & 23,6 & 23,6 & 20,1 & 25,5 & 11,9 & 0,4015 \\
FP & 75,2 & 23,6 & 76,2 & 20,4 & 74,5 & 11,9 & 0,3929 \\
\hline
\end{tabular}

Teste Kruskal Wallis para amostras independentes $\left(p \leq 0,05^{*}\right)$. As letras sobrescritas indicam as diferenças no pós-teste de Dunn. Grupos: DDF II: deformidade dentofacial padrão dentoesquelético II, DDF III: deformidade dentofacial padrão dentoesquelético III, GC: grupo controle. Variáveis: FE (distribuição de força do lado esquerdo), FD (distribuição de força do lado direito), FA (distribuição de força anterior), FP (distribuição de força posterior).

Fonte: Simões (2017, p.75). 


\section{5 Área de contato oclusal}

Diante da análise da área de contato oclusal, houve diferença significante $\left(p \leq 0,05^{*}\right)$ para todos os parâmetros investigados entre DDF e GC. Apenas para o parâmetro de assimetria de área entre os lados, na condição de máxima intercuspidação dentária, houve diferença também entre as deformidades padrão dentoesquelético II e padrão dentoesquelético III, como exposto na Tabela 6 a seguir.

Tabela 5. Média e desvio padrão dos parâmetros da área e assimetria de área oclusal na comparação entre os três grupos.

\begin{tabular}{lcrcrrrr}
\hline Parâmetros & \multicolumn{2}{c}{ DDF II (N=20) } & \multicolumn{2}{c}{ DDF III (N=32) } & \multicolumn{2}{c}{ GC (N=25) } & \multirow{2}{*}{ P Valor * } \\
\cline { 2 - 7 } & Média & DP & Média & DP & Média & DP & \\
\hline AE $\left(\mathbf{m m}^{2}\right)$ & $40,2^{\text {a }}$ & 22,5 & $25,6^{\text {a }}$ & 17,6 & $106,6^{\text {b }}$ & 39,7 & $<, 0001^{*}$ \\
AD $\left(\mathbf{m m}^{2}\right)$ & $41,4^{\text {a }}$ & 25,4 & $25,9^{\text {a }}$ & 16,0 & $103,9^{\text {b }}$ & 43,0 & $<, 0001^{*}$ \\
AT $\left(\mathbf{m m}^{2}\right)$ & $81,5^{\text {a }}$ & 45,0 & $51,4^{\text {a }}$ & 30,7 & $210,4^{\text {b }}$ & 80,9 & $<, 0001^{*}$ \\
ASADE (\%) & $21,6^{\text {a }}$ & 20,6 & $40,8^{\text {b }}$ & 23,6 & $14,6^{\text {a }}$ & 12,5 & $0,0001^{*}$ \\
\hline
\end{tabular}

Teste Kruskal Wallis para amostras independentes $\left(p \leq 0,05^{*}\right)$. As letras sobrescritas indicam as diferenças no pós-teste de Dunn. Grupos: DDF II: deformidade dentofacial padrão dentoesquelético II, DDF III: deformidade dentofacial padrão dentoesquelético III, GC: grupo controle. Variáveis: AE (área de contato oclusal do lado esquerdo), AD (área de contato oclusal do lado direito), AT (área de contato oclusal total), ASADE (assimetria de área de contato oclusal entre os lados direito e esquerdo).

Fonte: Simões (2017, p.76). 


\subsection{Correlação entre as distâncias antropométricas e proporções faciais e a força de mordida}

Tabela 6. Coeficiente de correlação entre as distâncias antropométricas faciais e proporções faciais e a força de mordida nos grupos deformidade dentofacial padrão dentoesquelético II, padrão dentoesquelético III e grupo controle.

\begin{tabular}{lcc}
\hline \multicolumn{1}{c}{ Força de Mordida (N) vs } & Spearman Rho & P valor* \\
\hline Distâncias antropométricas & & \\
- Altura facial $(\mathrm{mm})$ & -0.0710 & 0.5396 \\
- Largura facial $(\mathrm{mm})$ & 0.4469 & $<.0001^{*}$ \\
- Terço médio $(\mathrm{mm})$ & -0.0407 & 0.7253 \\
- Terço inferior $(\mathrm{mm})$ & -0.0863 & 0.4554 \\
- Altura maxilar (mm) & 0.0472 & 0.6833 \\
- Comprimento maxilar (mm) & 0.5189 & $<.0001^{*}$ \\
- Altura mandibular (mm) & -0.1794 & 0.1184 \\
- Comprimento mandibular (mm) & 0.2903 & $0.0104^{*}$ \\
- Td-Chd (mm) & 0.3561 & $0.0015^{*}$ \\
- Te-Che (mm) & 0.3574 & $0.0014^{*}$ \\
& & \\
Proporções & & \\
- Altura/largura (\%) & -0.4377 & $<.0001$ \\
- Terço médio/terço inferior (\%) & 0.0320 & 0.7823 \\
- Comprimento maxilar/mandibular (\%) & 0.1492 & 0.1952 \\
- Altura maxilar/mandibular (\%) & 0.1356 & 0.2398 \\
\hline
\end{tabular}

Teste de correlação de Spearman ( $\left.\leq \leq 0,05^{*}\right)$.Variáveis (distâncias): altura facial (G-Gn), largura facial (Td-Te), terço médio (G-Sn), terço inferior ( $\mathrm{Sn}-\mathrm{Gn}$ ), altura maxilar (Sn-Sto), altura mandibular (StoGn), comprimento maxilar (T-Sn), comprimento mandibular (T-Gn), Td-Chd, Te-Che. Variáveis (proporções): altura facial/largura facial (G-Gn/Td-Te), terço médio/terço inferior (G-Sn/Sn-Gn), comprimento maxilar/mandibular (T-Sn/T-Gn), altura maxilar/mandibular (Sn-Sto/Sto-Gn).

Fonte: Simões (2017, p.77). 


\subsection{Análise de regressão linear múltipla}

Tabela 7. Variáveis relacionadas às distâncias antropométricas significativamente associadas à força de mordida, segundo critério de informação de Akaike (AIC).

\begin{tabular}{cllcl}
\hline $\mathbf{R}^{\mathbf{2}}$ & $\mathbf{F}$ (P valor) & \multicolumn{1}{c}{ Variáveis } & Slope & p-valor* \\
\hline 0,382 & \multirow{2}{*}{, $77(<, 0001)$} & Idade (anos) & $-8,84$ & $0,0030^{*}$ \\
& & Largura facial $(\mathrm{mm})$ & 8,10 & $0,0012^{*}$ \\
& Altura mandibular $(\mathrm{mm})$ & $-12,07$ & $0,0023^{*}$ \\
& Altura maxilar $(\mathrm{mm})$ & 6,12 & $0,0329^{*}$ \\
& Comprimento maxilar $(\mathrm{mm})$ & 5,55 & $0,0480^{*}$ \\
\hline
\end{tabular}

$\mathrm{R}^{2}=$ coeficiente de determinação; $\mathrm{F}(\mathrm{P}$-valor) = avaliação do modelo; Slope= inclinação da reta de regressão; $p$-valor = avaliação da significância da variável no modelo. Variáveis: largura facial (Td-Te), altura mandibular (Sto-Gn), altura maxilar (Sn-Sto), comprimento maxilar (T-Sn).

Fonte: Simões (2017, p.78).

Tabela 8. Variáveis relacionadas às proporções faciais significativamente associadas à força de mordida, segundo critério de informação de Akaike (AIC).

\begin{tabular}{|c|c|c|c|c|}
\hline $\mathbf{R}^{2}$ & F (P valor) & Variáveis & Slope & p-valor* \\
\hline \multirow[t]{5}{*}{0,328} & $6,93(<, 0001)$ & Gênero $(0=F ; 1=M)$ & 77,81 & $0,0467^{*}$ \\
\hline & & Idade (anos) & $-8,39$ & $0,0069 *$ \\
\hline & & Altura/largura (\%) & $-10,03$ & $0,0037^{*}$ \\
\hline & & Altura maxilar/mandibular (\%) & 5,89 & $0,0505^{*}$ \\
\hline & & Comprimento maxilar/mandibular (\%) & 5,52 & 0,0773 \\
\hline
\end{tabular}

$\mathrm{R}^{2}=$ coeficiente de determinação; $\mathrm{F}(\mathrm{P}$-valor) = avaliação do modelo; Slope = inclinação da reta de regressão; $p$-valor = avaliação da significância da variável no modelo. Variáveis: altura facial/largura facial (G-Gn/Td-Te), altura maxilar/mandibular (Sn-Sto/Sto-Gn), comprimento maxilar/mandibular (T$\mathrm{Sn} / \mathrm{T}-\mathrm{Gn})$.

Fonte: Simões (2017, p.78). 
6. DISCUSSÃO 
Diante da relevância da função mastigatória no complexo estomatognático e da íntima relação dos músculos elevadores da mandíbula com a morfologia craniofacial, este trabalho se propôs investigar lacunas ainda não plenamente compreendidas em sujeitos com deformidades dentofaciais, nos quais a funcionalidade da mastigação é notoriamente prejudicada.

O termo antropometria refere-se à ciência que estuda as medidas de proporções do corpo humano. Para a confiabilidade das medidas é essencial a precisa localização dos marcadores na superfície da face. Estes foram pré-determinados com base em características anatômicas do tecido duro e tecido mole subjacente (Farkas, 1994).

A metodologia tridimensional empregada para a avaliação da morfologia facial, apesar de relativamente recente, já é descrita na literatura como confiável, reprodutível e útil para a exploração de parâmetros relacionados ao tecido mole facial, podendo ser utilizada para diagnóstico, planejamento terapêutico e follow-up do tratamento funcional, cirúrgico e estético da deformidade (Hajeer et al, 2004; Sforza et al., 2007; Alves et al., 2009; Verzé et al., 2011; Lippold et al., 2014; Zecca et al., 2016). São poucos os trabalhos que utilizaram o sistema de scanner a laser na deformidade dentofacial, e os mesmos o fazem principalmente na exploração de um único tipo de deformidade, assim como na comparação do antes e depois da cirurgia ortognática (Soncul e Bamber, 2004; Alves et al., 2009; Shimomatsu et al., 2012; Verzé et al., 2011, 2012; Ovsenik et al., 2013). Embora a investigação seja apenas de tecido mole, acredita-se na possível correlação do mesmo com o esqueleto facial (McCance et al., 1997). Por isso, a idéia de estimá-lo e associá-lo às características do próprio tecido mole facial, ao usufruir do diferencial caráter de profundidade da metodologia 3D, a fim de trazer conceitos novos, fidedignos à estrutura craniofacial e possivelmente complementares aos tradicionais, previamente estabelecidos em literatura.

Zecca et al (2016) avaliaram a morfologia facial por meio da cefalometria radiográfica tradicional e do scanner ótico 3D e compararam os métodos. Segundo seus resultados, o diagnóstico de tecido mole foi confiável na predição de resultados cefalométricos esqueléticos, sendo que fortes correlações sagitais entre tecido mole e duro foram 
encontradas principalmente no terço inferior da face. Contudo, o estudo foi realizado apenas na ausência de alteração dentária e esquelética maxilomandibular.

No presente trabalho, quando comparadas as distâncias lineares da morfologia facial entre os grupos (Tabela 1), todas as variáveis apresentaram diferença significativa, exceto a correspondente ao terço médio da face. Considera-se o achado pertinente uma vez que, parece que a deformidade dentofacial afeta, sobretudo, o terço inferior da face, no qual repercutem as maiores mudanças decorrentes da cirurgia ortognática (Verzé et al., 2012).

Em relação à distância linear referente à altura facial (Tabela 1), o GC apresentou menor altura entre os três grupos, o que traduz um aumento do componente vertical para o grupo DDF. O grupo DDF II destacou-se por apresentar maior terço inferior da face. Estudos prévios constataram que na presença da retrognatia pode haver o aumento da altura facial, o qual se associa ao excesso maxilar vertical (McNamara, 1981; Rosenblum, 1995; Zarrinkelk et al., 1996). No presente estudo, ainda que o grupo DDF II não tenha apresentado maior altura maxilar em relação ao grupo controle, o mesmo demonstrou tal excesso em relação ao grupo DDF III.

Além disso, o grupo DDF II, também obteve aumento da altura mandibular diferente do GC (Tabela 1). Tal fato pode ter contribuído para maior medida de altura facial. Considera-se que esse resultado pode estar associado à própria retrognatia mandibular (menor comprimento mandibular). Pois esta certamente está conectada ao componente vertical, visto que também, o ponto antropométrico é o mesmo para analisar as duas grandezas $(G n)$. Ainda, considera-se a relevância da metodologia empregada para a análise, tendo em vista que a literatura explicita que a deformidade dentofacial é complexa e ocupa os três planos do espaço em termos de desproporções faciais (Throckmorton et al., 1999; Relle e Silegy, 2004; AAOMS, 2012,2013). Sendo assim, se fosse analisada bidimensionalmente, a estrutura poderia sofrer a redução de medidas, por desprezar o eixo da profundidade. Porém, quando analisada a morfologia com metodologia fiel à estrutura, acredita-se na identificação precisa dos padrões morfológicos e, por isso, talvez o porquê da "retrognatia acentuada" associada à altura facial aumentada no grupo DDF II.

O grupo DDF III manteve igual vantagem quanto à altura facial em relação ao grupo DDF II (Tabela 1), já que ambos apresentaram aumento da altura mandibular e DDF III 
aumento do comprimento mandibular, o que também denuncia a intimidade entre os componentes vertical e sagital. Porém, sem diferenciação quanto ao GC. Essa distinção devese predominantemente à diminuição da altura maxilar da DDF III em relação à DDF II, contudo não diferente estatisticamente dos sujeitos controles. Além da prognatia da DDF III apresentar-se mais próxima do GC, do que a retrognatia da DDF II. Sforza et al. (2007), também com metodologia 3D, relataram aumento do terço inferior da face e diminuição da proeminência maxilar para sujeitos com deformidade esquelética classe III, na comparação desta deformidade pré e pós cirurgia ortognática.

A distância linear relacionada à largura facial revelou diferenças entre as deformidades, em que o grupo DDF III indicou valores semelhantes ao GC (Tabela 1). Porém, para o grupo DDF II, houve diminuição da largura facial. Ramires et al (2010), em sua revisão consideraram que o estreitamento da face associado à retrusão mandibular é característico do padrão face longa.

Quanto ao aspecto anteroposterior nas distâncias lineares (Tabela 1), as características encontradas no grupo DDF III foram as mesmas comumente associadas à essa deformidade, como já constatado em literatura (Ellis e McNamara, 1984; Ellis et al., 1996; Relle e Silegy, 2004; Sforza et al., 2007), sendo que houve retrusão maxilar ligada à protrusão mandibular. No que diz respeito à DDF II, o comprimento sagital maxilar ocupou posição neutra em relação à outra DDF e GC, entretanto, houve nítida retrusão mandibular diferentemente de todos os grupos, o que caracteriza também essa deformidade (McNamara, 1981; Rosenblum, 1995; Relle e Silegy, 2004).

Ainda na caracterização da morfologia facial, além das distâncias lineares, as proporções faciais foram criadas com o propósito de contribuir para a compreensão da face como uma estrutura única, a fim de não "desmembrá-la" em pequenas partes. Pois, a idéia de proporcionalidade se faz relevante uma vez que a estrutura facial é não planar e os desequilíbrios craniofaciais não são apenas discrepâncias anteroposterioes (Suzuki-Okamura et al., 2015). Portanto, não é possível tentar compreender um único aspecto e, simultaneamente, isolar outros com o mesmo grau de significância.

Sendo assim, diferentemente de estudos que mostraram que assimetrias podem ocorrer nos casos de deformidade dentofacial, principalmente no terço inferior da face 
(Severt e Proffit, 1997; Sforza et al., 2007; Shimomatsu et al., 2012; Patel et al., 2015), no presente estudo, esta foi a única proporção que não demonstrou diferença significativa na comparação entre os três grupos (Tabela 2). Fato que expõe traço de relativa homogeneidade entre os grupos, principalmente em virtude da proposital exclusão dos casos de extrema assimetria lateral da amostra, como os laterognatismos acentuados, comum nos pacientes com hiperplasia condilar.

A proporção que expressa a razão da altura com a largura facial se destaca pelo maior valor no grupo DDF II (Tabela 2), em função do aumento da componente vertical e redução da componente horizontal desse grupo.

Na DDF III (Tabela 2), houve uma nítida proeminência mandibular, tanto no sentido sagital quanto no vertical, que associando à deficiência maxilar em altura, bem como em comprimento, culminou para que a relação vertical maxilomandibular se distinguisse do GC e gerou diferença estatística para a relação maxilomandibular anteroposterior em relação ao GC e DDF II. Para esta última, não houve diferença em relação ao GC quanto à razão maxilomandibular no sentido sagital, em consequência de apenas um elemento alterado, a retrognatia mandibular, e consequente posição neutra sagital de maxila. Os respectivos achados corroboram o trabalho de Relle e Silegy (2004), que caracteriza tais deformidades, e podem ser considerados fiéis à estrutura 3D, por destacar a importância da profundidade, principalmente em relação à altura mandibular e comprimento mandibular.

Déficits significativos na função mastigatória em sujeitos com deformidade dentofacial são considerados justificativa para a submissão à cirurgia ortognática. E tais prejuízos podem ser demonstrados por meio da força de mordida (Throckmorton et al., 2000). Sem dúvida, há um evidente dano na força de mordida na presença das deformidades dentofacias classe II e classe III (Dean et al., 1992; Tate et al., 1994; Thomas et al., 1995; Throckmorton et al., 1995, 1996, 1998; Zarrinkelk et al., 1995,1996; Ellis et al., 1996; Iwase et al., 1998, 2006; Harada et al., 2000; Ohkura et al., 2001; Goto et al., 1998; Trawitzki et al., 2011; Karakis et al., 2013). Estudos apontam que há uma associação da má oclusão, independentemente do plano afetado, com a redução dos valores de força de mordida (Sonnesen et al., 2001; Miyawaki et al., 2005; Araújo et al., 2014). O mesmo pode ser 
confirmado no presente estudo, em que tanto para o grupo DDF II, como DDF III, houve diminuição dessa força em relação ao GC (Tabela 3).

Atualmente, considerada de origem multifatorial (Abrahamsson et al., 2013), as desordens temporomandibulares são desarranjos estruturais e funcionais do sistema estomatognático, sendo classificadas em musculares e articulares (De Felício et al., 2009; Okeson, 2013). Os sintomas mais comuns provenientes dessa disfunção são a dor orofacial e a limitação dos movimentos mandibulares (Michelotti et al., 2012). Os sujeitos com DTM apresentam alterações funcionais nos músculos mastigatórios (Mapelli et al., 2016), e assim estudos associaram essa patologia à redução de força de mordida (Wenneberg et al., 1995; Stohler, 1999; Andersen e Sonnesen, 2012). Além disso, em decorrência à oclusão dentária desfavorável e às discrepâncias maxilomandibulares, parece existir uma prevalência dessa desordem em sujeitos com deformidade dentofacial (Pereira e Bianchini, 2011; Silva et al., 2011; Nale, 2014), sendo esta também considerada um agente predisponente para o desenvolvimento da DTM (Egermark et al., 2000).

No presente estudo, todos os sujeitos com deformidade dentofacial estavam em processo de tratamento ortodôntico no momento da coleta dos dados. Alguns autores consideram que, com a finalidade de estabilizar a oclusão dentária após a cirurgia ortognática, a ortodontia pré operatória alinha os dentes à base óssea e culmina em aumento da severidade da má oclusão dentária, o que provoca dor e desconforto também para a realização da força de mordida e contribui para sua redução (Ellis et al., 1996; Kim et al., 1997; Iwase et al., 1998, 2006; Nagai et al., 2001). Além disso, eventual extração dentária é considerado um procedimento relativamente comum durante o tratamento ortodôntico na fase pré operatória (Hatch et al., 2001). Neste trabalho, certamente alguns dos sujeitos foram submetidos à essa estratégia, entretanto, foram excluídos da amostra aqueles com mais de uma ausência dentária do mesmo lado, por arcada, devido à dedução prévia da possibilidade da elevação do grau de interferência na variável força de mordida.

A literatura afirma que a área de contato oclusal exerce influência na magnitude dos valores de força de mordida (Harada et al., 2000; Ohkura et al., 2001; Goto et al., 2008) e que ambos podem afetar diretamente a performance mastigatória (Iwase et al., 1998; English et al., 2002). Diversos estudos demonstraram que na presença da deformidade 
dentofacial há uma redução da área de contato oclusal (Iwase et al., 1998, 2006; Harada et al., 2000; Bakke et al., 2006; Nakata et al., 2007). Analogamente a tais resultados, observouse também que as áreas de contato dos grupos DDF II e DDF III são notoriamente inferiores a do GC (Tabela 5). Nenhum estudo foi encontrado com a comparação entre as deformidades no que diz respeito à área de contato oclusal. Contudo, no presente trabalho o grupo DDF III revelou a área mais pobre dentre todos os outros grupos, sendo 4 vezes menor que a do GC.

É possível, ainda, que haja variação nos valores de força de mordida segundo a forma e local de mensuração no arco dentário (Bakke et al., 2006). Adotaram-se para as medidas em questão os primeiros molares como referência, por considerar, baseado em estudos prévios que, nessa região a força é maior e, portanto, se conseguiria extrair a força máxima realizada pelos músculos elevadores da mandíbula (Raadsheer et al., 1999; Hattori et al., 2003). Entretanto, apesar da consagração e tradição pela literatura quanto ao método empregado (gnatodinamômetro), pode-se ter excluído eventuais alterações ao longo da arcada dentária e possíveis discrepâncias entre os grupos, tendo em vista a diferença de área de contato oclusal entre as respectivas deformidades e a relevância desse fator para a magnitude da força de mordida.

Diante da clara associação entre os músculos mastigatórios com o crescimento e desenvolvimento craniofacial, a força de mordida e morfologia mantém relações ainda estudadas pela literatura (Proffit et al., 1983; Kiliaridis et al., 1993; Ingervall e Minder, 1997; Raadsheer et al., 1999; Sondang et al., 2003; Bonakdarchian et al., 2009; Custodio et al.,. 2010; Koç et al., 2010; van Spronsen, 2010). Contudo, a maior parte dos estudos investigou essas mesmas relações em sujeitos sem a deformidade dentofacial (Thcrockmorton et al., 1999, 2000).

Os marcadores de tecido mole bidimensionais (fotografias) também já foram correlacionados aos de tecido duro (radiografias). Parece que a vantagem mais óbvia da cefalometria radiográfica é a capacidade de visualizar os marcadores no tecido ósseo. Porém, pesquisadores encontraram que os marcadores em face foram localizados também de forma consistente. Apesar de considerarem o uso de fotografias como complemento à avaliação cefalométrica, seus resultados sugerem que ambas foram igualmente confiáveis, sendo que as maiores correlações foram relacionadas à altura facial vertical (Zhang et al., 
2007). Baseados nisso, outros estudos aplicaram a antropometria facial indireta em fotografias de sujeitos sem alterações craniofaciais, em que fortes correlações foram encontradas para o aumento da força de mordida em faces mais largas (Raadsheer et al., 1999; Bonackdarchian et al., 2009). Ou seja, houve correlações negativas em relação à proporção da altura/largura facial com a força de mordida (Koç et al., 2011). Tais achados apresentam semelhança aos estudos prévios com cefalometria, o que demonstra relativa correspondência entre os métodos bidimensionais (Proffit et al., 1983; Kiliaridis et al., 1993; Ingervall e Minder, 1997; Raadsheer et al., 1999; Throckmorton et al., 2000; Sondang et al., 2003; Alhaija et al., 2010; Custodio et al.,. 2010; Koç et al., 2010; van Spronsen, 2010).

Em sujeitos com deformidade dentofacial, estudos por meio de cefalometria também correlacionaram as variáveis da morfologia com a força de mordida (Throckmorton et al., 1995, 1999,2000; Zarrinkelk et al., 1995,1996; Thorckmorton e Ellis III, 2001; Harada et al., 2003). Dos estudos encontrados, Throckmorton et al. (2000), mesmo sem especificar a deformidade, avaliaram as possíveis variáveis biomecânicas relacionadas à força de mordida na fase pré operatória. Segundo seus resultados, parece que a relação anteroposterior maxilomandibular, a qual mais se associa à classificação dentária de Angle, exerce pouca ou nenhuma influência sobre a magnitude da força dos músculos elevadores da mandíbula. Achado tal, que corrobora os do presente estudo, em que a relação sagital maxilomandibular representou uma das variáveis com menor índice de correlação com a força de mordida (Tabela 6).

Entretanto, essa parece ser a relação mais considerada para a seleção das técnicas cirúrgicas empregadas na correção da deformidade (Throckmorton et al., 1999). Esses fatores se destacam quando são claros os prejuízos na função mastigatória dos sujeitos com deformidade dentofacial (van den Braber et al., 2002), sendo uma das mais relevantes queixas dos pacientes (Trawitzki et al., 2009) e a recuperação dessa função estomatognática um dos principais objetivos da cirurgia corretiva (Kobayashi et al., 2001; Iwase et al., 2006). A correção cirúrgica da má oclusão esquelética envolve uma variedade de modificações no tecido duro facial e as alterações nas dimensões sagital, vertical e transversal da mandíbula inevitavelmente estão associadas às estruturas do tecido mole. Portanto, os procedimentos cirúrgicos podem determinar as reações adaptativas dos músculos mandibulares (Grunheid et al., 2009). 
Por outro lado, parece que independentemente da presença da má oclusão dentária e da desproporção esquelética no sentido sagital, o componente vertical da morfologia facial é um potencial influenciador da força de mordida. Esta variável por si só é capaz de se relacionar com a redução dos valores de força de mordida, como visto em sujeitos com normoclusão e na ausência de discrepâncias de tecido duro (Proffit et al., 1983; Kiliaridis et al., 1993; Ingervall e Minder, 1997; Raadsheer et al., 1999; Sondang et al., 2003; Bonakdarchian et al., 2009; Custodio et al.,. 2010; Koç et al., 2010; van Spronsen, 2010). O mesmo padrão, então, parece se refletir nos sujeitos com deformidades dentofaciais. Esses outros trabalhos que também fizeram as mesmas comparações nessa população específica, analisaram apenas as mudanças pré e pós cirurgia ortognática, não comparam as deformidades classe II e classe III e são estudos mais antigos, apenas com metodologia bidimensional na avaliação da morfologia (Throckomorton et al., 1995; Zarrinkelk et al., 1995, 1996; Throckmorton e Ellis, 2001; Harada et al., 2003). Entretanto, no presente estudo, a maior correlação com a força de mordida foi encontrada na proporção da altura/largura facial (Tabela 6).

Pode-se afirmar que a explicação mais apropriada para essas relações é a respeito da vantagem biomecânica dos músculos elevadores da mandíbula, em que os músculos parecem ter maior potencial gerador de força com o ramo mandibular mais verticalizado e maior e o ângulo goníaco mais agudo, ou seja, quando a face apresenta menor altura. Portanto, o aumento do ângulo goníaco combinado à maior altura facial e redução do ramo mandibular, característicos de face longa, devem reduzir acentuadamente a vantagem biomecânica dos músculos elevadores da mandíbula (Throckmorton, 1980; Zarrinkelk et al., 1995).

No entanto, a vantagem biomecânica não é a única responsável pela redução da força de mordida, fato que se comprova quando a geometria esquelética mandibular já foi corrigida com a cirurgia ortognática e o processo de recuperação da força de mordida já é visível, porém a biomecânica, observada pelos níveis de atividade muscular, ainda apresenta-se em desvantagem (Zarrinkelk et al., 1995). Portanto, os contatos oclusais funcionais exercem também grande influência na magnitude da força (Throckmorton e Ellis, 2001). 
Acredita-se ainda, que a espessura dos músculos na deformidade dentofacial seja reduzida devido ao inapropriado uso dos mesmos na função mastigatória deficitária (Trawitzki et al., 2006). Até porque, a redução da habilidade mastigatória pode gerar diminuição do feedback sensorial na região dos receptores periodontais, que associada à redução da produção de força pode gerar atrofia muscular, a qual indica mudança na composição do tipo de fibra muscular (Grunheid et al., 2009). Portanto, músculos mais largos em espessura tem maior atuação na geração de força de mordida (van Spronsen et al., 1989; Raadsheer et al., 1999; Hatch et al., 2000; Throckmorton et al., 2000; Ueki et al., 2009). Nesse contexto, a composição da musculatura elevadora da mandíbula quanto ao tipo de fibra muscular pode variar segundo as dimensões craniofaciais (Rowlerson et al., 2005), em que na face curta há predominância de fibras rápidas tipo II e maior potencial gerador de força de mordida, em relação à face equilibrada. Sendo assim, o oposto ocorre também na face longa, na qual há escassez de fibras tipo II e a força oclusal é ainda mais fraca (Hunt et al., 2006).

Em relação à distribuição de força oclusal (Tabela 4), observou-se que não houve diferenciação entre os grupos estudados. Dos estudos que utilizaram metodologia semelhante (Iwase et al., 1998; Suda et al., 1999; Ohkura et al., 2001; Goto et al., 2008; Wang et al., 2013), alguns aplicaram em deformidade, porém apenas em sujeitos classe III (Iwase et al., 1998; Suda et al., 1999; Ohkura et al., 2001) e em assimetria mandibular (Wang et al., 2013). Entretanto, nenhum estudo utilizou a análise dos parâmetros correspondentes a este. Exceto o trabalho de Suda et al (1999), que analisou também o tempo oclusal em sujeitos com prognatismo mandibular, antes e depois da cirurgia ortognática.

Apesar de a literatura considerar o sistema T-Scan preciso e capaz de analisar quantitativamente determinadas características dos contatos oclusais (Koss et al., 2012; Wang e Yin, 2012), considera-se falha do método ao tentar investigar a proposta distribuição de força oclusal, pois o sensor fornecido pelo fabricante é de material flexível com sensibilidade na face superior e inferior. Porém, qualquer contato intraoral com o sensor, independentemente de onde são os contatos, superiores ou inferiores, o dispositivo capta a deformação numa certa região considerada anterior e posterior. Portanto, não necessariamente considerou a intercuspidação entre uma arcada e outra e qualquer contato gerou a pressão necessária para a interpretação pelo equipamento como uma porcentagem 
de distribuição de força relativa. Assim, não foram respeitados o overjet positivo da classe II, nem o overjet negativo da classe III, sem pretensão do fato, o que provocou a perspectiva errônea da deformidade. Portanto, não se pode afirmar que a distribuição de força na arcada dentária realmente não foi diferente entre os três grupos estudados, visto o que é considerado pelo equipamento e a discrepância de área de contato oclusal entre os grupos DDF e GC.

A área de contato oclusal foi calculada a partir do gráfico fornecido pelo T-Scan, porém por um programa distinto (criado em ambiente Matlab) e em momento diferente em relação à distribuição de força. Mas, pode-se dizer que, quanto ao tempo de oclusão apontado pelo T-Scan, os dois grupos DDF apresentaram maior tempo relativo ao GC, sendo que a DDF III levou o maior entre eles. O que pode ser explicado devido a essa deformidade revelar, também, a pior área de contato oclusal entre os grupos, necessitando de mais tempo para atingir a máxima intercuspidação dentária exigida para a prova. O trabalho de Suda et al (1999) também demonstrou que os sujeitos com prognatismo mandibular apresentaram maior tempo de oclusão antes da correção cirúrgica da deformidade do que após a mesma.

No entanto, tal como apresentado previamente por Trawitzki et al. (2011), não houve diferenciação quanto aos valores de força de mordida entre as deformidades estudadas (Tabela 3). Portanto, parece mesmo que fatores como a área de contato oclusal, a biomecânica maxilomandibular e os músculos mastigatórios estão mais interligados à variação da força muscular do que a própria classificação da deformidade (Bakke et al., 2006). Considera-se ainda que, mesmo sendo observadas diferenças entre a DDF II e DDF III quanto à morfologia facial, ambas as deformidades possuem igualmente semelhanças que são consideradas potenciais influenciadoras da força de mordida, a saber: componente vertical facial, largura facial e oclusão desestabilizada. Além disso, em modelo de regressão linear múltipla (Tabelas 7 e 8), a altura mandibular apresentou-se como forte elemento de relação negativa com a força de mordida. Essa, também, foi a única variável que demonstrou equidade entre as deformidades (aumento da altura mandibular para DDF II e DDF III), mas diferença significativa para o grupo controle. Além disso, apesar do grupo DDF II ter apresentado face estreita e longa, o que poderia refletir em menor força de mordida em relação ao grupo DDF III, este em compensação, demonstrou a área de contato oclusal mais 
pobre dentre todos. Esses aspectos são considerados relevantes e podem ter contribuído para não haver distinção quanto à força de mordida entre os grupos de deformidades estudados.

Embora não tenham sido encontrados estudos com metodologia 3D para a análise da morfologia facial em associação à avaliação da força oclusal e área de contato, parece pertinente criar analogias com estudos bidimensionais precedentes (antropometria indireta em fotografia e cefalometria radiográfica), visto que há relativa relação entre os achados. Considera-se os resultados do presente estudo fidedignos, uma vez que foram pertinentes e consistentes, além da fidelidade da metodologia à estrutura 3D.

Porém, pode-se dizer quanto ao erro do método de scanner ótico, que há dificuldades em marcar determinados pontos antropométricos faciais, em virtude da imprecisão do tecido mole escaneado em determinadas áreas, como a região de arco zigomático. Dessa forma, quando houve qualquer empecilho optou-se por fazer a substituição do ponto por outro equivalente, no caso pelo Tragus ( $T d$ e Te). Pode-se entender ainda, como limitação deste estudo, que com a finalidade de experenciar três métodos distintos de avaliação e explorar a tecnologia tridimensional, ainda pouco conhecida principalmente em contexto nacional, o número total da amostra estudada pode ter sofrido eventual atenuação.

Diferentemente da literatura que embasou este estudo, o mesmo evidenciou que há aumento também da altura mandibular, a qual interfere no comprimento e profundidade sagital da mandíbula, em ambas as deformidades dentofaciais. Fato este, que revelou que os sujeitos com padrão dentoesquelético II apresentam-se mais distantes da normalidade em termos de comprimento e profundidade mandibular, do que sujeitos prognatas.

Portanto, de maneira geral, por meio do caráter tridimensional com a informação do eixo de profundidade identifica-se com precisão a classificação das deformidades, além da clara associação entre os componentes verticais e sagitais da face. A correspondência entre a biomecânica dos músculos mastigatórios com as dimensões esqueletais, na presença da deformidade dentofacial, se mostrou clara e faz referência aos sujeitos sem tal deformidade. O método 3D reafirma, ainda, a necessidade de diagnóstico complementar dessa patologia por meios que sejam fiéis à estrutura tridimensional e à complexidade da deformidade 
dentofacial. E também, com a finalidade de atingir terapêuticas e prognósticos mais favoráveis aos sujeitos, em virtude de menor índice de eventuais imprecisões e maior número de informações. Além da demonstração real aos próprios sujeitos sobre as suas dimensões craniofaciais, com possibilidade de contribuição aos aspectos terapêuticos cirúrgico e fonoaudiológico clínico. 
7. CONCLUSÃO 
A avaliação da morfologia facial evidenciou que o terço inferior da face foi o mais afetado pelas deformidades dentofaciais e estas apresentaram características compatíveis com a classe II e classe III esqueléticas, com predomínio da componente vertical, principalmente em sujeitos com retrognatia. Houve semelhanças e particularidades entre as deformidades no quesito morfológico. E o método de análise tridimensional confirmou achados específicos e relevantes no que diz respeito às deformidades dentofacias estudadas.

Os indivíduos com deformidades dentofaciais apresentaram força de mordida diminuída em relação aos sujeitos controles, sem diferenças entre as deformidades e sem evidências de assimetrias nessas forças.

A distribuição de força oclusal não demonstrou disparidade entre os grupos estudados. Já a área de contato oclusal, mostrou-se reduzida para a deformidade dentofacial, em que o padrão dentoesquelético III foi o mais prejudicado nesse aspecto.

As correlações encontradas confirmaram que as proporções faciais indicam variações na magnitude da força de mordida também em sujeitos com deformidade dentofacial. Uma vez que, quanto maior a largura facial, maior também é a força dos músculos elevadores da mandíbula. Contudo, o aumento da altura maxilomandibular e facial está relacionado com a diminuição de força de mordida. O estudo também indicou alguns fatores como sendo potenciais influenciadores dessa grandeza, como o gênero, sendo a força maior para o sexo masculino, e a idade, podendo haver declínio da força com o prolongamento dos anos. 
REFERÊNCIAS 
Abrahamsson C, Henrikson T, Nilner M, Sunzel B, Bondemark L, Ekberg EC. TMD before and after correction of dentofacial deformities by orthodontic and orthognathic treatment. Int. J. Oral Maxillofac. Surg. 2013;42:752-758.

Akhil G, Kumar KPS, Raja S, Janardhanan K. Three-dimensional assessment of facial asymmetry: A systematic review. J Pharm Bioallied Sci. 2015 Aug;7 (Suppl 2):S433-S437.

Alessandri-Bonetti G, Ippolito DR, DÁntò V, Incerti-Parenti. Cephalometric predictors of treatment outcome with mandibular advancement devices in adult patients with obstructive sleep apnea: a systematic review. Korean J Orthod 2015;45(6):308-321.

Alhaija ESJA, Al Zo'ubi IA, Al Rousan ME, Hammad MM, Maximum occlusal bite forces in Jordanian individuals with different dentofacial vertical skeletal patterns. European Journal of Orthodontics. 2010;32:71-77.

Allanson JE, Objective Techniques for Craniofacial Assessment: What Are the Choices? Am J Med Genetics. 1997;70:1-5.

Alves PVM, Zhao L, Patel PK, Bolognese AM. Three-Dimensional Facial Surface Analysis of Patients With Skeletal Malocclusion. J Craniofac Surg. 2009;20: 290-296.

American Association of Oral and Maxillofacial Surgeons. Criteria for Orthognathic Surgery. 2013;1-9.

American Association of Oral and Maxillofacial Surgeons. Parameters of Care: Clinical Practice Guidelines for Oral and Maxillofacial Surgery: Surgical correction of maxillofacial skeletal deformities. 2012;107-136.

Andersen MK e Sonnesen L. Risk factors for low molar bite force in adult orthodontic patients. European Journal of Orthodontics. 2013;35:421-426.

Angle EH. Treatment of malocclusion of the teeth. $7^{\text {th }}$ ed. Philadelphia: White Dental Manufacturing Co; 1907.

*De acordo com o estilo Vancouver 
Antonarakis GS, Kiliaridis S. Predictive value of masseter muscle thickness and bite force on Class II functional appliance treatment: a prospective controlled study. Eur J Orthod. 2015;37(6):570-7.

Araújo SCCS, Vieira MM, Gasparotto CA, Bommarito S. Análise da força de mordida nos diferentes tipos de maloclusões dentárias, segundo Angle. Rev. CEFAC. 2014 Set-Out; 16(5):1567-1578.

Arnett GW, Bergman RT. Facial Keys to orthodontic diagnosis and treatment planning. Part I. Am J Orthod and Dentofacial Orthop. 1993;103(4):299-312.

Bailey LJ, Proffit WR, White Jr R. Assessment of Patients for Orthognathic Surgery. Semin Orthod. 1999;5:209-222.

Bakke M, Holm B, Jensen BL, et al: Unilateral, iso- metric bite force in 8-68-year-old women and men related to occlusal factors. Scand J Dent Res. 1990 98:149- 158.

Bakke M. Bite force and occlusion. Semin Orthod. 2006;12:120-126.

Becker OE, Avelar RL, Dolzan AN, HaasJr OL. Scolari N, Oliveira RB. Soft and hard tissue changes in skeletal Class III patients treated with double-jaw orthognathic surgerymaxillary advancement and mandibular setback. Int. J. Oral Maxillofac. Surg. 2014; 43: 204212.

Berretin-Félix G, Jorge TM, Genaro KF. Intervenção fonoaudiológica em pacientes submetidos à cirurgia ortognática. In: Fernandes FDM, Mendes BCA, Navas ALPGP. Tratado de Fonoaudiologia. 2ed. São Paulo. Rocca; 2010.

Bianchini EMG. Diagnóstico fonoaudiológico In: Bianchini EMG. A cefalometria nas alterações miofuncionais orais diagnóstico e tratamento fonoaudiológico. 5th ed. Carapicuíba. Pró-Fono; 2002.

Bonakdarchian M, Askari N, Askari M. Effect of face form on maximal molar bite force with natural dentition. Arch Oral Biol. 2009;54(3):201-4. 
Braun S, Bantleon HP, Hnat WP, Freudenthaler JW, Marcotte MR, Johnson BE. A study of bite force, part 1: relationship to various physical characteristics. The Angle Orthod. 1995;65:367372.

Braun S, Hnat WP, Freudenthaler JW, Honigle K, Marcotte MR, Johnson BE. A study of maximum bite force during growth and development. The Angle Orthod. 1996;66(4):261264.

Calderon P dos S, Kogawa EM, Lauris JR, Conti PC. The influence of gender and bruxism on the human maximum bite force. J Appl Oral Sci. 2006 Dec;14(6):448-53.

Capelozza Filho L. Diagnóstico em Ortodontia. $1^{\text {st }}$ ed. Maringá: Dental Press; 2004.

Castelo PM, Bonjardim LR, Pereira L, Gavião MBD. Facial dimensions, bite force and masticatory muscle thickness in preschool children with functional posterior crossbite. Braz Oral Res 2008;22(1):48-54.

Castelo PM, Pereira L, Bonjardim LR, Gavião BD. Changes in bite force, masticatory muscle thickness, and facial morphology between primary and mixed dentition in preschool children with normal occlusion. Annals of Anatomy. 2010;192:23-26.

Cheung LK, Chan YM, Jayarante YSN, Lo J. Three-dimensional cephalometric norms of Chinese adults in Hong Kong with balanced facial profile. Oral Surg Oral Med Oral Pathol Oral Radiol Endod. 2011;112:56-73.

Coelho-Ferraz MJP, Amorim FBCF, Romano FL, Queluz DP. Electromyographic and cephalometric correlation with the predominant masticatory movement. Stomatologia Baltic Dental and Maxillofacial Journal. 2010;12:51-55.

Custodio W, Gomes SGF, Faot F, Garcia RCMR, Del Bel Cury AA. Occlusal force, electromyographic activity of subjects with different facial types. J Appl Oral Sci. 2010;19(4):343-349.

Dagys AP. The use of proportions in planning surgical orthodontic treatment in young adult patients. In: Farkas LG e Munro IR. Anthropometric Facial Proportions in Medicine. 1st ed. Springfield. Charles C Thomas; 1987. 
De Felício CM, Folha GA, Ferreira CL, Medeiros AP. Expanded protocol of orofacial myofunctional evaluation with scores: validity and reliability. Int J Pediatr Otorhinolaryngol. 2010;74(11):1230-9.

De Felício CM, Medeiros AP, de Oliveira MM. Validity of the 'protocol of orofacial myofunctional evaluation with scores' for young and adult subjects. J Oral Rehabil. 2012;39(10):744-53.

De Felício CM, Melchior MO, Da Silva MAMR. Clinical Validity of the Protocol for MultiProfessional Center for the Determination of Signs and Symptoms of Temporomandibular Disorders. Part II. The Journal of Craniomandibular Practice. 2009;27(1):62-67.

Dean JS, Throckmorton GS, Eliis III E, Sinn DP. A Preliminary Study of Maximum Voluntary Bite Force and Jaw Muscle Efficiencyin Pre-Orthognathic Surgery Patients. J Oral Maxillofac Surg. 1992;50:1284-1288.

Douglas RC. Fisiologia do sistema estomatognático. In: Fisiologia aplicada à Fonoaudiologia. 2ed. Rio de Janeiro. Guanabara; 2006.

Egermark I, Blomqvist JE, Cromvik U, Isaksson S. Temporomandibular dysfunction in patients treated with orthodontics in combination with orthognathic surgery. Eur J Orthod. 2000;22(5):537-44.

Ellis III E, McNamara JA. Components of Adult Class III Malocclusion. J Oral Maxillofac Surg. 1984;42:295-305.

Ellis III E, Throckmorton GS, Sinn DP. Bite forces before and after surgical correction of mandibular prognathism. J Oral Maxillofac Surg. 1996;54(2):176-81.

Enlow DH. Conceitos introdutórios do processo de crescimento. In: Enlow DH. Crescimento Facial. 3ed. Philadelphia. Artes Médicas; 1993.

Enlow DH. Faces. In: Enlow DH. Crescimento Facial. 3ed. Philadelphia. Artes Médicas; 1993.

Enlow DH. Maturação da neuromusculatura orofacial. In: Enlow DH. Crescimento Facial. 3ed. Philadelphia. Artes Médicas; 1993. 
Farkas LG. Examination. In: Farkas LG. Anthropometry of the Head and Face. 2ed. New York. Raven Press; 1994.

Felício CM, Couto GA, Ferreira CLP, Mestriner Junior W. Confiabilidade da eficiência mastigatória com beads e correlação com a atividade muscular. Pró-Fono Revista de Atualização Científica. 2008;20(4):225-230.

Felício CM, Ferreira CL. Protocol of orofacial myofunctional evaluation with scores. Int J Pediatr Otorhinolaryngol. 2008;72(3):367-75.

Felício CM. Sistema estomatognático e funções. In: Fonoaudiologia Aplicada a Casos Odontológicos. 1st reimpressão.São Paulo. Pancast; 1999.

Ferrario VF, Sforza C, Schmitz JH, Santoro F. Three-dimensional facial morphometric assessment of soft tissue changes after orthognathic surgery. Oral Surg Oral Med Oral Pathol Oral Radiol Endod 1999;88:549-56.

Ferrario VF, et al. A direct in vivo measurement of the three-dimensional orientation of the occlusal plane and of the sagittal discrepancy of the jaws. Clin Orthod Res. 2000;3(1):15-22.

Gandini Jr LG, Dos Santos-Pinto A, Raveli DB, Sakima MT, Martins LP, Sakima T, Gonçalves JR, Barreto CS. Análise cefalométrica Padrão Unesp Araraquara. R Dental Press Ortodon Ortop Facial. 2005;10(1):139-157.

Geng J. Structured-light 3D surface imaging: a tutorial. Advances in Optics and Photonics 3. 2011;128-160.

Gomes SGF, et al. Chewing side, bite force symmetry, and occlusal contact area of subjects with different facial vertical patterns. Braz Oral Res. 2011 Sep-Oct;25(5):446-52.

Goto TK, Yamada T, Yoshiura K. Occlusal pressure, contact area, force and the correlation with the morphology of the jaw-closing muscles in patients with skeletal mandibular asymmetry. J Oral Rehabil. 2008;35(8):594-603.

Grünheid $T$, et al. The adaptive response of jaw muscles to varying functional demands. European Journal of Orthodontics. 2009;31:596-612. 
Hajeer MY, et al. Applications of 3D imaging in orthodontics: part I. J Orthod. 2004;31(1):6270.

Hannam AG, McMillan AS.Internal Organization in the Human Jaw Muscles. Critical Reviews in Oral Biology and Medicine. 1994;5(1):55-89.

Harada K, et al. Changes in bite force and dentoskeletal morphology in prognathic patients after orthognathic surgery. Oral Surg Oral Med Oral Pathol Oral Radiol Endod. 2003;95:64954.

Harada K, et al. Measure of bite force and occlusal contact area before and after bilateral sagittal split ramus osteotomy of the mandible using a new pressure-sensitive device: a preliminary report. J Oral Maxillofac Surg. 2000;58(4):370-3.

Harper RP, Bruin H, Burcea I. Muscle Activity During Mandibular Movements in Normal and Mandibular Retrogna thic Subjects. J Oral Maxillofac Surg. 1997;55:225-233.

Harridge SDR. Plasticity of human skeletal muscle: gene expression to in vivo function. Exp Physiol. 2007;92(5):783-797.

Hatch JP, et al. Determinants of masticatory performance in dentate adults. Archives of Oral Biology. 2000;46:641-648

Hattori Y, Satoh C, Seki S, Watanabe Y, Ogino Y. Watanabe M. Occlusal and TMJ Loads in Subjects with Experimentally Shortened Dental Arches. J Dent Res. 2003;82(7):532-536.

Hunt N, Shah R, Sinanan A, Lewis M. Muscling in on malocclusions: Current concepts on the role of muscles in the aetiology and treatment of malocclusion. Journal of Orthodontics. 2006;33:187-197.

Ikebe $\mathrm{K}$, et al. Association of masticatory performance with age, gender, number of teeth, occlusal force and salivary flow in Japanese older adults: is ageing a risk factor for masticatory dysfunction? Arch Oral Biol. 2011;56(10):991-6.

Ikebe $\mathrm{K}$, et al. Association of bite force with ageing and occlusal support in older adults. J Dent. 2005;33(2):131-7. 
Ingervall $B$, Minder $C$. Correlation between maximum bite force and facial morphology in children. Angle Orthod. 1997;67(6):415-424.

Iwase $\mathrm{M}$, et al. Bite force, occlusal contact area and masticatory efficiency before and after orthognathic surgical correction of mandibular prognathism. Int. J. Oral Maxillofac. Surg. 2006;35: 1102-1107.

Iwase $\mathrm{M}$, et al. Changes in bite force and occlusal contacts in patients treated for mandibular prognathism by orthognathic surgery. J Oral Maxillofac Surg. 1998;56(7):850-5.

Jacobson A, Sadowsky PL. Superimposition of cephalometric radiographs. In: Jacobson A. Radiographic Cephalometry: From Basics to Videoimaging. 1st ed. US:Quintessence Publishing Co Inc.,U.S.; 1995.

Johnston C, et al. Class III surgical-orthodontic treatment: a cephalometric study. Am J Orthod Dentofacial Orthop. 2006;130:300-9.

Julien KC, et al. Normal masticatory performance in young adults and children. Archs oral Biol. 1996;41(1):69-75.

Kang SH, et al. Early orthognathic surgery with three-dimensional image simulation during presurgical orthodontics in adults. J Craniofac Surg. 2011;22(2):473-81.

Karakis D, Kaymak D, Gogan A. The evaluation of maximum bite force in the occlusal rehabilitation of patient with Angle Class III malocclusion: a case report. J Adv Prosthodont. 2013;5:364-368.

Karkazis HC, Kossioni AE. Surface EMG activity of the masseter muscle in denture wearers during chewing of hard and soft food. J Oral Rehabil. 1998;25(1):8-14.

Kau CH, Cronin A, Durning P, Zhurov Al, Sandham A, Richmond S. A new method for the 3D measurement of postoperative swelling following orthognathic surgery. Orthod Craniofac Res. 2006;9(1):31-7.

Kiliaridis S, Kjellberg $\mathrm{H}$, Wenneberg B, Engstrom $\mathrm{C}$. The relationship between maximal bite force, bite force endurance, and facial morphology during growth. A cross-sectional study. Acta Odontol Scand. 1993;51(5):323-31. 
Kilinc A, Ertas U. An Assessment of the Quality of Life of Patients With Class III Deformities Treated With Orthognathic Surgery. J Oral Maxillofac Surg. 2015;73:1394.e1-1394.e5.

Kim YG, Hwan S. Effect of Mandibular Setback Surgery on Occlusal Force. J Oral Maxillofac Surg. 1997;55:121-126.

Kobayashi FY, et al. Evaluation of orofacial function in young subjects with temporomandibular disorders. J Oral Rehabil. 2014;41(7):496-506.

Kobayashi T, et al. Masticatory function in patients with mandibular prognathism before and after orthognathic surgery. J Oral Maxillofac Surg. 1993: 51: 997- 1001.

Kobayashi T, et al. Changes in masticatory function after orthognathic treatment in patients with mandibular prognathism. British Journal of Oral and Maxillofacial Surgery. 2001:39;260265.

Koç D, Dogan A, Bek B. Bite force and influential factors on bite force measurements: a literature review. Eur J Dent. 2010;4(2):223-32.

Koç D, Dogan A, Bek B. Effect of gender, facial dimensions, body mass index and type of functional occlusion on bite force. J Appl Oral Sci. 2011 May-Jun;19(3):274-9.

Korfage JAM, et al. Fiber-type Composition of the Human Jaw Muscles-(Part 1) Origin and Functional Significance of Fiber-type Diversity. J Dent Res.2005a;84(9):774-783.

Korfage JAM, et al. Fiber-type Composition of the Human Jaw Muscles-(Part 2) Role of Hybrid Fibers and Factors Responsible for Inter-individual Variation. J Dent Res. 2005b;84(9):784-793.

Koss B, et al. Time-dependent analysis and representation of force distribution and occlusion contact in the masticatory cycle. J Orofac Orthop 2012; 73:204-214.

Laufer D, Glick D, Gutman D, Sharon A. Patient motivation and responseto surgical correction of prognathism. Israel Oral Surfi. 1976;41(3):309-313. 
Lepley $\mathrm{CR}$, et al. Relative contributions of occlusion, maximum bite force, and chewing cycle kinematics to masticatory performance. American Journal of Orthodontics and Dentofacial Orthopedics. 2011;139:606-13.

Lippold C, et al. Facial landmark localization by curvature maps and profile analysis. Head Face Med. 2014;8;10:54.

Lund JP, Kolta A. Generation of the Central Masticatory Pattern and Its Modification by Sensory Feedback. Dysphagia. 2006;167-174

Maciel KRA, Albino RCM, Pinto MMA. A prevalência do distúrbio miofuncional orofacial nos pacientes atendidos no ambulatório de pediatria do Hospital Luís de França. Revista de Pediatria. 2007;8(2):81-90.

Mapelli A, et al. Reorganization of muscle activity in patients with chronic temporomandibular disorders. Archives of Oral Biology 72. 2016;164-171.

Marchesan IQ, Bianchini EMG. A Fonoaudiologia e a Cirurgia Ortognática. In: Araújo A. Cirurgia Ortognática. 1st ed. São Paulo: Livraria Santos; 1999.

Marquezin MCS, et al. Relationship between orofacial function, dentofacial morphology, and bite force in young subjects. Oral Diseases. 2014;20:567-573.

McCance AM, et al. A three-dimensional soft tissue analysis of 16 skeletal class III patients following bimaxillary surgery. Br J Oral Maxillofac Surg. 1992;30:221-232.

McNamara Jr JA. Components of class II malocclusion in children 8-10 years old. The Angle Orthodontist. 1981;51(3):177-202.

Melo DG, Bianchini EMG. Relações entre potenciais elétricos dos músculos temporais e masseteres, força de mordida e índice morfológico da face. CoDAS. 2016;28(4):409-416.

Michelotti A, et al. Evaluation of the short-term effectiveness of education versus an occlusal splintfor the treatment of myofascial pain of the jaw muscles. JADA. 2012;143(1):47-53. 
Miyawaki S, et al. Occlusal force and condylar motion in patients with anterior open bite. J Dent Res. 2005;84(2):133-7.

Moorees CFA, Efstratiadis SS, Kent Jr RL. The Complexity os Facial Growth Analysis. In: Jacobson A. Radiographic Cephalometry: From Basics to Videoimaging. 1st ed. US:Quintessence Publishing Co Inc.,U.S.; 1995.

Moroi $A$, et al. The amount of mandibular setback influence on occlusal force following sagittal split ramus osteotomy. J Craniomaxillofac Surg. 2015;43(9) 1743-8.

Murphy C, et al. The clinical relevance of orthognathic surgery on quality of life. Int. J. Oral Maxillofac. Surg. 2011;40:926-930.

Nagai I, et al. Changes in occlusal state of patients with mandibular prognathism after orthognathic surgery: a pilot study. British Journal of Oral and Maxillofacial Surgery. 2001;39:429-433.

Nakata $Y$, et al. Changes in stomatognathic function induced by orthognathic surgery in patients with mandibular prognathism. J Oral Maxillofac Surg. 2007;65(3):444-51.

Nale JC. Orthognathic Surgery and the Temporomandibular Joint Patient. Oral Maxillofacial Surg Clin N Am 26. 2014;551-564.

Nooreyazdan M, Trotman CA, Faraway JJ. Modeling facial movement: II. A dynamic analysis of differences caused by orthognathic surgery. J Oral Maxillofac Surg. 2004 Nov;62(11):13806.

Ohkura K, et al. Changes in bite force and occlusal contact area after orthognathic surgery for correction of mandibular prognathism. Oral Surg Oral Med Oral Pathol Oral Radiol Endod. 2001;91(2):141-5.

Okazaki LK. Quando indicar uma cirurgia ortognática. In: Araújo A. Cirurgia Ortognática. 1st ed. São Paulo: Livraria Santos; 1999.

Okeson JP. Evaluation of the Research Diagnostic Criteria for Temporomandibular Disorders for the Recognition of an Anterior Disc Displacement with Reduction. Journal of Orofacial Pain. 2009;23(4):312-315. 
Ovsenik $M$, et al. Three-dimensional assessment of facial asymmetry among pre-pubertal class III subjects: a controlled study. European Journal of Orthodontics. 2014;36:431-435.

Palinkas $M$, et al. Age and gender influence on maximal bite force and masticatory muscles thickness. Archives of oral biology. 2010;55:797-802.

Patel A, et al. Facial asymmetry assessment in adults using three-dimensional surface imaging. Progress in Orthodontics. 2015;16:36.

Pellizer EP, Muench A. Forças de mordida relacionadas a próteses removíveis inferiores. Rev Odontol Univ São Paulo. 1998;12(4):401-407.

Pellizer EP, Muench A. Forças de mordida relacionadas a próteses removíveis inferiores [tese]. São Paulo (SP): Faculdade de Odontologia de São Paulo, Universidade de São Paulo; 1997.

Pereira AC, et al. Características das funções orais de indivíduos com má oclusão Classe III e diferentes tipos faciais. R Dental Press Ortodon Ortop Facial. 2005;10(6):111-119.

Pereira JBA, Bianchini EMG. Functional characterization and temporomandibular disorders before and after orthognathic surgery and myofunctional treatment of Class II Dentofacial deformity. Rev. CEFAC. 2011 Nov-Dez;13(6):1086-1094.

Pereira $\sqcup$, et al. Muscle thickness, bite force, and craniofacial dimensions in adolescents with signs and symptoms of temporomandibular dysfunction. European Journal of Orthodontics. 2007;29:72-78.

Pereira-Cenci T, et al. Maximal bite force and its association with temporomandibular disorders. Braz Dent J. 2007;18(1):65-68.

Pereira-Stabile $\mathrm{CL}$, et al. Preoperative incisor inclination in patients with Class III dentofacial deformities treated with orthognathic surgery. Br J Oral Maxillofac Surg. 2012;50;533-536.

Picinato-Pirola MNC, et al. Masticatory efficiency in class II and class III dentofacial deformities. Int. J. Oral Maxillofac. Surg. 2012;41:830-834. 
Pizolato RA, et al. Trindade-Junior AST. Maximal bite force in young adults with temporomandibular disorders and bruxism. Braz Oral Res. 2007;21(3):278-83.

Plooij JM, et al. Digital three-dimensional image fusion processes for planning and evaluating orthodontics and orthognathic surgery. A systematic review. J. Oral Maxillofac. Surg. 2011;40:341-352.

Porto $\mathrm{OCL}$, et al. The use of three-dimensional cephalometric references in dentoskeletal symmetry diagnosis. Dental Press J Orthod. 2014 Nov-Dec;19(6):78-85.

Proffit WR, Fieds HW, Sarver DM. Malocclusion and Dentofacial Deformity in Contemporary Society. In: Proffit WR, Fieds HW, Sarver DM. Contemporary Orthodontics. $5^{\text {th }}$ ed. St Louis: Elsevier; 2013.

Proffit WR, Fields HW, Nixon WL. Occlusal forces in normal and long face adults. J Dent Res. 1983;62:566-70.

Proffit WR, et al. The Effect of Orthognathic Surgery on Occlusal Force. J Oral Maxillofac Surg. 1989;47:457-463.

Raadsheer MC, et al. Contribution of Jaw Muscle Size and Craniofacial Morphologyto Human Bite Force Magnitude. J Dent Res. 1999;78(1):31-42.

Ramires RR, et al. Facial types applied to Speech-Language Pathology: literature review. Rev Soc Bras Fonoaudiol. 2010;15(1):140-5.

Rankin M, Borah G. Perceived Functional Impact of Abnormal Facial Appearance. Plast. Reconstr. Surg. 2003;111:2140-2146.

Relle R, Silegy T. Orthognathic Surgery: Diagnosis and Treatment of Dentofacial Deformities. Journal of The California Dental Association. 2004;32(10):831-836.

Rentes AM, Gaviao MB, Amaral JR. Bite force determination in children with primary dentition. J Oral Rehabil. 2002;29(12):1174-80. 
Roldán SI, et al. Are maximum bite forces of subjects 7 to 17 years of age related to malocclusion? Angle Orthod. 2015;00:000-000.

Rosenblum RE. Class II malocclusion: mandibular retrusion or maxillary protrusion? The Angle Ortodontist. 1995;65(1):49-62.

Rowlerson A, et al. Fiber-type differences in masseter muscle associated with different facial morphologies. Am J Orthod Dentofacial Orthop. 2005; 127:37-46.

Schlickmann ICA, Moro A, Dos Anjos A. Análise do perfil facial masculino adulto jovem, esteticamente agradável, em fotografias padronizadas: comparação da medição manual com a computadorizada. Rev. Dent. Press Ortodon. Ortop. Facial. 2008;13(6)98-107.

Severt TR, Proffit WR. The prevalence of facial asymmetry in the dentofacial deformities population at the University of North Carolina. Int J Adult Orthod Orthognath Surg. 1997;12:171-6.

Sforza C, et al. Three-dimensional facial morphometry in skeletal Class III patients. A noninvasive study of soft-tissue changes before and after orthognathic surgery. British Journal of Oral and Maxillofacial Surgery. 2007;45(2):138-44.

Shimomatsu $k$, et al. Three-dimensional analyses of facial soft tissue configuration of Japanese females with jaw deformity - A trial of polygonal view of facial soft tissue deformity in orthognathic patients. Journal of Cranio-Maxillo-Facial Surgery.2012;40:559-567.

Silva MMA, et al. Influence of orthodontic-surgical treatment on signs and symptoms of temporomandibular dysfunction in subjects with dentofacial deformities. Rev Soc Bras Fonoaudiol. 2011;16(1):80-4

Simões, JCM. Análise da morfologia facial e da força de mordida das deformidades dentofaciais [dissertação]. Ribeirão Preto: Universidade de São Paulo, Faculdade de Medicina de Ribeirão Preto; 2017.

Soh CL, Narayanan V. Quality of life assessment in patients with dentofacial deformity undergoing orthognathic surgery-A systematic review. Int. J. Oral Maxillofac. Surg. 2013; 42: 974-980. 
Soncul M, Bamber MA. Evaluation of facial soft tissue changes with optical surface scan after surgical correction of Class III deformities. J Oral Maxillofac Surg. 2004;62(11):1331-40.

Sondang $\mathrm{P}$, et al. Correlation between maximum bite force and craniofacial morphology of young adults in Indonesia. J Oral Rehabil. 2003;30(11):1109-17.

Sonessen L, Bakke M, Solow B. Bite force in pre-orthodontic children with unilateral crossbite. Eur J Orthod. 2001;23(6):741-749.

Sonnessen L, Bakke M. Bite force in children with unilateral crossbite before and after orthodontic treatment. A prospective longitudinal study. Eur J Orthod. 2007;29(3):310-313.

Steinbacher DM. Three-Dimensional Analysis and Surgical Planning in Craniomaxillofacial Surgery. J Oral Maxillofac Surg. 2015;73:S40-S56.

Steinhauser EW. Historical development of orthognathic surgery. Journal of CranioMaxillofacial Surgery. 1996;24:195-204.

Stohler CS. Muscle-Related Temporomandibular Disorders. Journal of Orofacial Pain. 1999;3(4):273-284.

Suda S, et al. A multiparametric analysis of occlusal and periodontal jaw reflex characteristics in adult skeletal mandibular protrusion before and after orthognathic surgery. Journal of Oral Rehabilitation. 1999;26:686-690.

Suzuki-Okamura E, et al. Three-dimensional analysis of hard and soft tissue changes in patients with facial asymmetry undergoing 2-jaw surgery. Oral Surg Oral Med Oral Pathol Oral Radiol. 2015;120:299-306.

Takaki P, Vieira M, Bommarito S. Maximum bite forces analysis in different age groups. Int Arch Otorhinolaryngol. 2014;18:272-276.

Tate GS, et al. Masticatory Performance, Muscle Activity, and Occlusal Force in Preorthognathic Surgery Patients. Oral Maxillofac Surg. 1994;52:476-481. 
Tecco S, et al. Relation between facial morphology on lateral skull radiographs and sEMG activity of head, neck, and trunk muscles in Caucasian adult females. J Electromyogr Kinesiol. 2011;21(2):298-310.

Terajima $\mathrm{M}$, et al. A 3-dimensional method for analyzing the morphology of patients with maxillofacial deformities. Am J Orthod Dentofacial Orthop. 2009;136(6):857-67.

Terajima $\mathrm{M}$, et al. Three-dimensional analysis system for orthognathic surgery patients with jaw deformities. Am J Orthod Dentofacial Orthop. 2008;134:100-11.

Thali MJ, Braun M, Dirnhofer R: Optical 3D surface digitizing in forensic medicine: 3D documentation of skin and bone injuries. Forensic Sci Int. 2003;137:203-208.

Thomas GP, et al. The Effects of Orthodontic Treatment on Isometric Bite Forces and Mandibular Motion in Patients Before Orthognathic Surgery. Oral MaxillofacSurg. 1995;53:673-678.

Throckmorton GS e Ellis III E. The Relationship Between Surgical Changes in Dentofacial Morphology and Changes in Maximum Bite Force. J Oral Maxillofac Surg. 2001;59:620-627.

Throckmorton GS, Buschang PH, Ellis E 3rd. Morphologic and biomechanical determinants in the selection of orthognathic surgery procedures. J Oral Maxillofac Surg. 1999;57(9):104456.

Throckmorton GS, Buschang PH, Ellis III E. Improvement of Maximum Occlusal Forces After Orthognathic Surgery. J Oral Maxillofac Surg. 1996; 54:1080-1086.

Throckmorton GS, Ellis E 3rd, Sinn DP. Functional characteristics of retrognathic patients before and after mandibular advancement surgery. J Oral Maxillofac Surg. 1995;53(8):898908.

Throckmorton GS, Ellis E, Buschang PH. Morphologic and Biomechanical Correlates With Maximum Bite Forces in Orthognathic Surgery Patients. J Oral Maxillofac Surg. 2000;58:515524.

Throckmorton GS, Finn RA, Bell WH. Biomechanics of differences in lower facial height. Am J Orthod. 1980;77(4):410-420. 
Throckmorton GS. Changes in bite force and occlusal contacts in patients treated for mandibular prognathism by orthognathic surgery. J Oral Maxillofac Surg. 1998;56:855-856.

Throckmorton GS. Functional Deficits in Orthognathic Surgery Patients. Semin Orthod. 2006;12:127-137.

Trawitzki LVV, et al. Effect of treatment of dentofacial deformities on the electromyographic activity of masticatory muscles. Int. J. Oral Maxillofac. Surg. 2006a; 35: 170-173.

Trawitzki LVV, et al. Effect of treatment of dentofacial deformity on masseter muscle thickness. Archives of Oral Biology. 2006b;51:1086-1092.

Trawitzki LVV, et al. Masticatory muscle function three years after surgical correction of class III dentofacial deformity. Int. J. Oral Maxillofac. Surg. 2010;39: 853-856.

Trawitzki LVV, et al. Effect of class II and class III dentofacial deformities under orthodontic treatment on maximal isometric bite force. Arch Oral Biol. 2011 Oct;56(10):972-6.

Trawitzki LVV. Fonoaudiologia nas deformidades dentofaciais junto à equipe de cirurgia ortognática. In: Felício CM e Trawitzki LVV. Interfaces da medicina odontologia e fonoaudiologia no complexo cérvico craniofacial. 1st ed. Barueri. Pró-Fono; 2009.

Turker KS. Reflex Control of Jaw Muscles. Crit Rev Oral Biol Med. 2002;13(1):85-104.

Uchida $Y$, et al. Relationship between masseter muscle size and maxillary morphology. Eur J Orthod. 2011;33(6):654-9.

Ueki K, et al. Assessment of ramus, condyle, masseter muscle, and occlusal force before and after sagittal split ramus osteotomy in patients with mandibular prognathism. Oral Surg Oral Med Oral Pathol Oral Radiol Endod. 2009;108(5):679-86.

Valizadeh S, et al. Correlation of Shape and Size of Sella Turcica With the Type of Facial Skeletal Class in an Iranian Group. Iran J Radiol. 2015;22;12(3). 
van den Braber W, van der Glas H, van der Bilt A. Masticatory Function in Retrognathic Patients, Before and After Mandibular Advancement Surgery. J Oral Maxillofac Surg. 2004;62:549-554.

van den Braber W, van der Glas HW, van der Bilt A, Bosman F. The influence of orthodontics on selection and breakage underlying food comminution in pre-orthognathic surgery patients. Int J Oral Maxillofac Surg. 2002;31(6):592-7.

van der Bilt $A$, et al. Bite force and electromyography during maximum unilateral and bilateral clenching. Eur J Oral Sci. 2008;116:217-222.

van der Bilt A. Assessment of mastication with implications for oral rehabilitation: a review. J Oral Rehabil. 2011;38(10):754-80.

van Spronsen PH. Long-Face Craniofacial Morphology: Cause or Effect of Weak Masticatory Musculature? Semin Orthod. 2010;16:99-117.

Varga S, et al. Maximum voluntary molar bite force in subjects with normal occlusion. Eur J Orthod. 2011;33(4):427-33.

Verzé L, et al. Facial Mobility After Bimaxillary Surgery in Class III Patients: A ThreeDimensional Study. J Craniofac Surg. 2011;22:2304-2307.

Verzé L, et al. Soft tissue changes after orthodontic surgical correction of jaws asymmetry evaluated by three dimensional surface laser scanner. J Craniofac Surg. 2012 Sep;23(5):144852.

Wang XR, et al. Stable tooth contacts in intercuspal occlusion makes for utilities of the jaw elevators during maximal voluntary clenching. J Oral Rehabil. 2013;40(5):319-28.

Wang YL, et al. Patterns and forces of occlusal contacts during lateral excursions recorded by the T-Scan II system in young Chinese adults with normal occlusions. J Oral Rehabil. 2011;38(8):571-8.

Wang C, Yin X. Occlusal risk factors associated with temporomandibular disorders in young adults with normal occlusions. Oral Surg Oral Med Oral Pathol Oral Radiol. 2012;114:419423. 
Ward RE, Jamison PL, Allanson JE. Quantitative Approach to Identifying Abnormal Variation in the Human Face Exemplified by a Study of 278 Individuals With Five Craniofacial Syndromes. Am. J. Med. Genet. 2000;91:8-17.

Wen Y F, et al. Longitudinal Photogrammetric Analysis of Soft Tissue Facial Changes: A Systematic Review of the Literature and a Summary of Recommendations. J Craniofac Surg. 2015;26: 1830-1834.

Wenneberg B, Kjellberg $\mathrm{H}$, Kiliaridis S. Bite force and temporomandibular disorder in juvenile chronic arthritis. Journal of Oral Rehabilitation. 1995;22:633-6.

Xavier SP, Ribeiro HT, Pedrosa Jr WF. Cirurgia ortognática: noções de técnicas cirúrgicas. In: Felício CM e Trawitzki LVV. Interfaces da medicina odontologia e fonoaudiologia no complexo cérvico craniofacial. 1st ed. Barueri. Pró-Fono; 2009.

Zarrinkelk $\mathrm{HM}$, et al. Functional and morphologic alterations secondary to superior repositioning of the maxilla. J Oral Maxillofac Surg. 1995;53(11):1258-67.

Zarrinkelk HM, et al. Functional and Morphologic Changes After Combined Maxillary Intrusion and Mandibular Advancement Surgery. J Oral Maxillofac Surg. 1996;54:20-837.

Zecca PA, et al. Correlation Assessment between Three-Dimensional Facial Soft Tissue Scan and Lateral Cephalometric Radiography in Orthodontic Diagnosis. International Journal of Dentistry. 2016;2016:1-8.

Zhang $X$, et al. Correlations between cephalometric and facial photographic measurements of craniofacial form. Am J Orthod Dentofacial Orthop. 2007;131:67-71. 


\section{APÊNDICE A}

\section{TERMO DE CONSENTIMENTO LIVRE E ESCLARECIDO}

\section{Grupo Estudo}

Nós, Fga. Joana Carolina Martins Simões e Profa. Dra. Luciana Vitaliano Voi Trawitzki, convidamos o Sr. (a) a participar da pesquisa "ANÁLISE DA MORFOLOGIA FACIAL E DA FORÇA DE MORDIDA NAS DEFORMIDADES DENTOFACIAIS". Caso concorde em participar, nós faremos algumas perguntas para saber se Sr. (a) se encontra dentro dos critérios da pesquisa.

Informo que esse Termo de Consentimento Livre e Esclarecido será duas vias e que uma ficará com o Sr. (a) e a outra arquivada com a pesquisadora responsável. E que as pesquisadoras manterão sigilo sobre a sua participação na pesquisa, ou seja, o seu nome não será divulgado.

\section{DO QUE SE TRATA A PESQUISA?}

Esse estudo tem como objetivo avaliar a relação entre a morfologia facial (que é a forma do seu rosto) e a força de mordida em pessoas com alterações dentofaciais (ou seja, pessoas que não possuem uma relação harmoniosa e adequada entre os dentes de cima e de baixo e suas bases óssea). Serão analisadas as dimensões das estruturas do crânio e da face e sua relação com a força de mordida exercida pelos músculos que fazem a mastigação. Os resultados serão comparados entre pessoas que possuem e que não possuem esse problema (a deformidade dentofacial). Vários exames serão realizados nesse estudo antes da cirurgia ortognática (que é a cirurgia dos ossos da mandíbula e/ou da maxila usada para corrigir a diferença entre os maxilares e os dentes de cima e os dentes de baixo).Os mesmos exames serão realizados novamente nos períodos de 6 meses e 1 ano após a cirurgia.

\section{COMO SERÁ REALIZADA? E ONDE?}

Será feita uma avaliação na sua boca e na face, verificando como estão suas estruturas como dentes, língua, lábios, bochechas, mandíbula; sua aparência e os movimentos dessas estruturas. Essa avaliação será filmada para poder ser melhor analisada 
depois e o resultado dessa avaliação será anotado em um protocolo. O tempo total dessa avaliação é de aproximadamente 20 minutos.

Para avaliar a sua força de mordida/oclusal e a área de contato oclusal, o Sr. (a) deverá realizar o máximo apertamento dos dentes sobre uma lâmina de plástico posicionada entre as arcadas dentárias, por aproximadamente 15 segundos. Após, será solicitado que o Sr. (a) realize a máxima força de mordida em um outro equipamento posicionado nos dentes molares. O Sr. (a) será instruído a morder o mais forte possível, do lado direito e esquerdo, alternadamente, por três vezes, com um intervalo de 2 minutos entre cada vez. E, além disso, o Sr. (a) será submetido a um exame que fará uma "cópia" do seu rosto. Para tal, o Sr. (a) será convidado a permanecer em pé, com os olhos fechados e o avaliador irá deslizar um equipamento com laser na direção da sua face, sem encostar, causar dor ou desconforto, em um tempo total de aproximadamente 10 minutos.

Todos esses exames descritos acima serão feitos em um único lugar, no Laboratório de Fonoaudiologia, na casa de número 18 da Rua das Paineiras, dentro do Campus da USP. Para isso o Sr. (a) receberá um mapa e nós nos comprometemos a explicar-lhe como chegar, caso ainda não saiba.

\section{OS EXAMES SÃO DESCONFORTÁVEIS OU GERAM RISCOS?}

Toda pesquisa com seres humanos envolve risco em tipos e gradações variados. Devem ser analisadas possibilidades de danos imediatos ou posteriores, no plano individual ou coletivo (Resolução no 466, de 12 de dezembro de 2012).

Os exames propostos não causam nenhum prejuízo. Mas, existe um risco mínimo de o Sr. (a), por algum motivo que não conhecemos, sentir algum tipo de dor, desconforto ou cansaço nos músculos da rosto durante a realização dos exames. Caso isso aconteça, as examinadoras vão parar de fazer as avaliações. Depois, elas verão se é possível continuar os exames ou se serão agendados para outro dia ou ainda, se não serão mais realizados.

As pesquisadoras manterão sigilo sobre a sua identidade e o Sr. (a) será esclarecido quanto aos procedimentos realizados e informado sobre os resultados que vamos ter com a pesquisa, sendo que tem total garantia de acesso aos resultados da pesquisa. E a qualquer 
momento, o Sr. (a) poderá desistir que esses dados sejam utilizados na presente pesquisa. Portanto, as pesquisadoras tomarão todos os cuidados possíveis em manter o sigilo a respeito da sua identidade e participação no estudo. Entretanto, caso o Sr. (a) sinta-se lesado, é de seu direito solicitar indenização, conforme legislação vigente.

\section{O PARTICIPANTE TERÁ GASTOS OU DESPESAS?}

Caso o Sr. (a) tenha que se deslocar até o Hospital das Clínicas ou ao Laboratório de Fonoaudiologia para realização exclusiva dos exames da pesquisa, nós nos comprometemos a dar assistência e fornecer recursos para o transporte (valor em reais equivalente às passagens de ida de volta, seja de dentro de Ribeirão Preto ou de alguma cidade vizinha) e também quanto ao lanche que poderá serdisponibilizado antes ou após a realização dos exames, conforme solicitada e afirmada a necessidade.

Nada será cobrado, assim como o Sr.(a) também não receberá qualquer benefício financeiro.

As pesquisadoras se comprometem a prestar assistência integral no decorrer da pesquisa, se algum problema decorrer desta.

A indenização, a título de cobertura material, para reparação de danos imediatos ou tardios, decorrentes da sua participação na pesquisa, caso ocorra, será realizada pelas pesquisadoras, não cabendo ao Hospital das Clínicas de Ribeirão Preto qualquer responsabilidade quanto aos referidos pagamentos.

\section{A PESQUISA TRARÁ ALGUM BENEFÍCIO PARA O PARTICIPANTE?}

Não há proveito direto ou indireto, imediato ou posterior, recebido pelo participante em decorrência de sua participação na pesquisa. Entretanto, existem os benefícios gerais da pesquisa, que incluem a obtenção de diagnósticos mais precisos e busca de tratamentos mais favoráveis aos indivíduos.

\section{O QUE ACONTECE COM QUEM NÃO PARTICIPA DA PESQUISA?}

A sua participação no estudo é voluntária, não acarretando absolutamente nada ao Sr. (a) caso não aceite participar. O Sr. (a) tem a liberdade de se recusar a participar ou 
poderá interromper a pesquisa a qualquer momento, sem qualquer risco de prejuízos ou penalidades.

Concordando em participar da pesquisa o Sr. (a) assinará o Termo de Consentimento Livre e Esclarecido, o qual consta os dados das Pesquisadoras Responsáveis, para caso necessite de maiores informações, ou por qualquer outra necessidade e poderá entrar em contato a qualquer momento, assim como poderá entrar em contato com o Comitê de Ética em pesquisa do Hospital da Clínicas da Faculdade de Medicina de Ribeirão Preto caso tenha alguma reclamação, recurso ou dúvida, pelo telefone (16) 3602-2228.

Dados das pesquisadoras responsáveis para eventuais necessidades: Profa. Dra. Luciana Vitaliano Voi Trawitzki e Fga. Joana Carolina Martins Simões End: Av. Bandeirantes, 3900, Monte Alegre, Ribeirão Preto, Cep: 14.049.900 Tel: (16) 3602-0592 (Laboratório de Fonoaudiologia).

Email: joanacmsimoes@gmail.com

Pesquisadora:

Participante:

Data: 


\section{APÊNDICE B}

\section{TERMO DE CONSENTIMENTO LIVRE E ESCLARECIDO}

\section{Grupo Controle}

Nós, Fga. Joana Carolina Martins Simões e Profa. Dra. Luciana Vitaliano Voi Trawitzki, convidamos o Sr. (a) a participar da pesquisa intitulada "ANÁLISE DA MORFOLOGIA FACIAL E DA FORÇA DE MORDIDA NAS DEFORMIDADES DENTOFACIAIS". Caso concorde em participar, nós faremos algumas perguntas para saber se Sr. (a) se encontra dentro dos critérios da pesquisa.

Informo que esse Termo de Consentimento Livre e Esclarecido será duas vias e que uma ficará com o Sr. (a) e a outra arquivada com a pesquisadora responsável. E que as pesquisadoras manterão sigilo sobre a sua participação na pesquisa, ou seja, o seu nome não será divulgado.

\section{DO QUE SE TRATA A PESQUISA?}

Esse estudo tem como objetivo avaliar a relação entre a morfologia facial (que é a forma do seu rosto) e a força de mordida em pessoas com alterações dentofaciais (ou seja, pessoas que não possuem uma relação harmoniosa e adequada entre os dentes de cima e de baixo e suas bases óssea). Serão analisadas as dimensões das estruturas do crânio e da face e sua relação com a força de mordida exercida pelos músculos que fazem a mastigação. Os resultados serão comparados entre pessoas que possuem e que não possuem esse problema (a deformidade dentofacial). Vários exames serão realizados nesse estudo antes da cirurgia ortognática (que é a cirurgia dos ossos da mandíbula e/ou da maxila usada para corrigir a diferença entre os maxilares e os dentes de cima e os dentes de baixo).Vários exames serão realizados nesse estudo, de uma única vez.

Será feita uma avaliação na sua boca e na face, verificando como estão suas estruturas como dentes, língua, lábios, bochechas, mandíbula; sua aparência e os movimentos dessas estruturas. Essa avaliação será filmada para poder ser melhor analisada depois e o resultado dessa avaliação será anotado em um protocolo. O tempo total dessa avaliação é de aproximadamente 20 minutos. 
Para avaliar a sua força de mordida/oclusal e a área de contato oclusal, o Sr. (a) deverá realizar o máximo apertamento dos dentes sobre uma lâmina de plástico posicionada entre as arcadas dentárias, por aproximadamente 15 segundos. Após, será solicitado que o Sr. (a) realize a máxima força de mordida em um outro equipamento posicionado nos dentes molares. O Sr. (a) será instruído a morder o mais forte possível, do lado direito e esquerdo, alternadamente, por três vezes, com um intervalo de 2 minutos entre cada vez. $E$, além disso, o Sr. (a) será submetido a um exame que fará uma "cópia" do seu rosto. Para tal, o Sr. (a) será convidado a permanecer em pé, com os olhos fechados e o avaliador irá deslizar um equipamento com laser na direção da sua face, sem encostar, causar dor ou desconforto, em um tempo total de aproximadamente 10 minutos.

Todos esses exames descritos acima serão feitos em um único lugar, no Laboratório de Fonoaudiologia, na casa de número 18 da Rua das Paineiras, dentro do Campus da USP. Para isso o Sr. (a) receberá um mapa e nós nos comprometemos a explicar-lhe como chegar, caso ainda não saiba.

\section{OS EXAMES SÃO DESCONFORTÁVEIS OU GERAM RISCOS?}

Toda pesquisa com seres humanos envolve risco em tipos e gradações variados. Devem ser analisadas possibilidades de danos imediatos ou posteriores, no plano individual ou coletivo (Resolução no 466, de 12 de dezembro de 2012).

Os exames propostos não causam nenhum prejuízo. Mas, existe um risco mínimo de o Sr. (a), por algum motivo que não conhecemos, sentir algum tipo de dor, desconforto ou cansaço nos músculos da rosto durante a realização dos exames. Caso isso aconteça, as examinadoras vão parar de fazer as avaliações. Depois, elas verão se é possível continuar os exames ou se serão agendados para outro dia ou ainda, se não serão mais realizados.

As pesquisadoras manterão sigilo sobre a sua identidade e o Sr. (a) será esclarecido quanto aos procedimentos realizados e informado sobre os resultados que vamos ter com a pesquisa, sendo que tem total garantia de acesso aos resultados da pesquisa. E a qualquer momento, o Sr. (a) poderá desistir que esses dados sejam utilizados na presente pesquisa. Portanto, as pesquisadoras tomarão todos os cuidados possíveis em manter o sigilo a 
respeito da sua identidade e participação no estudo. Entretanto, caso o Sr. (a) sinta-se lesado, é de seu direito solicitar indenização, conforme legislação vigente.

\section{O PARTICIPANTE TERÁ GASTOS OU DESPESAS?}

Caso o Sr. (a) tenha que se deslocar até o Hospital das Clínicas ou ao Laboratório de Fonoaudiologia para realização exclusiva dos exames da pesquisa, nós nos comprometemos a dar assistência e fornecer recursos para o transporte (valor em reais equivalente às passagens de ida de volta, seja de dentro de Ribeirão Preto ou de alguma cidade vizinha) e também quanto ao lanche que poderá ser disponibilizado antes ou após a realização dos exames, conforme solicitada e afirmada a necessidade.

Nada será cobrado, assim como o Sr.(a) também não receberá qualquer benefício financeiro.

As pesquisadoras se comprometem a prestar assistência integral no decorrer da pesquisa, se algum problema decorrer desta.

A indenização, a título de cobertura material, para reparação de danos imediatos ou tardios, decorrentes da sua participação na pesquisa, caso ocorra, será realizada pelas pesquisadoras, não cabendo ao Hospital das Clínicas de Ribeirão Preto qualquer responsabilidade quanto aos referidos pagamentos.

\section{A PESQUISA TRARÁ ALGUM BENEFÍCIO PARA O PARTICIPANTE?}

Não há proveito direto ou indireto, imediato ou posterior, recebido pelo participante em decorrência de sua participação na pesquisa. Entretanto, existem os benefícios gerais da pesquisa, que incluem a obtenção de diagnósticos mais precisos e busca de tratamentos mais favoráveis aos indivíduos.

\section{O QUE ACONTECE COM QUEM NÃO PARTICIPA DA PESQUISA?}

A sua participação no estudo é voluntária, não acarretando absolutamente nada ao Sr. (a) caso não aceite participar. O Sr. (a) tem a liberdade de se recusar a participar ou poderá interromper a pesquisa a qualquer momento, sem qualquer risco de prejuízos ou penalidades. 
Concordando em participar da pesquisa o Sr. (a) assinará o Termo de Consentimento Livre e Esclarecido, o qual consta os dados das Pesquisadoras Responsáveis, para caso necessite de maiores informações, ou por qualquer outra necessidade e poderá entrar em contato a qualquer momento, assim como poderá entrar em contato com o Comitê de Ética em pesquisa do Hospital da Clínicas da Faculdade de Medicina de Ribeirão Preto caso tenha alguma reclamação, recurso ou dúvida, pelo telefone (16) 3602-2228.

Dados das pesquisadoras responsáveis para eventuais necessidades: Profa. Dra. Luciana Vitaliano Voi Trawitzki e Fga. Joana Carolina Martins Simões End: Av. Bandeirantes, 3900, Monte Alegre, Ribeirão Preto, Cep: 14.049.900 Tel: (16) 3602-0592 (Laboratório de Fonoaudiologia).

Email: joanacmsimoes@gmail.com

Pesquisadora:

Participante:

Data: 


\section{APROVAÇÃO PELO COMITÊ DE ÉTICA EM PESQUISA}

HOSPITAL DAS CLÍNICAS DA FACULDADE DE MEDICINA DE RIBEIRÃO PRETO DA UNIVERSIDADE DE SÃO PAULO

Oficio $n^{\circ} 2054 / 2014$

CEP/MGV

Prezadas Senhoras,

O trabalho intitulado "ANÁLISE DA MORFOLOGIA FACIAL E DA FORÇA DE MORDIDA NAS DEFORMIDADES DENTOFACIAIS” - Versão 2, de 01/06/2014, foi analisado pelo Comitê de Ética em Pesquisa, em sua $388^{\mathrm{a}}$ Reunião Ordinária realizada em 09/06/2014 e enquadrado na categoria: APROVADO, bem como os Termos de Consentimento Livre e Esclarecido - GC e GE - versão 2, de 01/06/2014, de acordo com o Processo HCRP $\mathrm{n}^{\circ}$ $7722 / 2014$

De acordo com Carta Circular $n^{\circ}$ 003/2011/CONEP/CNS, datada de 21/03/2011, o sujeito de pesquisa ou seu representante, quando for o caso, deverá rubricar todas as folhas do Termo de Consentimento Livre $e$ Esclarecido - TCLE - apondo sua assinatura na última do referido Termo; o pesquisador responsável deverá da mesma forma, rubricar todas as folhas do Termo de Consentimento Livre e Esclarecido - TCLE - apondo sua assinatura na última página do referido Termo.

Este Comitê segue integralmente a Conferência Internacional de Harmonização de Boas Práticas Clínicas (IGH-GCP), bem como a Resolução $n^{o}$ 466/12 CNS/MS.

Relatório Parcial e o Relatório Final da pesquisa.

Lembramos que devem ser apresentados a este CEP, o

Atenciosamente.

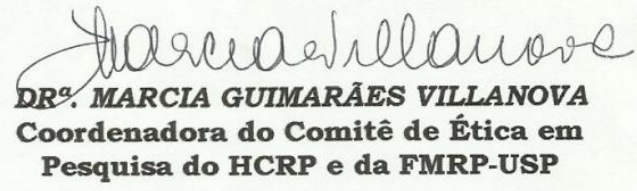

Ilustríssimas Senhoras

JOANA CAROLINA MARTINS SIMÕES

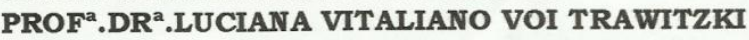

Depto. de Oftalmologia, Otorrinolaringologia e Cirurgia de Cabeça e Pescoço 